\title{
Sistemas Especialistas Modulados e Abrangentes para a Gestão de Operações
}

Tese apresentada à Escola Politécnica da Universidade de São Paulo, para obtenção do Título de Doutor em Engenharia.

São Paulo

Dezembro / 2000 


\section{WAGNER DÄUMICHEN BARRELLA}

\section{Sistemas Especialistas Modulados e Abrangentes para a Gestão de Operações}

Tese apresentada à Escola Politécnica da Universidade de São Paulo, para obtenção do Título de Doutor em Engenharia.

ÁREA DE CONCENTRAÇÃO:

Engenharia de Produção - Produtividade

ORIENTADOR:

Prof. Dr. Israel Brunstein 


\section{BARRELLA, WAGNER DÄUMICHEN}

Sistemas Especialistas Modulados e Abrangentes para a Gestão de Operações - São Paulo, 2000. $159 \mathrm{p}$.

Tese (Doutorado) - Escola Politécnica da Universidade de São Paulo - Departamento de Engenharia de Produção.

1. Sistemas Especialistas - 2. Suporte a Tomada de Decisões. I Universidade de São Paulo. Escola Politécnica. Departamento de Engenharia de Produção II.t. 


\section{DE D I C A T Ó R I A}

Até este momento, não havia passado pela minha cabeça a necessidade de dedicar o fruto do trabalho realizado nos últimos cinco anos.

$E$, contrariando situações anteriores, eu simplesmente não sei como resolver essa questão, cuja importância desaparece ao ser comparada com o conteúdo da pesquisa.

Com certeza, há muitas pessoas que merecem a gratidão pelo êxito desta tese, mas esta dedicatória é um assunto que pode, no mínimo, ser considerado delicado.

Decidi optar por dedicar este trabalho às pessoas que me rodeiam e deram, de uma maneira ou de outra, todo tipo de suporte para tornar realidade o ideal de obtenção do título de Doutor, cujo projeto foi iniciado em 1992.

Sendo assim, eu dedico este trabalho à minha família e aos meus amigos. 


\section{A G R A DECIMENTOS}

Ao amigo e orientador, Prof. Dr. Israel Brunstein, pelo apoio, pelo incentivo, pela liberdade de trabalho e pela confiança que sempre depositou em mim.

Ao amigo, Prof. Dr. Oduvaldo Vendrameto, por ter cobrado exaustivamente o término deste trabalho, fazendo com que eu chegasse ao fim das pesquisas o mais depressa possível.

À minha esposa e à minha filha, que suportaram meus momentos de mau humor, durante o desenvolvimento deste trabalho.

Aos professores Tamio Shimizu e Celma de Oliveira Ribeiro, pelos relevantes comentários e sugestões feitos, tornando o trabalho mais completo e adequado aos tempos atuais.

Aos colegas da Poli (EPUSP) e da Technische Universität HamburgHarburg (TUHH), não só pelas críticas e auxílio na execução deste trabalho, mas também, pelo incentivo pessoal.

Aos funcionários e professores do Departamento de Engenharia de Produção da EPUSP, sem os quais minhas idéias não teriam adquirido asas para alçar vôo.

Ao CNPq, pelo auxílio financeiro que me foi concedido no período em que estive realizando meu mestrado.

A todos aqueles, com os quais cometo nesse momento a ingratidão de não mencionar os nomes. 


\section{LISTA DE ABREVIATURAS}

\begin{tabular}{|c|c|}
\hline MRP & Material Requirement Planning \\
\hline ERP & Enterprise Resources Planning \\
\hline IA & Inteligência Artificial \\
\hline E-ERP & Expert Enterprise Resources Planning \\
\hline I-ERP & Intelligent Enterprise Resources Planning \\
\hline CMM & Capability Maturity Model \\
\hline SEI & Software Engineering Institute \\
\hline PSP & Personal Software Process \\
\hline SI & Sistemas de Informação \\
\hline SAP & Systemanalyse and Programmentwicklung \\
\hline DEM & Dynamics of Enterprise Model \\
\hline CRP & Planejamento de Necessidades de Capacidade \\
\hline MPS & Programa Mestre de Produção \\
\hline DSS & Decision Support Systems \\
\hline CAD & Computer Aided Design \\
\hline APS & Advanced Planning System \\
\hline CAM & Computer Aided Manufacturing \\
\hline CIM & Computer Integrated Manufacturing \\
\hline GP & Gerência da Produção \\
\hline MA & Matemática \\
\hline IN & Informática \\
\hline BCD & Banco Central de Dados \\
\hline
\end{tabular}




\section{LISTA DE FIGURAS}

\begin{tabular}{|c|c|}
\hline Figura 1 - Evolução do Pensamento Administrativo & 3 \\
\hline Figura 2 - Fluxo de informações & 5 \\
\hline Figura 3 - Arquitetura dos Sistemas Especialistas & 23 \\
\hline Figura 4 - Exemplo das inter-relações de um Sistema Integrado & 26 \\
\hline Figura 5 - Estrutura Administrativa das Empresas & 41 \\
\hline Figura 6 - Estrutura Administrativa das Empresas & 41 \\
\hline Figura 7 - Estrutura Administrativa de Empresas Modernas & 42 \\
\hline Figura 8 - Exemplos de Telas de Módulo & 48 \\
\hline Figura 9 - Estrutura de Trabalho do Oracle R11 & 49 \\
\hline Figura 10 - Estrutura do Sistema Oracle R11 & 50 \\
\hline $\begin{array}{l}\text { Figura } 11 \text { - Possibilidades de Flexibilização/Adequação do } \\
\text { Sistema }\end{array}$ & 51 \\
\hline Figura 12 - Módulo de Manufatura & 51 \\
\hline Figura 13 - Desenhos e Dados Técnicos & 52 \\
\hline Figura 14 - Fluxo de Processo & 53 \\
\hline Figura 15 - Exemplo de Interfaces dos Dados do Projeto & 54 \\
\hline Figura 16 - Estrutura do Sistema BAAN & 57 \\
\hline Figura 17 - Tipo de Formatação de Tela e Interface Gráfica & 59 \\
\hline
\end{tabular}




\begin{tabular}{|c|c|}
\hline Figura 18 - Exemplo de Tela com Divisão de Módulos & 60 \\
\hline Figura 19 - Estrutura do Sistema EMS & 64 \\
\hline Figura 20 - Tela de Interface Sistema x Usuário & 71 \\
\hline $\begin{array}{l}\text { Figura } 21 \text { - Esquema de Fluxo de Informações do Sistema } \\
\text { Micro-Siga }\end{array}$ & 72 \\
\hline $\begin{array}{l}\text { Figura } 22 \text { - Estrutura de Integração entre Áreas Administrativa e } \\
\text { Produtiva }\end{array}$ & 81 \\
\hline Figura 23 - Arquitetura ERP & 83 \\
\hline Figura 24 - Estrutura Modular do Sistema Especialista & 84 \\
\hline Figura 25 - Integração Manufatura-Administração & 86 \\
\hline Figura 26 - Administração através de Conexão Remota & 87 \\
\hline Figura 27 - Seqüência de Desenvolvimento de Análises & 88 \\
\hline Figura 28 - Diagrama de Fluxo (Simplificado) & 107 \\
\hline $\begin{array}{l}\text { Figura } 29 \text { - Exemplo de Estrutura Organizacional Hierárquica } \\
\text { Atual }\end{array}$ & 108 \\
\hline Figura 30 - Estrutura Organizacional Proposta & 110 \\
\hline Figura 31 -Estrutura de processamento Proposta & 111 \\
\hline Figura 32 - Esquema de Processos Proposta & 114 \\
\hline Figura 33 - Linha-Mestre da Criação do Programa & 116 \\
\hline Figura 34 - Ilustração da Estrutura do Plano de Contas Utilizada & 125 \\
\hline
\end{tabular}




\begin{tabular}{|l|c|}
\hline Figura 35 - Tela Inicial do Protótipo & 127 \\
\hline Figura 36 - Exemplo de Tela do Protótipo & 128 \\
\hline Figura 37 - Exemplo de Tela do Protótipo & 128 \\
\hline Figura 38 - Exemplo de Tela do Protótipo & 129 \\
\hline Figura 39 - Exemplo de Tela do Protótipo & 129 \\
\hline Figura 40 - Exemplo de Tela do Protótipo & 129 \\
\hline Figura 41 - Exemplo de Tela do Protótipo & 130 \\
\hline Figura 42 - Exemplo de Tela do Protótipo & 130 \\
\hline Figura 43 - Exemplo de Tela do Protótipo & 131 \\
\hline Figura 44 - Exemplo de Tela do Protótipo & 131 \\
\hline Figura 45 - Exemplo de Tela do Protótipo & 132 \\
\hline Figura 46 - Exemplo de Tela do Protótipo & 132 \\
\hline Figura 47 - Exemplo de Tela do Protótipo & 133 \\
\hline Figura 48 - Exemplo de Tela do Protótipo & 133 \\
\hline Figura 49 - Exemplo de Tela do Protótipo & 134 \\
\hline Figura 50 - Exemplo de Tela do Protótipo & 134 \\
\hline Figura 51 - Exemplo de Tela do Protótipo & 136 \\
\hline Figura 52 - Exemplo de Tela do Protótipo & 136 \\
\hline Figura 53 - Exemplo de Tela do Protótipo & Exo \\
\hline
\end{tabular}




\section{LISTA DE TABELAS}

\begin{tabular}{|l|r|}
\hline Tabela 1 - Evolução Histórica das Teorias Administrativas & 4 \\
\hline $\begin{array}{l}\text { Tabela } 2 \text { - Resumo das Características dos Sistemas } \\
\text { Analisados }\end{array}$ & 77 \\
\hline Tabela 3 - Aspectos de Interface Homem x Sistema & 106 \\
\hline Tabela 4 - Exemplo de Controle Financeiro de Contas & 123 \\
\hline Tabela 5 - Exemplo de Controle Financeiro de Contas & 123 \\
\hline
\end{tabular}




\section{S U M Á R I O}

\begin{tabular}{|l|r|}
\hline 1 - INTRODUÇÃO & 1 \\
\hline 1.1) Motivação do Trabalho & 1 \\
\hline 1.2) Apresentação do Assunto & 3 \\
\hline 1.3) Ambiente de Trabalho & 11 \\
\hline 1.4) Escopo & 13 \\
\hline & \\
\hline 2 - DEFINIÇÕES BÁSICAS E HISTÓRICO DE EVOLUÇÃO & 16 \\
\hline 2.1) Definições & 16 \\
\hline 2.1.a) Conhecimento & 17 \\
\hline 2.1.b) Sistema & 19 \\
\hline 2.1.c) Especialista & 19 \\
\hline 2.1.d) Sistemas Especialistas & 20 \\
\hline 2.1.e) Saber Especializado & 24 \\
\hline 2.1.f) Sistema (Software) de Gestão & 25 \\
\hline 2.1.g) Sistema Integrado de Gestão & 25 \\
\hline 2.1.h) Base de Conhecimento & 27 \\
\hline 2.1.i) Inteligência & 27 \\
\hline 2.1.j) Inteligência Artificial & 28 \\
\hline 2.1.k) Conjuntos Difusos (Lógica Fuzzy) & 16 \\
\hline 2.1.I) Redes Neurais & 28 \\
\hline & 27 \\
\hline
\end{tabular}




\begin{tabular}{|c|c|}
\hline 2.1.m) Sistemas de Informação & 29 \\
\hline 2.1.n) Simulação & 29 \\
\hline 2.1.0) Interface & 29 \\
\hline 2.1.p) Interfaces Amigáveis & 30 \\
\hline 2.2 Histórico da Inteligência Artificial & 31 \\
\hline 2.2.a) ANOS 40 & 32 \\
\hline 2.2.b) ANOS 50 & 33 \\
\hline 2.2.c) ANOS 60 & 34 \\
\hline 2.2.d) ANOS 70 & 35 \\
\hline 2.2.e) ANOS 80 & 37 \\
\hline 2.2.f) ANOS 90 & 38 \\
\hline 3 - SISTEMAS ATUAIS & 40 \\
\hline 3.a.1) SAP / R3 & 45 \\
\hline 3.a.2) Oracle Applications (R11) & 49 \\
\hline 3.a.3) BAAN & 56 \\
\hline 3.a.4) EMS & 64 \\
\hline 3.a.5) Siga Advanced & 70 \\
\hline 3.b) Comentários Gerais & 75 \\
\hline
\end{tabular}




\begin{tabular}{|l|c|}
\hline 4 - MODELO DE UM SISTEMA PROPOSTO PARA GERENCIAMENTO & 79 \\
\hline 4.a) O que fazer ? & 80 \\
\hline 4.b) Como fazer ? & 84 \\
\hline 4.c) Para quem fazer ? & 90 \\
\hline & \\
\hline & 92 \\
\hline 5. DESENVOLVIMENTO & 92 \\
\hline 5.1.a) Capability Maturity Model (CMM) & 92 \\
\hline 5.1.b) Personal Software Process (PSP) & 92 \\
\hline & 93 \\
\hline 5.2) Atividades de Pesquisa & 97 \\
\hline 5.2.a) Gerência da Produção & 97 \\
\hline 5.2.a.1) Processos de Manufatura & 96 \\
\hline 5.2.a.2) Planejamento, Programação e Controle da Produção & 96 \\
\hline 5.2.a.3) Critérios e Métodos para a Resolução dos Problemas & 96 \\
\hline 5.2.a.4) Critérios e Parâmetros de Análises de Produtividade & 98 \\
\hline 5.2.a.5) Layout de Fábrica & 98 \\
\hline 5.2.a.6) Qualidade do Produto e Processo & 97 \\
\hline 5.2.a.7) Escolha dos Dados a Serem Introduzidos no Banco de Dados & 98 \\
\hline 5.2.a.8) Simulações & 97 \\
\hline & 96 \\
\hline
\end{tabular}




\begin{tabular}{|l|r|}
\hline 5.2.b) Matemática & 98 \\
\hline 5.2.b.1) Desenvolvimento e Análise de Algoritmos & 99 \\
\hline 5.2.b.2) Ferramentas Matemáticas & 99 \\
\hline 5.2.b.3) Pesquisa Operacional e Métodos Quantitativos & 99 \\
\hline 5.2.b.4) Análise Estatística de Dados & 99 \\
\hline & \\
\hline 5.2.c) Informática & 100 \\
\hline 5.2.c.1) Elaboração de Algoritmos & 100 \\
\hline 5.2.c.2) Qualidade de Software & 101 \\
\hline 5.2.c.3) Redes de Computadores & 101 \\
\hline 5.2.c.4) Sistemas Flexíveis de Informação e Banco de Dados & 101 \\
\hline 5.2.c.5) Sistemas de Introdução de Dados & 101 \\
\hline 5.2.c.6) Possibilidade de Alternativas & 102 \\
\hline & 102 \\
\hline 5.2.d) Interfaces e Ergonomia & 103 \\
\hline 5.2.d.1) Programador x Usuário & 103 \\
\hline 5.2.d.2) Organização x Usuário & 104 \\
\hline 5.2.d.3) Programa x Organização & 104 \\
\hline 5.2.d.4) Usuário x Programa & \\
\hline
\end{tabular}




\begin{tabular}{|l|l|}
\hline 6 - ESTRUTURAS & 108 \\
\hline 6.1) Estrutura Hierárquica & 108 \\
\hline 6.2) Estrutura de Processamento & 111 \\
\hline 6.3) Estrutura de Comunicações & 113 \\
\hline 6.4) Seqüência Lógica do Programa & 115 \\
\hline 6.5) Componentes do Sistema & 117 \\
\hline 6.5.a) Banco de Dados & 117 \\
\hline 6.5.b) Dispositivo de Inferência & 118 \\
\hline 6.5.c) Cadastros & 118 \\
\hline 6.5.c.1) Matéria-Prima & 118 \\
\hline 6.5.c.2) Produto Acabado & 118 \\
\hline 6.5.c.3) Fornecedores & 118 \\
\hline 6.5.c.4) Clientes & 118 \\
\hline 6.5.c.5) Processos & 118 \\
\hline 6.5.c.6) Funcionários & 119 \\
\hline 6.5.d) Atividades & 119 \\
\hline 6.5.d.1) Compra & 119 \\
\hline 6.5.d.2) Venda & 119 \\
\hline 6.5.d.3) Manufatura & 119 \\
\hline 6.5.d.4) Logística & 120 \\
\hline 6.5.d.5) Serviços & 12 \\
\hline 6.5.e) Customização & 19 \\
\hline
\end{tabular}




\begin{tabular}{|c|c|}
\hline 6.5.f) Módulos & 120 \\
\hline 6.5.f.1) Vendas & 120 \\
\hline 6.5.f.2) Compras & 120 \\
\hline 6.5.f.3) Logística & 121 \\
\hline 6.5.f.4) Contabilidade & 121 \\
\hline 6.5.f.5) Manufatura & 121 \\
\hline 6.5.f.6) Análises & 121 \\
\hline 6.5.f.7) Relatórios & 122 \\
\hline 6.5.f.8) Simulações & 122 \\
\hline 6.5.f.9) Comunicações & 122 \\
\hline 6.6) Estrutura do Plano de Contas & 122 \\
\hline 6.6.a) Financeira & 123 \\
\hline 6.6.b) Contábil & 124 \\
\hline 7 - PROTÓTIPO & 127 \\
\hline 7.1) Cadastros & 128 \\
\hline 7.2) Atividades & 130 \\
\hline 7.3) Contabilidade & 131 \\
\hline 7.4) Manufatura & 132 \\
\hline 7.5) Análises & 133 \\
\hline 7.6) Customizações & 134 \\
\hline 7.7) Relatórios & 135 \\
\hline 7.8) Comunicações & 135 \\
\hline
\end{tabular}




\begin{tabular}{|l|c|}
\hline 8- ANÁLISE DO PROTÓTIPO & 137 \\
\hline 8.1) Características Gerais do Protótipo & 138 \\
\hline 8.1.a) Concepção & 139 \\
\hline 8.1.b) Estruturas e Formas de Organização & 139 \\
\hline 8.1.c) Variedade de Técnicas & 139 \\
\hline 8.1.d) Critérios e Parâmetros & 139 \\
\hline 8.1.e) Conhecimento de Condições & 139 \\
\hline 8.1.f) Customização & 139 \\
\hline 8.1.g) Banco de Dados & 140 \\
\hline 8.1.h) Simulação & 140 \\
\hline 8.1.i) Redução de Níveis Hierárquicos & 140 \\
\hline 8.1.j) Administração em Tempo Real & 140 \\
\hline 8.1.k) Desenvolvimento Conjunto & 140 \\
\hline 8.1.I) Aumento de Qualificação de Funcionários & 140 \\
\hline & 141 \\
\hline 8.2) Características Específicas & 142 \\
\hline 8.2.a) Desenvolvimento do Software & 142 \\
\hline 8.2.b) Estruturas & 142 \\
\hline 8.2.c) Módulos & 142 \\
\hline 8.2.d) Banco de Dados & 142 \\
\hline 8.2.e) Telas de Interface & 139 \\
\hline & 140 \\
\hline
\end{tabular}




\begin{tabular}{|l|c|}
\hline 8.2.f) Cálculos & 143 \\
\hline 8.2.g) Cadastros & 143 \\
\hline 8.2.h) Administração a Distância & 143 \\
\hline 8.2.i) Integração com a Manufatura & 143 \\
\hline & \\
\hline 8.3) Avaliação Preliminar do Protótipo & 144 \\
\hline 8.3.1) Vantagens do Sistema & 144 \\
\hline 8.3.2) Desvantagens do Sistema & 145 \\
\hline 8.3.3) Impactos Decorrentes da Implementação & 146 \\
\hline & \\
\hline 9 - CONSIDERAÇÕES FINAIS & \\
\hline & 150 \\
\hline 10 - REFERÊNCIAS BIBLIOGRÁFICAS & 153 \\
\hline
\end{tabular}




\section{RES U M O}

\section{Palavras-chave: sistemas especialistas; módulos administrativos; manufatura integrada; informática aplicada; registro de conceitos.}

A existência de novas condições econômicas e de trabalho tem conduzido as empresas a uma modernização de técnicas e metodologias para a resolução de problemas em Engenharia de Produção.

Embora seja rápido o surgimento de novas ferramentas de informática e haja uma grande preocupação, no sentido de empregar a informática como suporte à tomada de decisões, o que se tem notado é que a utilização dos computadores nas empresas não tem sido feita na plenitude de suas possibilidades, ou seja, os usuários (especialmente os engenheiros) fazem uso de programas especialistas para chegarem a decisões isoladas e, posteriormente, transferem os resultados obtidos para outros aplicativos e/ou realização das análises.

Este trabalho desenvolveu estudos multidisciplinares que envolvem as novas ferramentas oferecidas pelos avanços da Informática e pelos modernos conceitos de administração e otimização de processos, estudados em Engenharia de Produção. Tais estudos foram direcionados para a obtenção de resultados práticos que possam ser rapidamente aplicados nas empresas brasileiras, ou seja, dentro do contexto financeiro-tecnológico nacional.

Estas pesquisam procuraram documentar qual é o formato do sistema, para que sejam capazes de facilitar e automatizar o planejamento da produção de uma indústria ou de uma empresa de serviços.

Pretendeu-se, assim, registrar os conceitos e filosofias necessários para se construir uma ferramenta para otimização de processos produtivos que resolva, ou atenue, eventuais problemas causados por restrições na disponibilidade de recursos (equipamento, mão-de-obra, material e tempo) ou de outra natureza. 


\section{A B S T R A C T}

Key words: expert systems; administrative modules; integrated manufacturing; applied computer science; registration of concepts.

The existence of new economic and work conditions has been driving the companies to a modernization of techniques and methodologies for resolution of problems in Production Engineering.

Although be fast the appearance of new computer science tools and there be a great concern in the sense of using the computer science as support to the taking of decisions, which one has been noticing is that the use of the computers in the companies has not been made in the fullness of its possibilities, that is to say, the users (especially the engineers) make use of expert programs for they arrive to isolated decisions, and later, they transfer the results obtained for another applications and/or accomplishment of the analyses.

This research developed multidisciplinaries studies involving the new tools offered by the progresses of the Computer Science and by the modern administration concepts, and optimization of processes studied by the Production Engineering. Such studies were addressed for the obtaining of practical results that they can be quickly applied in the Brazilian companies, that is to say, inside the national financial-technological context.

Those researches tried to document which is the format of the system, so that they are capable to facilitate and to automate the planning of the production of an industry or company of services.

It was intended like this to register the concepts and necessary philosophies to build a tool for optimization of productive processes that it solves, or attenuate, eventual problems caused by restrictions in the readiness of resources (equipment, work-hand, material and time) or by another nature. 


\section{1) INTRODUÇÃO}

\section{1 - MOTIVAÇÃO DO TRABALHO}

O presente trabalho teve sua motivação principal originada em decorrência de alguns estudos realizados no período compreendido entre 1994 e 1996, quando houve a análise de alguns softwares auxiliares de gestão e sistemas de informações, desenvolvidos internamente pelas empresas. Nesses sistemas, foram observados alguns fatos relevantes e, paralelamente, foi constatada uma série de exigências do mercado em relação a esses sistemas.

Nas análises citadas, buscou-se a princípio conhecer premissas e bases conceituais que direcionaram o desenvolvimento e os procedimentos de utilização desses sistemas. Nessa ocasião, observou-se que as instruções e demais explicativos ou eram insuficientes para o uso, ou encontravam-se em manuais, normalmente guardados nas gavetas dos usuários. Além disso, notou-se que esses programas eram extremamente rígidos, não permitindo variações na maneira de manipulá-los nem nos dados transmitidos. Em outras palavras, os softwares engessavam o usuário e a administração da empresa.

Ao longo da pesquisa, vários outros inconvenientes foram observados, o que, em determinado momento, implicou a conclusão que seria mais indicado repensar as filosofias de aplicação desses sistemas do que tentar contornar as falhas existentes. 
Em 1995, enquanto realizava um período de pesquisas na Technische Universität Hamburg - Harburg (Alemanha), houve um contato mais profundo com alguns programas administrativos do tipo Enterprise Resources Planning (ERP), BAAN e SAP. Nessa ocasião, constatou-se que a velocidade e a precisão dos cálculos desses sistemas procuravam atender às necessidades das empresas quanto ao então vigente sistema globalizado de administração.

Porém, de maneira geral, as dificuldades na interpretação do manual de instruções e a interação com o usuário (feita através da comunicação por telas muito confusas) acabavam por inibir a utilização dos sistemas.

Outra característica observada foi que esses sistemas não permitiam uma troca simples dos critérios aplicados nos sistemas decisórios nem a modificação dos parâmetros que utilizavam, tornando-se inflexíveis e, por conseqüência, incompatíveis com as necessidades das empresas.

É importante destacar que os programas não previam a utilização dos seus módulos em localidades distintas, ou ainda, a compatibilidade com outros aplicativos.

Todas essas observações, somadas ao fato dos sistemas ERP, na sua maioria, serem fruto de trabalho empírico, motivaram a preparação de um conjunto de características mínimas que um sistema especialista de gestão integrada deve conter. 


\section{2 - APRESENTAÇÃO DO ASSUNTO}

Ao se observarem as transformações ocorridas nas empresas nos últimos anos, constata-se que as novas políticas industriais, assim como a globalização de mercados, têm impelido o desenvolvimento e a utilização de novas tecnologias e sistemas administrativos.

Essa modernização faz parte de uma evolução lógica - exigida pelas condições de competitividade de mercado - ocorrida nos sistemas e nas filosofias administrativos das empresas (longamente discutida por GUERRINI, 1999, e resumida como mostra a Figura 1).

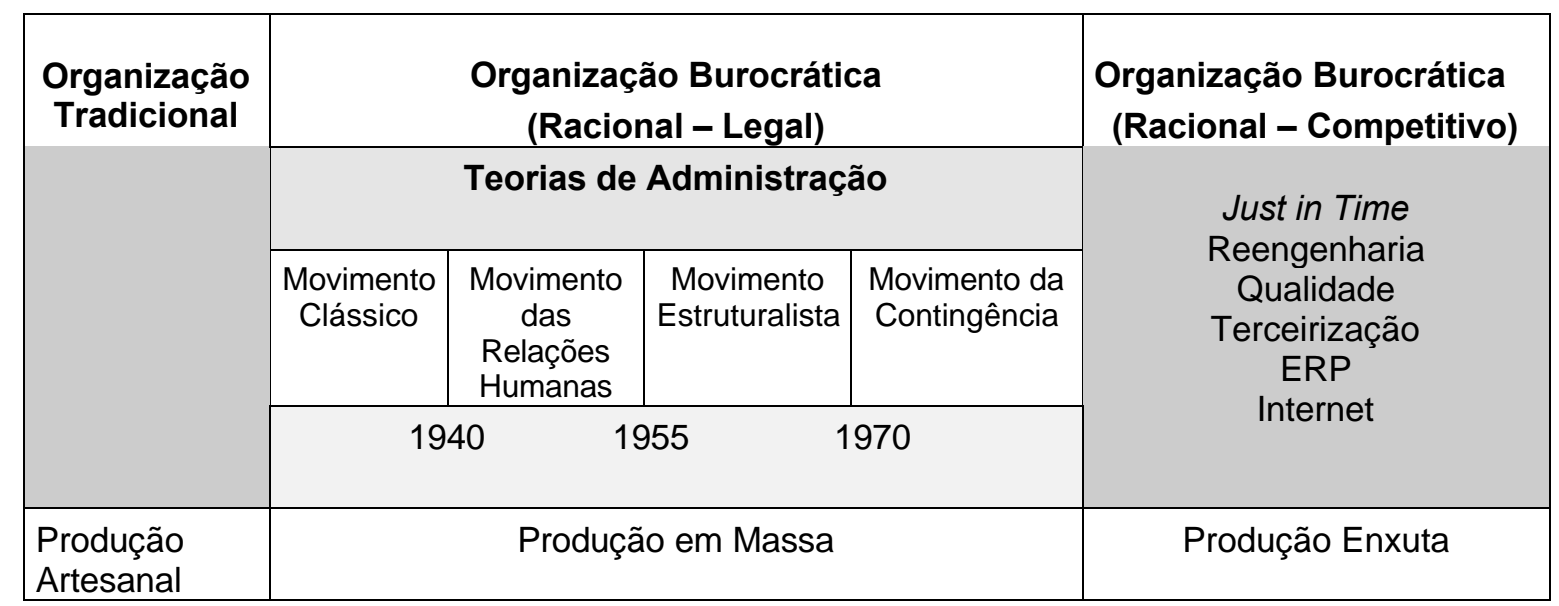

Figura 1 - Evolução do Pensamento Administrativo.

(Fonte: Escrivão Filho, 1997, apud GUERRINI, 1999).

Ainda nesse trabalho, GUERRINI registrou a evolução histórica das principais teorias administrativas propostas entre 1900 e 1990.

A evolução apresentada na tabela 1 ilustra com propriedade as mudanças ocorridas nas políticas administrativas através dos anos, contendo não só os seus principais autores, mas também, os movimentos e datas que os caracterizaram. 


\begin{tabular}{|c|c|c|c|c|c|c|}
\hline $\begin{array}{l}\text { Disciplina } \\
\text { Movimento }\end{array}$ & Engenharia & \multicolumn{2}{|c|}{ Psicologia } & $\begin{array}{l}\text { Psicologia } \\
\text { Social }\end{array}$ & Sociologia & Administração \\
\hline $\begin{array}{l}1900 \\
\text { Movimento de } \\
\text { Racionalização } \\
\text { do Trabalho }\end{array}$ & $\begin{array}{c}\text { Gerência } \\
\text { Científica } \\
\text { Taylor } \\
\text { Gannt } \\
\text { Gilbreth }\end{array}$ & \multicolumn{4}{|c|}{ Psicologia Industrial } & $\begin{array}{c}\text { Gerência } \\
\text { Administrativa } \\
\text { Fayol } \\
\text { Gulick } \\
\text { Urwick } \\
\text { Mooney } \\
\text { Davis } \\
\end{array}$ \\
\hline $\begin{array}{l}1930 \\
\text { Movimento das } \\
\text { Relações } \\
\text { Humanas }\end{array}$ & $\begin{array}{c}\begin{array}{c}\text { Production } \\
\text { Management }\end{array} \\
\text { Kimball } \\
\text { Filipetti }\end{array}$ & \multicolumn{2}{|c|}{$\begin{array}{c}\text { Relações Humanas } \\
\text { Mayo } \\
\text { Lewin } \\
\text { Homans } \\
\text { Roethlisberger } \\
\text { JCA Brown } \\
\text { Zaleznick } \\
\end{array}$} & $\begin{array}{c}\text { Sistema } \\
\text { Cooperativo } \\
\text { Barnard } \\
\text { Follet }\end{array}$ & $\begin{array}{l}\text { Sistema } \\
\text { Social } \\
\text { Parsons } \\
\text { Mierton }\end{array}$ & $\begin{array}{l}\text { Processual } \\
\text { Newman } \\
\text { Koontz \& } \\
\text { O'Donnel } \\
\text { Dale } \\
\text { Terry } \\
\end{array}$ \\
\hline $\begin{array}{l}\text { Movimento do } \\
\text { Estruturalismo } \\
\text { Sistêmico } \\
\text { (fase 1) }\end{array}$ & $\begin{array}{c}\text { Management } \\
\text { Science } \\
\text { Churchmen } \\
\text { Ackoff }\end{array}$ & $\begin{array}{c}\text { Sócio- } \\
\text { Técnico } \\
\text { Trist } \\
\text { Bramf } \\
\text { Rice } \\
\text { Miller } \\
\text { Emery }\end{array}$ & $\begin{array}{l}\text { Pós- } \\
\text { Hawthorne } \\
\text { Maslow } \\
\text { McGregor } \\
\text { Lickert } \\
\text { Herze }\end{array}$ & $\begin{array}{l}\text { Racionalidade } \\
\text { Limitada } \\
\text { Simon }\end{array}$ & $\begin{array}{l}\text { Selznick } \\
\text { Gouldner }\end{array}$ & $\begin{array}{l}\text { Gerência por } \\
\text { Objetivos }\end{array}$ \\
\hline $\begin{array}{l}1955 \\
\text { Movimento do } \\
\text { Estruturalismo } \\
\text { Sistêmico } \\
\text { (fase 2) }\end{array}$ & $\begin{array}{c}\text { Operations } \\
\text { Management } \\
\text { Buffa } \\
\text { Skinner } \\
\text { Hayes } \\
\text { Wheel Wright }\end{array}$ & $\begin{array}{c}\text { Job } \\
\text { Design }\end{array}$ & $\begin{array}{c}\text { Comportam. } \\
\text { Organiz. } \\
\text { Argyrus } \\
\text { Schein } \\
\text { Bennis }\end{array}$ & $\begin{array}{l}\text { Coalizões } \\
\text { March } \\
\text { Cyert }\end{array}$ & $\begin{array}{c}\text { Controle } \\
\text { Organizac. } \\
\text { Blau } \\
\text { Etzione } \\
\text { W. R. Scott }\end{array}$ & $\begin{array}{l}\text { Planejamento } \\
\text { Estratégico } \\
\\
\text { Chandler } \\
\text { Ansoff } \\
\text { Andrews } \\
\end{array}$ \\
\hline $\begin{array}{l}\text { Movimento das } \\
\text { Contingências } \\
\text { Abertas }\end{array}$ & $\begin{array}{l}\text { Tecnologia } \\
\text { Woodward } \\
\text { Thompson } \\
\text { Lawrence } \\
\text { Lorsh } \\
\text { Perrow }\end{array}$ & $\begin{array}{c}\text { Qual Vida } \\
\text { Trabalho } \\
\text { Davis } \\
\text { Cherm }\end{array}$ & $\begin{array}{l}\text { Cultura } \\
\text { Shein } \\
\text { Kotter }\end{array}$ & $\begin{array}{c}\text { Papéis } \\
\text { Gerenciais } \\
\text { Mintsberg } \\
\text { Pettigrew }\end{array}$ & $\begin{array}{c}\text { Estrutural. } \\
\text { Empírico } \\
\text { Hall } \\
\text { Pugh } \\
\text { Hage } \\
\text { Aiken } \\
\end{array}$ & $\begin{array}{l}\text { Competitividade } \\
\text { Miles \& Snow } \\
\text { Porter }\end{array}$ \\
\hline $\begin{array}{l}1970 \text { / } 1990 \\
\text { Movimento da } \\
\text { Produção } \\
\text { Enxuta }\end{array}$ & $\begin{array}{c}\text { Tecnologia } \\
\text { da } \\
\text { Informação } \\
\text { Davenport }\end{array}$ & $\begin{array}{r}\text { Qualic } \\
\text { D } \\
\text { IsI } \\
\text { C }\end{array}$ & $\begin{array}{l}\text { ade Total } \\
\text { ming } \\
\text { uran } \\
\text { ikawa } \\
\text { osby }\end{array}$ & Conhecimento & $\begin{array}{c}\text { Just in } \\
\text { time }\end{array}$ & $\begin{array}{c}\text { Terceirização / } \\
\text { empregabilidade } \\
\text { Rifkin }\end{array}$ \\
\hline $\begin{array}{l}\text { Tema } \\
\text { Organizacional } \\
\text { Relevante }\end{array}$ & Tecnologia & Comp & rtamento & Decisão & Estrutura & Estratégia \\
\hline
\end{tabular}

Tabela 1 - Evolução histórica das teorias administrativas. Fonte: Escrivão Filho (1995), apud GUERRINI, 1999. Adaptado com a inclusão do Movimento da Produção Enxuta e com a integração do Movimento Estruturalista-Sistêmico.

Entretanto, ao se analisarem os sistemas de programação e de controle da produção, utilizados nas últimas décadas, constata-se que, 
paralelamente ao desenvolvimento desses sistemas, há um período usado para divulgação e disseminação da nova filosofia administrativa. Esse período inicia-se, em geral, com um processo não acadêmico de observação e análise de características, para uma posterior redação de relatório, ou ensaio, comentando a filosofia administrativa em questão, cujos pontos controversos são esclarecidos ou solucionados.

Para reforçar essas constatações, deve-se recordar que ZACCARELLI (1967) já havia definido Planejamento e Controle da Produção (PCP) como "... um conjunto de funções inter-relacionadas que objetivam comandar o processo produtivo e coordená-lo com demais setores administrativos da empresa" e estabeleceu que o fluxo de informações deveria ter o formato mostrado na Figura 2. Embora não houvesse um sistema computadorizado de apoio, o autor concebeu o PCP como um sistema integrado.

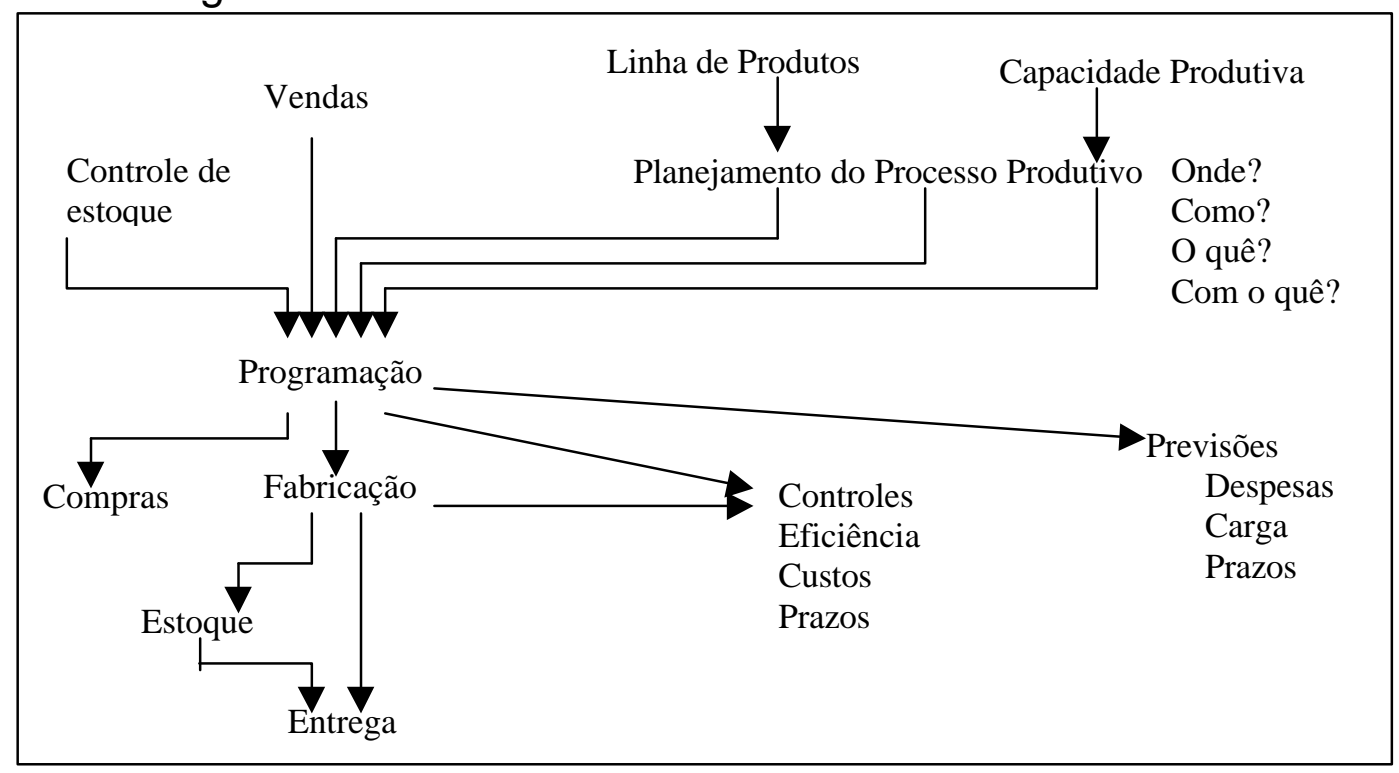

Figura 2 - Fluxo de Informações (Fonte: ZACCARELLI, 1967). 
Por sua vez, BURBIDGE (1972) definiu o Controle da Produção como a função da administração relacionada com planejamento, direção e controle do suprimento de materiais e das atividades de processo em uma empresa. Portanto, as atividades consideradas foram: finanças, pessoal, projeto, planejamento industrial, marketing, controle de produção, compras e administração geral.

BURBIDGE afirmou também que o principal motivo do controle da produção ficar em evidência foi a introdução do computador, pois grande parte do trabalho de controle da produção estava relacionada com centenas de cálculos similares, simples e baseados em dados fixos.

ORLICKY (1975), que se destacou pelo pioneirismo no desenvolvimento e na implementação de sistemas Material Requirements Planning (MRP) por computador, cita que, em 1971, havia cerca de cento e cinqüenta empresas utilitárias do sistema MRP e que esse número aumentou para setecentas empresas, em 1974.

Ainda segundo ORLICKY, a falta de literatura adequada motivou-o a escrever seu livro, baseando-se em observações técnicas e insights sobre o assunto, cujo objetivo era o ensino da filosofia MRP e do software utilizado (COPICS). Esse trabalho acabou se tornando inclusive referência acadêmica, reafirmando a idéia de que as técnicas de MRP foram desenvolvidas empiricamente, e não, por teóricos ou pesquisadores. 
Entre 1988 e 1990, SACOMANO (1990) analisou vinte e seis empresas de grande porte, utilitárias de MRPII, e verificou que nenhuma delas operava o Capacity Requirements Planning (CRP), o que descaracterizava o sistema como MRPII. Pelo porte das empresas e pela importância dos seus sistemas de gestão, concluiu-se que não havia sistema MRPII em operação no Brasil. A mesma constatação pôde ser feita em RESENDE (1989), que analisou trinta e uma empresas de lead time rápido.

Dessa forma, analisando-se as mudanças na administração das empresas e conhecendo-se muitas das novas tecnologias utilizadas, seja nas indústrias ou nas prestadoras de serviços, verifica-se que a informática vem se constituindo numa das ferramentas mais utilizadas para alcançar novos patamares de eficiência.

É importante lembrar que as novas tecnologias de comunicação (rede de computadores, intranet, internet e outras) constituem a infra-estrutura sobre a qual são, ou deveriam ser, aplicadas as políticas e técnicas de administração. Esses fatos tornam interessante e necessário iniciar uma discussão sobre os fatores que devem ser levados em consideração na preparação, e no posterior uso, de programas de computador responsáveis ou auxiliares pela administração das empresas.

Também relevante é o fato de as empresas, sob o impacto da atual fase de globalização e inovações, serem obrigadas a buscar, cada vez mais, 
alternativas para manter ou aumentar suas condições de competitividade e produtividade.

Essa dinâmica de modernização tem levado a modificações nos procedimentos de manufatura, que devem ser acompanhadas de algumas atualizações na metodologia administrativa das empresas.

A modernização dos procedimentos produtivos, acima citada, tem sido alcançada através da automatização de processos e da aplicação de novas técnicas na organização da produção.

Porém verifica-se que todas essas inovações e desenvolvimentos perdem sua força, se não forem preparados para trabalhar em conjunto e de maneira harmônica, ou seja, as políticas de organização industrial devem ser preparadas para serem utilizadas através de estruturas informativas adequadas. Entenda-se por estrutura informativa a metodologia e o sistema de informações que, atualmente, devem utilizarse de redes de computadores (intranet, internet ou outras).

A aplicação dessas modificações nos sistemas informativos visa a, além da possibilidade de implementação de novos grupos de trabalho e de processos decisórios, uma melhor distribuição das informações gerenciais, através da utilização da tecnologia disponível, alcançando os níveis de produtividade e competitividade desejados.

Também é correto dizer que grandes e significativos avanços tecnológicos foram centrados nos computadores e nas suas formas de 
utilização, porém isso não significa que as maneiras de administrar a produção tenham atingido o máximo de sua potencialidade, ao contrário, essas têm se mostrado insuficientes e carentes de mais desenvolvimento.

As novas condições econômicas e de trabalho enfrentadas pelas empresas de manufatura e serviços têm demonstrado novas necessidades na sistemática da resolução de problemas em Engenharia de Produção.

O aparecimento de computadores cada vez menores e mais rápidos, juntamente com as tecnologias de interligação em redes, vem fazendo com que os engenheiros deixem paulatinamente de apenas realizar cálculos, repetitivos e demorados e sejam colocados novamente em atividades de pesquisa e desenvolvimento de novos e melhores métodos de manufatura, assim como, direcionando-os na busca de metodologias modernas e que satisfaçam às necessidades do mercado. No caso dos engenheiros de produção, a maior parte das atividades de pesquisa refere-se à procura de flexibilidade de manufatura (ex: seqüência de processamento) e tomada de decisões (ex: mix de produção, quantidades e datas de execução) corretas e, principalmente, com maior velocidade.

Em função dessas novas exigências de mercado, esta pesquisa (baseada na observação de alguns sistemas administrativos computadorizados, sejam do tipo Enterprise Resources Planning - ERP - 
ou Sistema Integrado de Gestão - SIG - ou semelhante) procura realizar uma análise, imparcial e criteriosa, e fornecer uma orientação ao desenvolvimento de um sistema que possa se tornar opção moderna, e principalmente aplicável, para o gerenciamento empresarial.

Também é preciso destacar que as características de ambientel equipamento, existentes num ambiente simulado (laboratório acadêmico) não possibilitam a emulação dos dados de uma empresa adequados às condições de testes. 


\section{3 - AMBIENTE DE TRABALHO}

Este estudo foi desenvolvido para ser aplicado no ambiente de uma organização dentro dos moldes realistas e dentro do contexto deste trabalho e da engenharia de produção. Define-se que uma organização (empresa) é constituída por pessoas que possuem como objetivo proceder à manufatura ou ao oferecimento de produtos e/ou serviços (GRUDNITSKI \& BURCH, 1989).

Para orientar essas pessoas no funcionamento cotidiano da empresa, existem normas, métodos e costumes que são considerados os fatores que determinam a filosofia de trabalho da companhia, também conhecidos como Cultura da Empresa.

A Cultura da Empresa está sujeita a variações de acordo com os diferentes elementos que a compõem. Em outras palavras, ela depende de estruturação dos recursos, mão-de-obra e métodos produtivos e administrativos que lhe estejam disponíveis.

É importante ressaltar que este trabalho foi idealizado e desenvolvido para empresas que utilizam um sistema atuando em rede de computadores com a finalidade de integrar, inclusive remotamente (distante do local físico onde seja executado), as informações, decisões e ações no processo administrativo da corporação.

Essa condição não exclui as pequenas empresas, ao contrário, o trabalho busca difundir essa sistemática administrativa entre as 
companhias de pequeno e médio porte, tornando-as mais competitivas, ágeis e flexíveis e aptas a atenderem um mercado exigente.

O ambiente imaginado para o desenvolvimento deste trabalho é um protótipo de uma empresa real, com seus departamentos básicos e, se possível, incluindo filiais em outras localidades. Dessa forma, estaria garantida a semelhança proporcional com os elementos que podem ser considerados críticos em uma empresa. 


\section{4 - ESCOPO}

Partindo da premissa de que tudo o que tem sido falado sobre esse tema representa pouca literatura técnica, ou seja, pouca teoria sobre o assunto, e que a observação de fatos é o que, na realidade, leva a geração e sistemas que reorganizam a estrutura da empresa e do trabalho, o que se tem observado é uma corrida em que a indústria tem superado a academia. Sendo assim, esta tese de doutorado pretende fornecer literatura acadêmica sobre sistemas administrativos computadorizados, baseada em observações, análises e insights, suprindo uma lacuna que remonta a 1975.

Além disso, busca-se estabelecer um conjunto de características mínimas, necessárias à elaboração, à estruturação e ao funcionamento de um sistema especialista abrangente e modulado, portanto flexível, para a gestão de operações industriais. É importante que esse sistema esteja preparado para, no futuro, ser compatível com as condições e características dos sistemas inteligentes.

O programa aplicativo resultante deverá servir como um sistema computacional integrado que possibilite a administração geral da empresa, através de cálculos, decisões ou sugestões e ações relativas ao planejamento das necessidades de materiais, comerciais, financeira, logística, técnicas e simulações.

Diante do fato de que muitos dos conceitos aplicados no desenvolvimento deste trabalho ainda se encontrarem no estado da arte, 
pode-se dizer que o sistema, teoricamente, independe das características da empresa que se relacionem à localização, ao ramo ou setor de atuação e até mesmo ao porte da companhia, entretanto ressalta-se que o foco das pesquisas concentra-se em empresas produtoras de bens duráveis.

Outro detalhe que merece ser citado é o fato de que as pesquisas e análises e o desenvolvimento do sistema proposto foram realizados no período compreendido entre 1994 e 2000.

Este estudo não pretende discutir a comparação das vantagens entre make-or-buy, uma vez que a proposta aqui feita é documentar as condições e justificativas da criação do sistema, não se importando com a autoria ou como local do desenvolvimento do programa.

Deve-se também destacar que esse tipo de aplicativo necessita de um período de customização em que as características individuais da empresa são identificadas e respeitadas, permitindo adaptações inerentes à flexibilidade do software. Destaca-se também que os aspectos custos e prazos não serão relevados nessa fase de investigação, uma vez que o estudo ainda se encontra no estado da arte. Além disso, a atual velocidade de avanço científico mostra que o custo não tem limitado por muito tempo a utilização dos progressos tecnológicos, ou seja, os avanços são rapidamente popularizados devido à sua veloz queda de custo. 
Uma discussão sobre o aspecto prazo poderia acarretar uma série de diferentes pontos de vista e, desse modo, desviar a direção principal deste estudo. Sendo assim, pode-se dizer que esta pesquisa discute os principais pontos e aspectos na elaboração e na utilização de um programa especialista na administração de empresas. 


\section{2) DEFINIÇÕES BÁSICAS E HISTÓRICO DE EVOLUÇÃO}

Antes de prosseguir com 0 assunto, são necessários alguns esclarecimentos sobre o que se entende por Conhecimento, Sistemas Especialistas, Inteligência e outros conceitos, no contexto deste trabalho, apresentando uma breve introdução daqueles que serão os principais pontos enfocados neste estudo. Também neste capítulo será mostrada rapidamente a evolução dos sistemas especialistas.

\subsection{Definições:}

As definições feitas neste trabalho foram parcialmente extraídas do trabalho de doutorado de BELHOT (1991) e de várias páginas da internet, entre as quais faz-se uma especial referência às seguintes:

- http://www.bus.orst.edu/faculty/brownc/es_tutor/es_tutor.htm;

- http://www.din.uem.br/ia/especialistas/Elementos.html;

- http://www.catalao.com.br/alta2.htm;

- http://www.inf.ufsc.br/ lea/paulase1.htm;

- http://www.eps.ufsc.br/disserta/jamilton/capit_2/imagens/f22_jam.htm 
2.1.a) Conhecimento: é a combinação de instintos, dados, informações, regras e procedimentos que servem de suporte para análises de fatos e situações cotidianas, ou ainda para soluções de problemas baseadas em experiências prévias. De maneira geral, o conhecimento é volumoso e possui diversos aspectos, características e detalhes.

A caracterização do conhecimento é considerada complexa, pois, muitas vezes, tem-se apenas o conhecimento, mas não se sabe como foi adquirido nem como explicá-lo. Na realidade, muitas vezes, não se tem consciência do conhecimento possuído, até porque ele está em constante mudança, sendo aperfeiçoado, ou seja, o conhecimento está sempre crescendo e se modificando.

Também se pode dizer que o conhecimento é composto de dados organizados de forma lógica, de modo a permitir sua interpretação, mas é importante destacar que o conhecimento é uma aquisição individual, uma vez que duas pessoas não adquirem o mesmo conhecimento de uma forma idêntica. Pode-se afirmar que duas pessoas possuem um mesmo conhecimento genérico, mas não como um conceito idêntico, uma vez que cada indivíduo faz sua interpretação do conhecimento.

Por outro lado, para utilizarmos o conhecimento num sistema computacional, há necessidade de elaborar uma estruturação do 
que será utilizada pelo sistema e, para tanto, utiliza-se de uma representação do conhecimento. Ao contrário do conhecimento em si, a representação do conhecimento tem como características principais:

- Generalização: a representação do conhecimento é generalizável, ou seja, uma representação deve possuir vários pontos de vista do mesmo conhecimento, de modo que possa ser atribuído a diversas situações e interpretações.

- Representação passível de atualização/correção do conhecimento: a atualização e a correção do conhecimento formalizado devem ser possíveis, uma vez que o conhecimento não é estático.

- Utilização, ainda que incompleto e impreciso: uma representação do conhecimento deve ser múltipla, isto é, permitir sua utilização mesmo que não aborde todas as situações possíveis.

- Compreensão: é necessário que a representação computacional do conhecimento seja compreensível ao ser humano. Caso seja necessário avaliar o estado de conhecimento do sistema, a representação do conhecimento deve permitir a sua interpretação. 
Tais características não são apenas recomendadas, mas sim, necessárias nos sistemas computacionais de Inteligência Artificial. Levando-se em conta que, em Inteligência Artificial (IA), o que se buscam são repetições do comportamento humano, deve-se procurar copiar a estruturação de seu conhecimento. Nem todas as aplicações de IA envolvem conhecimento estruturado, porém todas necessitam pré-processar o conhecimento existente, o que equivale a dizer que, em sistemas de IA são sempre utilizadas representações do conhecimento humano em formas computacionais.

2.1.b) Sistema: é a disposição das partes (ou elementos) de um todo coordenadas entre si, que funcionam como uma estrutura organizada (FERREIRA, 1994).

2.1.c) Especialista: é a pessoa que se consagra com particular interesse e cuidado a certo estudo. Pessoa que tem habilidade, ou prática especial, em determinado assunto. Conhecedor, perito. (FERREIRA, 1994). 
2.1.d) Sistemas Especialistas: segundo FEIGENBAUM (1977), são sistemas que solucionam problemas que, normalmente, apenas pessoas especialistas conseguem resolver. Pode-se defini-los também como programas de computador que analisam situações problemáticas, ou dificuldades, em um determinado ambiente e buscam a melhor forma de eliminar tais problemas, emulando o raciocínio de um especialista e aplicando conhecimentos específicos e inferências.

Os sistemas especialistas, inspirados na lógica do raciocínio humano e em conhecimentos acerca de um determinado assunto, são expressos em regras. O sistema se encarrega de avaliar quando esse conhecimento deve ser utilizado. Para isso, é preciso que o sistema especialista conheça todas, ou quase todas, formas de resolução de problemas ou de execução de tarefas, sejam cálculos ou procedimentos.

Em geral, eles são projetados e desenvolvidos para atenderem a uma aplicação determinada e limitada do conhecimento humano. São capazes de emitir uma decisão, apoiados em conhecimento justificado, a partir de uma base de dados, tal qual um especialista de determinada área do conhecimento humano.

Um especialista chega a uma decisão sobre um determinado assunto analisando os fatos que encontra, formulando hipóteses e 
usando conhecimento prévio, armazenado durante anos em sua memória. Durante o processo de raciocínio, verifica-se qual a importância dos fatos encontrados, comparando-os com as informações já contidas no seu conhecimento acumulado sobre esses fatos e hipóteses. Nesse processo, formulam-se novas hipóteses, verificando novos fatos.

Esses novos fatos influenciam o processo de raciocínio, que é sempre baseado no conhecimento prévio acumulado.

Com esse processo de raciocínio, um especialista pode não chegar a uma decisão adequada, se os fatos de que dispõe para aplicar o seu conhecimento prévio não forem suficientes.

Os sistemas especialistas são enriquecidos pelo conhecimento de peritos em campos específicos, auxiliando os processos de tomada de decisão. Tais sistemas também são conhecidos como Sistemas que manipulam informações armazenadas em bases de conhecimento e que retratam o raciocínio de especialistas (ROCKART, 1986), onde é possível guardar as decisões tomadas e o raciocínio utilizado para se chegar a elas. Os sistemas especialistas podem buscar informações nessas bases de conhecimento para auxiliar futuras decisões.

As tarefas especialistas são distintas das formais pela sua característica de ser atrelada ao conhecimento prático e por ter sua 
aplicação determinada por regras baseadas no comportamento humano. São, portanto, mais complexas que as tarefas formais e envolvem maior gama de implementações computacionais necessárias.

\section{A Arquitetura do Sistema}

A arquitetura é talvez o ponto crucial para o desenvolvimento do programa que utiliza know-how e abordagens de resolução de problemas com capacidade comparável à dos peritos humanos e deve conter:

1. banco de conhecimentos (contendo fatos, regras e padrões da situação). $\mathrm{O}$ banco de conhecimentos armazena regras, refletindo caminhos de raciocínio empregados pelos peritos e, assim, pelo sistema na resolução de um problema específico;

2. dispositivo de inferência (capaz de tomar decisões num dado domínio). Esse dispositivo controla o processo de invocação das regras pertencentes à solução do problema colocado para o sistema; 
3. linguagem, destinada a escrever as regras e estabelecer a comunicação máquina-homem. Um gerador de aplicações pode ser utilizado para apresentar como o sistema chegou a essa conclusão. As regras devem também ser incorporadas para funcionarem como ferramentas de aquisição de conhecimentos;

4. programa base que engloba o dispositivo de inferência, o administrador de conhecimento e as interfaces de usuários. Usualmente devem refletir técnicas utilizadas para extrair conhecimento do domínio e, posteriormente, representá-lo no sistema.

\section{Arquitetura dos Sistemas Especialistas}

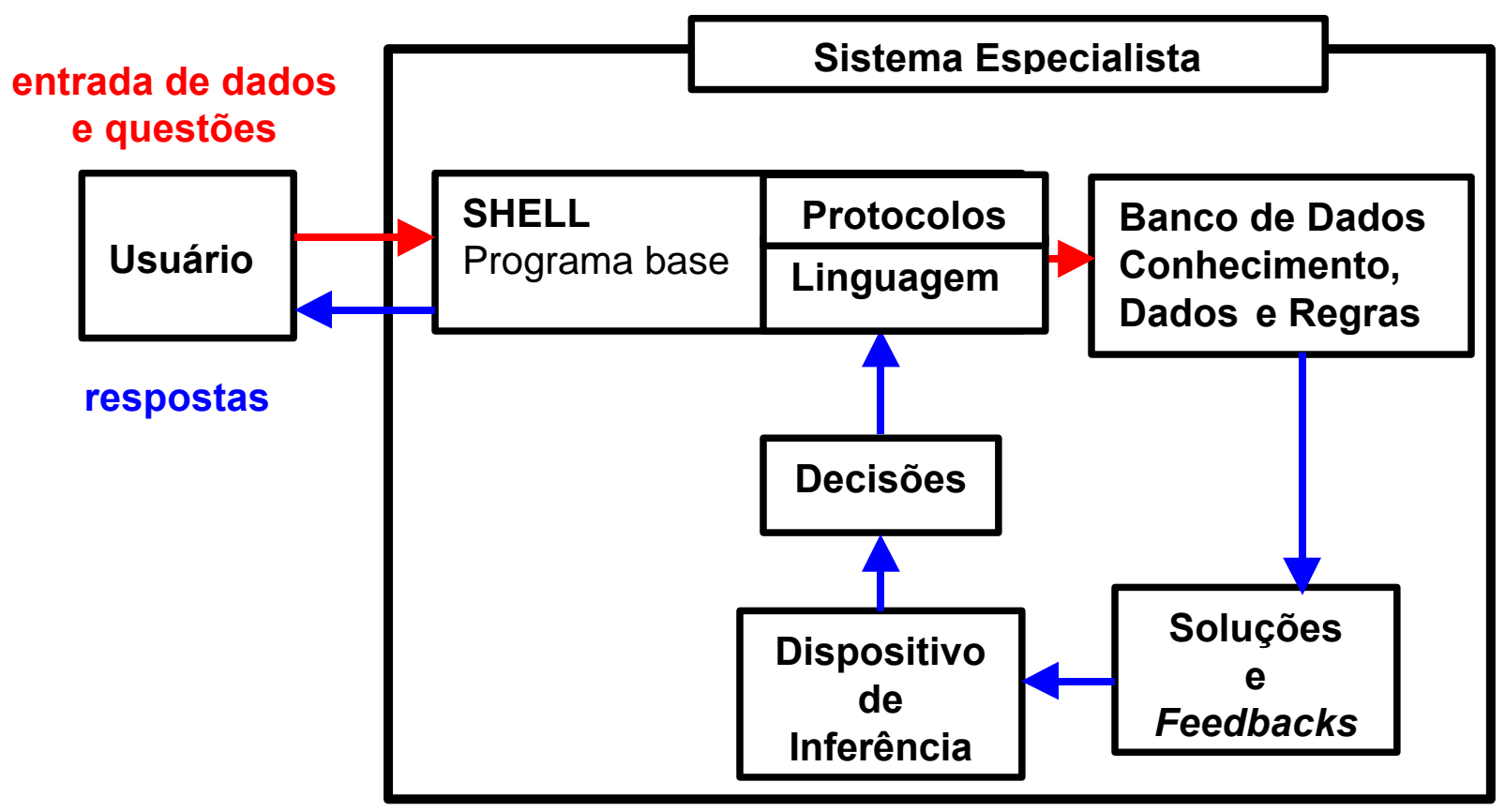

Figura 3 - Estrutura dos Sistemas Especialistas. 
$\mathrm{Na}$ Engenharia, deve-se considerar o auxílio do computador em tarefas de projeto, permitindo a aceleração do desenvolvimento e a otimização dos recursos envolvidos. Além do projeto, também se utilizam de sistemas especialistas para detecção e correção de erros, administração e verificação de qualidade em empreendimentos na área.

2.1.e) Saber Especializado: é o conhecimento utilizado para objetivos e aplicações bem específicas e dentro de um universo delimitado, que serve de base para tarefas, como armar uma estratégia num jogo, realizar cálculos matemáticos ou até mesmo solucionar um problema. Essas atividades são mais facilmente implementáveis em computadores, uma vez que se encontram em uma área bem definida de aplicação e possuem um contexto de conceitos e regras a serem aplicados para a resolução de um problema específico.

No caso de jogos, é necessária a organização das ações e reações dos jogadores, todas elas previsíveis e, portanto, manipuláveis dentro de regras claras. Da mesma forma, nos problemas matemáticos, há regras para a construção de formas geométricas, encadeamento de expressões de lógica e derivação no cálculo integral, entre outras aplicações. 
O conhecimento de um sistema especialista consiste em fatos e heurísticas. Os fatos constituem um corpo de informações largamente compartilhado, publicamente disponível e geralmente aceito pelos especialistas em um campo. As heurísticas são, em sua maioria, privadas; são regras pouco discutidas e de bom discernimento (regras do raciocínio plausível, regras de boa conjectura), que caracterizam a tomada de decisão em nível especializado. O nível de desempenho de um sistema especialista é função principalmente do tamanho e da qualidade do banco de conhecimento que possui (HARMON, 1988).

2.1.f) Sistema (ou software) de Gestão: é um programa de computador que auxilia na administração, total ou parcial, da empresa, podendo ser composto por vários módulos, cada qual com uma finalidade. Em geral, não possui estrutura lógica para trabalhar em rede com outros computadores e/ou usuários.

2.1.g) Sistema Integrado de Gestão - SIG: é um conjunto de programas e cálculos realizados para administração da empresa, que consideram a mesma base de dados para todos os departamentos e setores. O Sistema Integrado de Gestão é uma evolução dos sistemas administrativos que busca garantir a unificação e a 
confiabilidade dos números e cálculos, necessários para a administração da empresa, fazendo com que as orientações e ações tomadas pela empresa sejam mais seguras. As resultantes dos cálculos, assim como as previsões e estimativas assumidas, influenciam, direta ou indiretamente, em diferentes graus os demais setores da empresa, conforme ilustra a Figura 4 abaixo.

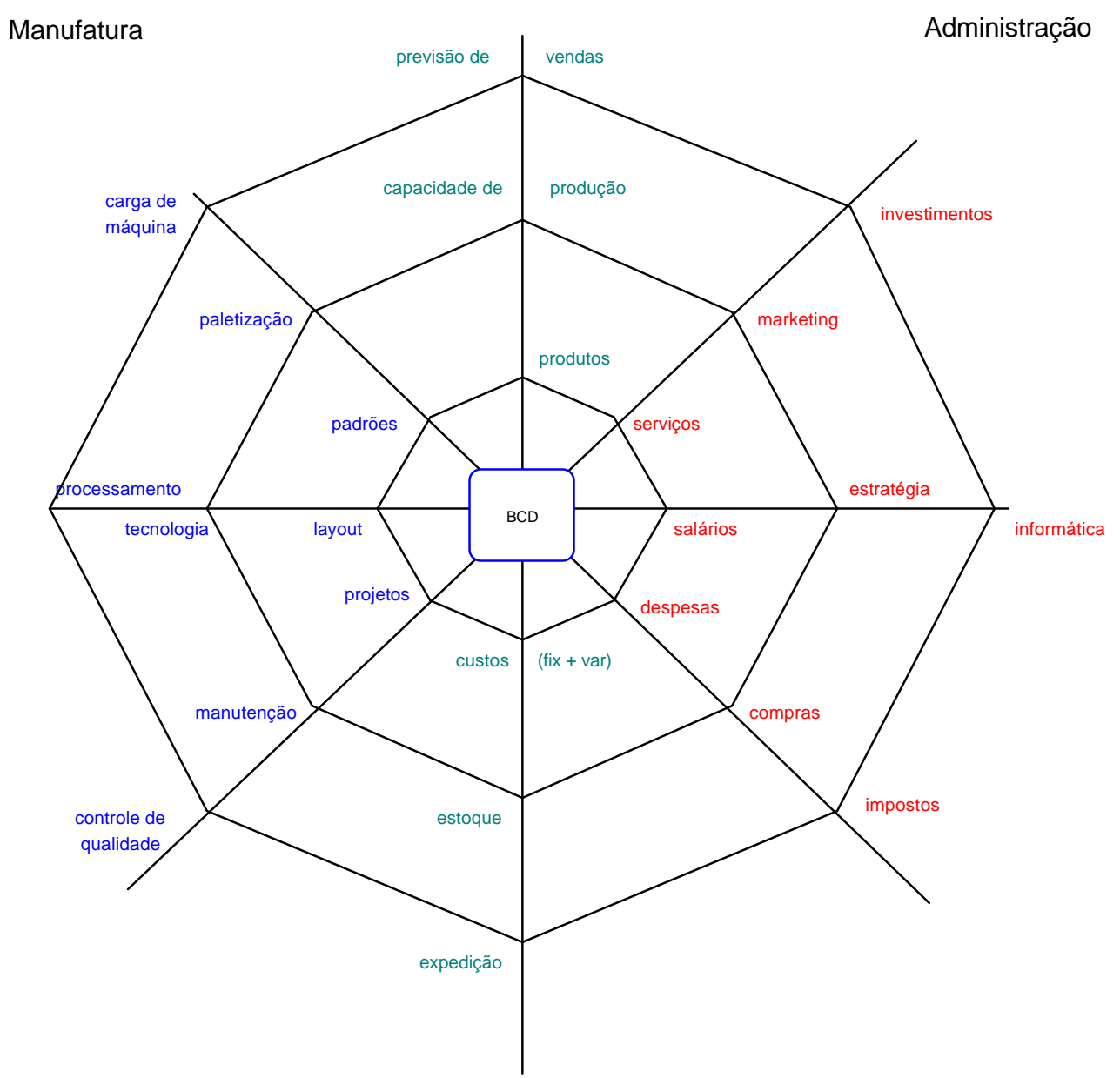

Figura 4 - Exemplo das Inter-Relações de um Sistema Integrado. (Fonte: Barrella, 1995). 
2.1.h) Base de Conhecimento: é um elemento residente e específico de um sistema especialista, onde estão armazenados os dados (fatos e regras), nos quais se baseiam as análises e decisões do sistema.

2.1.i) Inteligência: é a faculdade de aprender ou compreender. Qualidade ou capacidade de compreender, perspicácia. Destreza mental, habilidade. (FERREIRA, 1994).

2.1.j) Inteligência Artificial: é o conhecimento embutido no "hardware" para a solução de problemas, o que permite um determinado conjunto de estados possíveis de funcionamento através de programas.

A inteligência de máquina é uma ferramenta construída pelo homem, portanto, artificial.

Mas o conceito de Inteligência Artificial (IA) abrange mais do que a inteligência de máquina. Busca-se, com ela, capacitar o computador com um comportamento inteligente.

Entende-se por comportamento inteligente as atividades que envolvem, entre outras, tarefas de aprendizado e raciocínio (planejamento e estratégia).

Também se pode dizer que inteligência artificial é um conjunto de sistemas cooperativos que assistem de perto os humanos em seu 
trabalho diário e, em alguns casos, são sistemas autônomos que podem operar sem intervenção humana. Isso inclui a aquisição, o aprendizado, a especificação da base de conhecimento direcionado e as metodologias de trabalho.

2.1.k) Conjuntos Difusos (Lógica Fuzzy): são os sistemas inspirados nos adjetivos característicos da linguagem humana. Baseia-se na representação matemática da incerteza. Variáveis lingüísticas, não determinísticas, tais como os adjetivos alto e baixo, para a característica altura, podem ser utilizadas e combinadas. Esses sistemas têm como principais características a capacidade de utilizar, manipular e combinar dados imprecisos.

2.1.I) Redes Neurais: são sistemas que possuem inspiração nos princípios do processamento neurofisiológico, baseado no processamento paralelo e distribuído de informações. Esses sistemas têm como principais características o aprendizado através de exemplos, a capacidade de generalização e a execução em tempo real. 
2.1.m) Sistemas de Informação: são sistemas que permitem a coleta, o armazenamento, o processamento, a recuperação e a disseminação de informações. Esses sistemas são hoje, quase sem exceção, baseados no computador e apoiam as funções operacionais, gerenciais e de tomada de decisão existentes na organização. Os usuários de SI são provenientes tanto do nível operacional, como do nível tático e estratégico e utilizam o SI para alcançar os objetivos e as metas de suas áreas funcionais.

2.1.n) Simulação: é a experiência ou o ensaio realizado com auxílio de moldes (FERREIRA, 1994).

Muitas decisões poderão ser tomadas através de modelos simulados em computadores, que servirão para analisar e avaliar um amplo conjunto de problemas do mundo real (FITZPATRICK, 1993). As alternativas poderão ser analisadas e validadas através de simulação, antes que a decisão final seja tomada.

2.1.o) Interface: é o conjunto de dispositivos, métodos e filosofias responsáveis pela conexão e integração entre o homem e a máquina - mais especificamente, o computador. Na atual situação tecnológica existente, é impossível não considerar as benesses 
dos sistemas multimídias, nos quais são utilizados componentes audiovisuais, além do teclado e dos sensores de toque.

2.1.p) Interfaces Amigáveis: é a representação da informação exibida através de várias mídias (voz, sons, imagens, animação, texto etc.) de maneira simples, auto-explicável e, principalmente, agradável aos usuários. 


\section{2) Histórico da Inteligência Artificial}

A Inteligência Artificial (IA) não é recente; sua história se inicia nos idos dos anos 40 , quando havia alguma pesquisa em torno de seqüências de estratégia e análise do funcionamento do cérebro, com objetivos de formalização de seu comportamento.

Essas pesquisas ainda não demonstravam nenhuma preocupação com a construção de uma Inteligência Artificial, buscavam-se apenas novas alternativas de utilização do computador.

Com o passar dos anos, foram sendo distinguidas duas linhas de pesquisa: uma biológica (calcada no funcionamento do cérebro e dos neurônios) e outra baseada no raciocínio (fruto do estudo da cognição) e ambas procuravam acrescentar a capacidade de aprendizado aos programas de computador.

Entendo que o desenvolvimento da IA contém aspectos interessantes e que indicam quais as direções a serem tomadas no futuro, fazendo um apanhado dos principais fatos, disponibilizados em vários locais na internet, mas descritos principalmente nestas páginas:

- http://sis.bris.ac.uk/ ma7170/public_html/history.html;

- http://www.icmsc.sc.usp.br/ solange/IA/iag_in/;

- http://www.ulbra.tche.br/ danielnm/ia/defbas/de.html. 


\section{2.a) ANOS 40}

Durante a segunda guerra mundial, cresceu a necessidade do avanço tecnológico, para fornecer mais instrumentos para o combate bélico. Naquele período, o apoio financeiro estava à disposição dos cientistas para desenvolver mecanismos de morte em massa, de modo a fazer com que a guerra fosse ganha pelo poder tecnológico.

A arma mais letal idealizada na época era a bomba atômica mas, para seu desenvolvimento, era necessária uma quantidade gigantesca de cálculos, que deveriam ser extremamente precisos. Nesse contexto e para que fosse possível o cálculo da bomba atômica, alavancou-se o desenvolvimento do computador como o concebemos atualmente, mas não somente para cálculos: o computador foi utilizado também em outros recursos voltados para fins militares, como o planejamento de ações estratégicas de exércitos - simulações do avanço de tropas era possível, informando-se as variáveis envolvidas na ação e permitindo, assim, a elaboração de diversas hipóteses de estratégias. Tal como em um jogo de guerra, as combinações de possibilidades eram simuladas.

Esse foi o ponto de partida dos jogos por computador, utilizados também para situações mais reais, além de jogos de dama e xadrez e pode ser considerado o início da inteligência artificial tradicional baseada em regras. 
Por outro lado, havia um segundo ramo de pesquisas interessado na realização da representação das células nervosas do ser humano no computador - uma vez que o cérebro é formado de neurônios e é ele que realiza o processamento das informações do corpo. Essa linha de pesquisas originou o desenvolvimento de uma formalização matemática para o neurônio, estabelecendo o neurônio formal.

Tal formalização permitiu a realização de diversas concepções matemáticas sobre a forma de aprendizado dos neurônios, ou seja, como os neurônios armazenam informações. Essa linha motivou o desenvolvimento de modelos de redes de neurônios artificiais na década seguinte.

\section{2.b) ANOS 50}

Nessa década, iniciaram-se os estudos na linha psicológica, baseada na lógica de estratégia para finalidades matemáticas, como a prova de teoremas. Iniciou-se também a modelagem através de regras de produção, baseadas na lógica de predicados.

A introdução da programação através de comandos de lógica de predicados proporcionou um grande avanço para a programação de sistemas que utilizassem esquemas de raciocínio. 
A partir desse fato foi possível o aperfeiçoamento dos jogos já existentes, de aplicações matemáticas e de simuladores. Esse avanço foi tão significativo que provocou, nos anos 60 , uma euforia diante do potencial tecnológico vislumbrado.

Em paralelo, para a linha biológica, essa foi uma década de grande sucesso, dada a implementação do primeiro simulador de redes neurais artificiais e do primeiro neuro-computador, possível a partir do modelo matemático de MACCULLOC e PITTS (1943) e da teoria de aprendizado de HEBB (1949), que permitiu a união de conhecimentos no modelo de rede neural artificial, chamado Perceptron.

\section{2.c) ANOS 60}

$\mathrm{Na}$ linha biológica, prosseguiram os desenvolvimentos de conceitos relativos às redes neurais artificiais, com o aprimoramento do modelo Perceptron e o surgimento de uma variante, o Adaline. Ambos utilizavam as mesmas idéias de rede, porém a lógica de aprendizado os diferenciava.

Para a linha psicológica, essa década foi a descoberta da Inteligência Artificial. Utopicamente, os pesquisadores dessa área acreditavam ser possível realizar tarefas humanas, tais como o pensamento e a compreensão da linguagem, através do computador. 
Realmente, acreditava-se ser possível a reprodução pura e simples do raciocínio humano no computador.

Nesse sentido, foi tentada a interpretação da linguagem no computador, tal como compreendida pelo ser humano. No ímpeto da racionalização imposta pelo desenvolvimento das pesquisas, acreditava-se que apenas através do raciocínio seria possível a interpretação da linguagem.

Obviamente a linguagem humana não é fruto apenas da razão, mas de todo o aparato sensorial e lógico do ser humano.

Por outro lado, em 1969, Marvin Minsky e Seymour Papert publicaram um livro, denominado Perceptrons, o qual destinava-se a ridicularizar as pesquisas em torno das redes neurais artificiais. Os autores sustentavam a hipótese de que os modelos apresentados não tinham sustentação matemática para terem credibilidade. Ambos tiveram êxito na sua empreitada, levando ao ostracismo os pesquisadores da linha biológica.

\section{2.d) ANOS 70}

$\mathrm{Na}$ década de setenta, houve uma revolução na área computacional, culminando com a criação dos sistemas especialistas. O objetivo dos cientistas da Inteligência Artificial era desenvolver programas de computador que pudessem, em alguns sentidos, pensar, isto é, resolver problemas de maneira que fossem considerados inteligentes, se fossem feitos pelo homem. 
Os sistemas especialistas são fruto de vinte anos de pesquisa e seu uso tem se difundido por todo o mundo, obtendo-se sucesso. Apesar de essa ter sido uma década negra para a linha biológica, houve pesquisadores que, por outros caminhos, chegaram a novas concepções de redes neurais artificiais.

Essas concepções analisavam o aprendizado de informações, como o fruto de uma união das potencialidades de redes de neurônios interagindo entre si. Nasciam as redes neurais, representadas na forma de mapas cerebrais, onde não havia o aprendizado de um neurônio, mas de toda uma rede, através do compartilhamento de recursos.

$\mathrm{Na}$ linha psicológica, estudos mais aprofundados demonstraram o óbvio: que não seria possível a representação numa máquina dos estados mentais humanos responsáveis pelo pensamento - ao menos naquele estágio da tecnologia.

A saída para essa linha de desenvolvimento era dada por uma empresa, a Rand Corporation. Foi de sua equipe de pesquisa que partiram os sistemas especialistas responsáveis pela ampliação da Inteligência Artificial Tradicional. 


\section{2.e) ANOS 80}

Em Singapura, desde 1980, têm sido utilizados sistemas especialistas em setores bancários, na área financeira e na manufatura, dentre outros. Podem ser citados alguns dos importantes sistemas especialistas desenvolvidos em Singapura: Audit Expert System, no setor de contabilidade, Credit Evaluation, no setor bancário e Intelligent Fuzzy Logic Tutor, no setor de educação. Vale ressaltar que um sistema especialista nunca atingirá a capacidade cognitiva do especialista humano, porém, na sua ausência, é uma válida ferramenta para resolução de problemas. As redes neurais artificiais tiveram seu reconhecimento recuperado através do físico Jonh Hopfield que, em 1982, provou ser possível a simulação de um sistema físico através de um modelo matemático baseado na teoria das redes neurais. Assim, em 1986, uma equipe de especialistas das mais diversas áreas reuniu-se para validar as pesquisas em torno das redes neurais, possibilitando a volta a essa linha de pesquisa.

Uma das formas de recuperação do prestígio das redes neurais foi a proposta de um modelo, chamado Backpropagation, que ampliava o potencial do Perceptron de modo a permitir a superação das limitações do modelo primitivo. Enquanto isso, na IA tradicional, ampliavam-se as técnicas e aplicações dos sistemas especialistas. Além disso, houve o interesse de trabalho conjunto com outras áreas, tais como: interfaces inteligentes, sistemas de apoio à decisão, controle de robôs, entre outros. 


\section{2.f) ANOS 90}

Nessa década, as redes neurais tiveram uma explosão exponencial de aplicações e desenvolvimento de modelos. São centenas de propostas de novos modelos, ou de aperfeiçoamento dos já existentes, a cada ano, tal o interesse pela área. A partir daí, consolidam-se as redes neurais como parte integrante do estudo da Inteligência Artificial propriamente dita. Reconhece-se também que os paradigmas biológico e psicológico são complementares e necessários para sistemas mais evoluídos. Dessa forma, começam nessa década a serem construídos os chamados Sistemas Híbridos, ou seja a união de concepções das duas linhas de pesquisa, permitindo a construção de grandes sistemas que pretendem abranger uma forma mais completa de representação do comportamento humano, ideal da própria Inteligência Artificial.

No Japão, tem sido desenvolvido um grande número de sistemas especialistas para diagnósticos, planejamento, escalonamento e para indústrias pesadas. Aplicações de lógica difusa estão se multiplicando, principalmente na área de eletrodomésticos.

Na Alemanha, os sistemas especialistas são utilizados principalmente para as indústrias pesadas e o uso da lógica difusa está crescendo rapidamente.

Nos Estados Unidos, existem várias tendências no uso dos sistemas especialistas, como o movimento contínuo em direção à integração e aos 
sistemas híbridos; a ênfase no problema de solução de negócios; o crescimento da tendência de sistemas de informação ativos, bases de conhecimento amplas, compartilhamento desse conhecimento e sistemas inteligentes híbridos; a necessidade de fornecer suporte de alto nível para pesquisa em Inteligência Artificial; e o uso de metodologias estruturadas para desenvolvimento de sistemas especialistas.

\section{Comentário:}

Após avaliar informações apresentadas neste capítulo, entende-se que um sistema especialista nunca atingirá a capacidade cognitiva do especialista humano, porém muitas das tarefas humanas já podem ser reproduzidas por esses sistemas, constituindo-se numa ferramenta válida de resolução de problemas, com a ressalva de que os sistemas não resolvem problemas, simplesmente repetem soluções previstas. 


\section{3) SISTEMAS ATUAIS}

Nos últimos anos, a informática tornou-se uma importante ferramenta para todas as áreas do conhecimento, transformando-se, em alguns casos, num instrumento não apenas relevante, mas imprescindível para o desenvolvimento das mais diversas atividades.

Um bom exemplo desse fato é a aplicação dessa ferramenta na Engenharia de Produção, que procura principalmente as melhores soluções para vários problemas relacionados à melhoria da produtividade, dos custos e da qualidade dentre outros.

Para iniciar a discussão sobre os sistemas especialistas e suas funções é necessário antes entender como os sistemas estão atualmente inseridos nas estruturas empresariais.

Para o bom funcionamento da empresa, é preciso que haja uma troca intensa de dados e informações, entre as áreas de manufatura e administrativa.

Entretanto, ao se analisar essa estrutura com mais profundidade, observa-se que, ao contrário das informações, o fluxo de decisões flui num único sentido. 
A Figura 5, abaixo, ilustra a estrutura administrativa de uma empresa, conforme as observações e análises deste estudo.

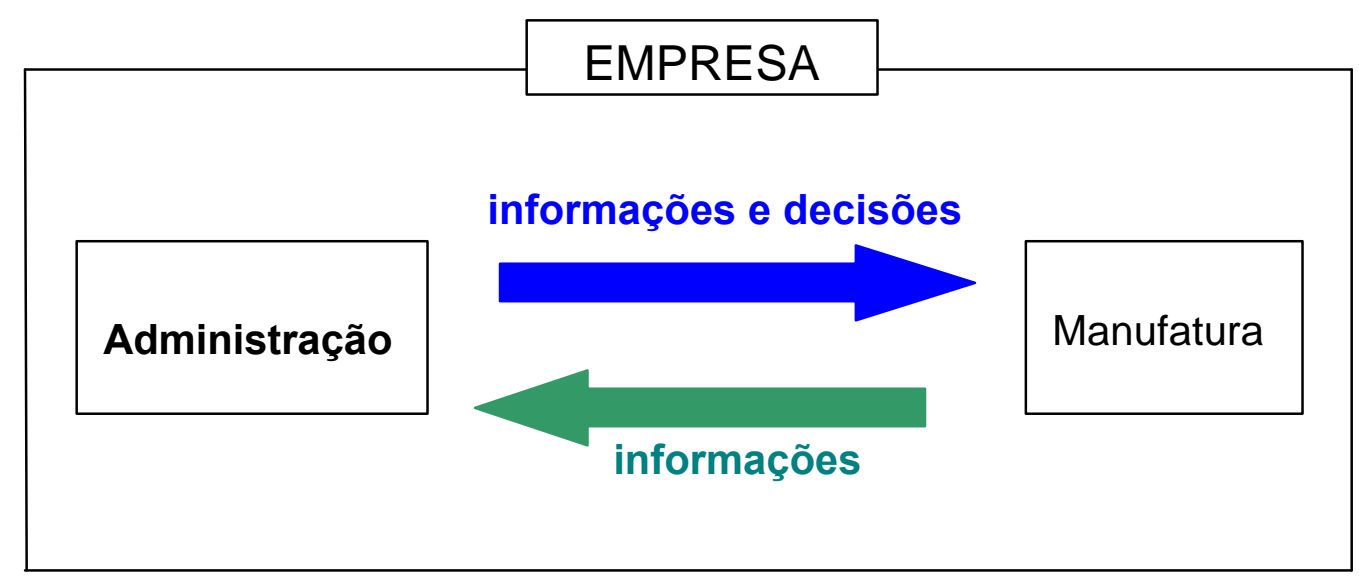

Figura 5 - Estrutura Administrativa das Empresas.

Examinando-se mais detalhadamente essa estrutura, chega-se à conclusão de que, mesmo sem ser informatizado, existe um componente intermediário (Banco de Dados), utilizado como depósito na troca de informações entre as áreas administrativa e produtiva. Esse banco de dados que, em geral, está agregado à área administrativa, completa a estrutura básica da empresa, como mostra a Figura 6, abaixo:

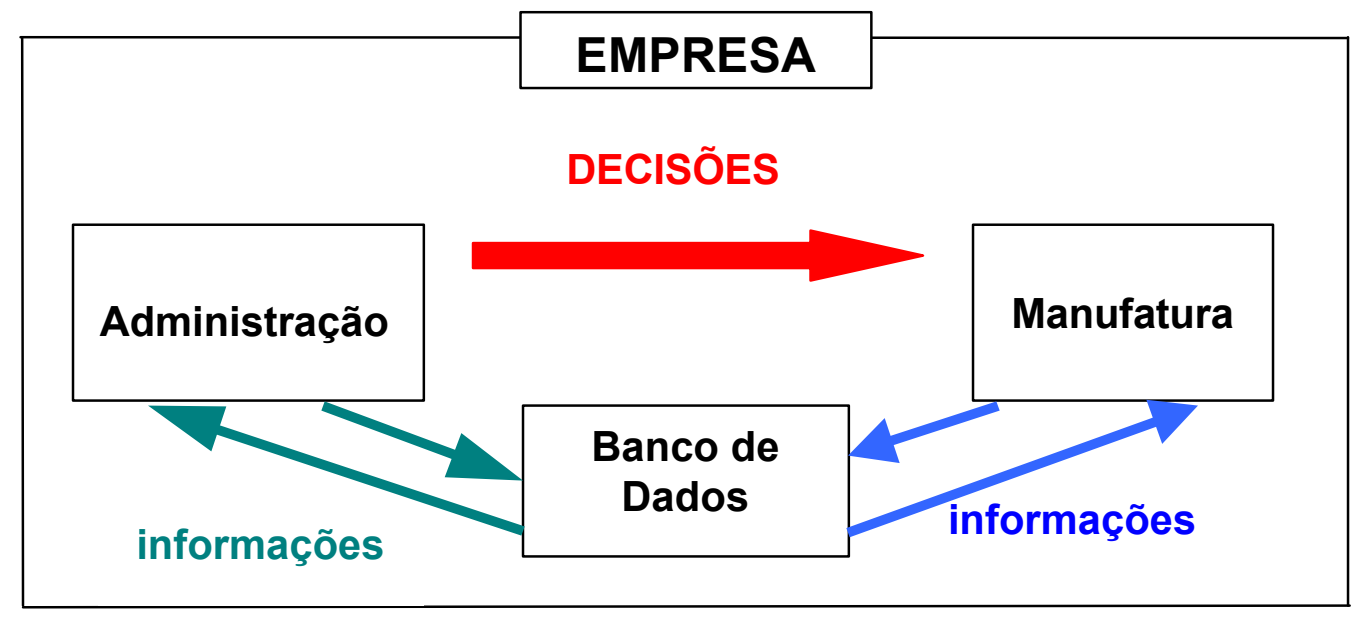

Figura 6 - Estrutura Administrativa das Empresas. 
Considerando-se que as alterações de condições econômicas e tecnológicas (exemplos: variações cambiais, demanda, consumo etc.) têm sido cada vez mais velozes, é natural que haja também um aumento na velocidade de tomadas de decisões e, mais do que isso, que essas decisões sejam mais acuradas. Então, aproveitando os avanços alcançados, acrescentou-se um novo elemento - o sistema especialista para auxiliar na execução das tarefas e melhorar o desempenho da empresa. Esse elemento é normalmente inserido na estrutura, conforme ilustra a Figura 7, abaixo:

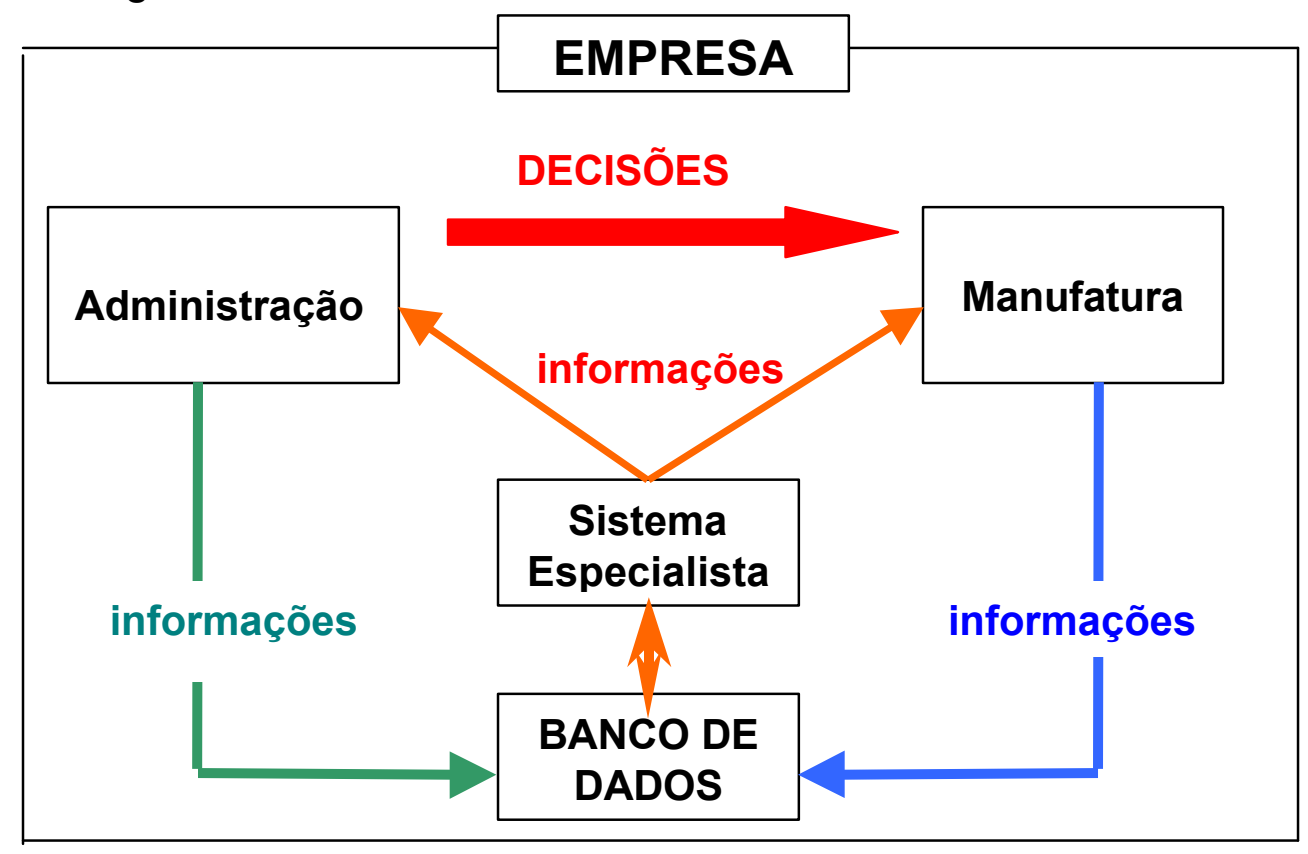

Figura 7 - Estrutura Administrativa de Empresas Modernas.

Embora esse novo elemento não garanta que as decisões tomadas (ou sugeridas) sejam $100 \%$ corretas, ou ainda que o desempenho individual dos departamentos melhore imediatamente, ele aumenta a possibilidade de que isso ocorra. 
O tipo de arquitetura, ou Filosofia de trabalho, mostrado na Figura 7, é normalmente utilizada nos sistemas ERP (Enterprise Resource Planning). Convém esclarecer que ERP é o termo usado para denominar o software multimodular que executa um conjunto de atividades, com o objetivo de auxiliar a gestão de uma empresa nas importantes fases de seu negócio. (HABERKORN, 1999); (http://www.whatis.com/erp.htm - 14/10/99); (http://bis.cba.cmich.edu/whatiserp.htm - 14/10/99).

Em outras palavras, ERP caracteriza uma arquitetura de software que facilita o fluxo de informações entre todas as atividades da empresa.

Tal comunicação é realizada através de um banco de dados que interage com um conjunto integrado de aplicações, consolidando todas as operações do negócio em um único ambiente computacional. (CORRÊA, 1997) (http://ourinhos.com.br/perin/interest.html - 22/07/99)

Também é conveniente lembrar que a instalação de um sistema especialista passa por um processo que inclui instalação, conFiguração e treinamento no uso do sistema. Além disso, o Sistema Especialista nem sempre está apto a executar todas as tarefas desejadas, o que significa que ele deve estar numa constante evolução.

Sendo assim, torna-se interessante comentar algumas características, observadas nos principais sistemas de gestão empresarial, atualmente em uso. 
Destaque-se o fato de que as observações e comentários, a seguir, estão baseados no material técnico-demonstrativo fornecido, ou disponibilizadas na Internet, pelas empresas produtoras.

Ressalta-se ainda que, apesar de os sistemas ora apresentados serem desenvolvidos empiricamente, não se pretende de maneira alguma retirar seus méritos, mas apenas lembrar que não houve o desenvolvimento acadêmico de uma teoria que orientasse ou limitasse as atividades desses sistemas.

3.a) Para melhor compreensão das funções e características inerentes aos sistemas ERP, foram analisados alguns dos sistemas mais utilizados comercialmente. A escolha desses sistemas foi realizada em função da porcentagem de mercado atendida (http://ourinhos.com.br/perin/interest.html); da existência de material informativo na Internet; e pela análise de material complementar fornecido pelos respectivos fabricantes.

3.a.1) SAP / R3

3.a.2) Oracle Applications

3.a.3) BAAN

3.a.4) EMS

3.a.5) Siga Advanced. 


\section{3.a.1) SAP / R3}

Em 1972, na cidade de Mannheim, na Alemanha, três engenheiros começaram a produzir um software para soluções integradas de negócios. Foi então criada a empresa S. A. P. (Systemanalyse und Programmentwicklung), a fim de desenvolver e comercializar um software de gerenciamento de empresas e de seus diversos módulos. O sistema R3 foi desenvolvido com uma estrutura modular integrada, oferecendo capacidade de integração com diversos sistemas externos e interface gráfica do usuário.

Esse software funciona na maioria das plataformas de hardware e principais sistemas operacionais, com conexões aos bancos de dados e às aplicações existentes, feitas automaticamente.

Outra característica do R3 é que, à medida que a empresa cresce, podem ser incluídos novos usuários e módulos, ativar funções adicionais e adaptar o sistema para que esteja sempre adequado às estratégias da empresa.

\section{Os principais módulos do R3 são:}

- Recursos Humanos

- Materiais

- Contabilidade Financeira

- Controle de Qualidade

- Controladoria

- Projetos

- Investimentos de Capital 
- Produção

- Tesouraria

- Produção em Indústria de Processos

- Vendas e Distribuição

- Controle de Empresa

- Manutenção

- Workflow

O R3 foi projetado para satisfazer as necessidades desde a pequena à grande empresa, pois, apesar dos tamanhos diferentes, as empresas possuem as mesmas funções básicas (comprar, vender, produzir, gerenciar clientes, recursos e funcionários) e devem estar aptas a lidar com as constantes mudanças, típicas da economia moderna.

Certamente as grandes empresas estão melhor aparelhadas e farão maior e melhor uso desse sistema, porém o tamanho da empresa não será fator restritivo para o seu uso.

Também convém lembrar que as pequenas empresas reagem mais rapidamente às pressões do mercado e, nesse caso, a chave para a obtenção de vantagens competitivas é ter os processos integrados. Isso equivale a dizer que o R3 deve preparar as empresas para:

- reagir rápida e precisamente às demandas;

- acessar dados críticos para sua missão; e

- reduzir estoques. 
Em outras palavras, o R3 assegura que as atividades da empresa (financeira, industrial, vendas, distribuição, recursos humanos) sejam integradas dentro de um único ambiente de software, interligando-as através de uma conexão em tempo real e compartilhada.

Dessa forma, entende-se que o objetivo do R3 é permitir o gerenciamento mais eficiente da companhia através da otimização das operações, podendo reduzir estoques e despender mais tempo analisando dados ao invés de prepará-los.

Enquanto isso, na parte de simulações, o R3 fornece inúmeros cenários de negócios, permitindo a escolha daquele mais adequado às necessidades específicas da empresa, assegurando flexibilidade e escalonamento, para responder rápida e precisamente às condições dinâmicas do mercado.

Analisando as informações sobre o R3, entende-se que o sistema analisa a empresa, partindo do ponto de vista financeiro e administrativo, fazendo com que a manufatura seja apenas mais um agregado, e não, o ponto de partida para a gestão da empresa.

Outra característica observada é que, esse sistema utiliza conceitos diferentes daqueles normalmente usados em empresas nacionais. Tais diferenças são justificadas pelo fato de cada país possuir características especiais na sua cultura popular, empresarial e financeira. 
A Figura 8, abaixo, ilustra alguns exemplos dos tipos de telas existentes no sistema R3.
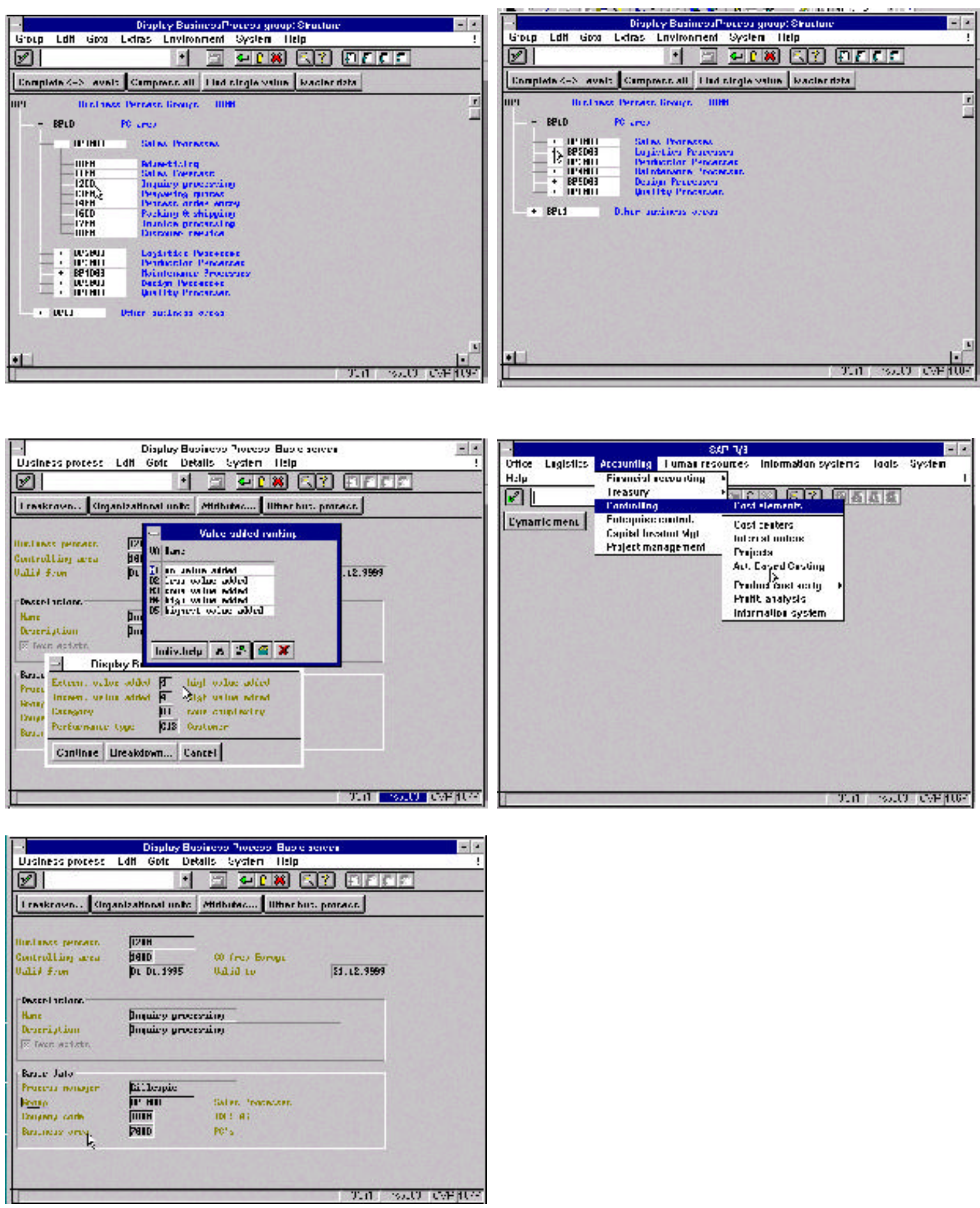

Figura 8 - Exemplos de Telas de Módulo.

(material fornecido pelo fabricante) 


\section{3.a.2) ORACLE APPLICATIONS (R11)}

O sistema Oracle Applications Release 11 foi desenvolvido pela empresa Oracle, conhecida do ramo de programas de Banco de Dados e, assim como o sistema anterior, o Oracle R11 também é formado por um conjunto de módulos de aplicativos (integrados para a administração de manufatura, suprimentos, finanças, projetos, recursos humanos etc.), que tornam possível, ou facilitam, a administração da empresa.

A idéia inicial do Oracle $\mathbf{R} 11$ é basear seus vários módulos (responsáveis pela orientação das soluções dos problemas do cotidiano da companhia), sobre um eficiente sistema de banco de dados (que centraliza um alto número de informações da empresa), conforme ilustra a Figura 9.

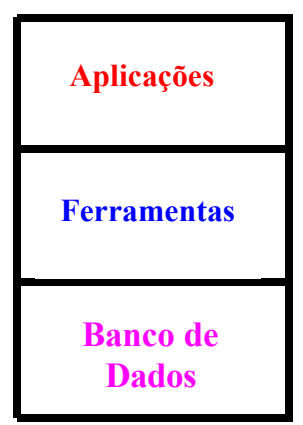

Figura 9 - Estrutura de Trabalho do Oracle R11.

(material fornecido pelo fabricante)

Para fornecer orientações e soluções desejadas, a Oracle desenvolveu seis módulos principais, conforme mostra a Figura 10, a seguir. 


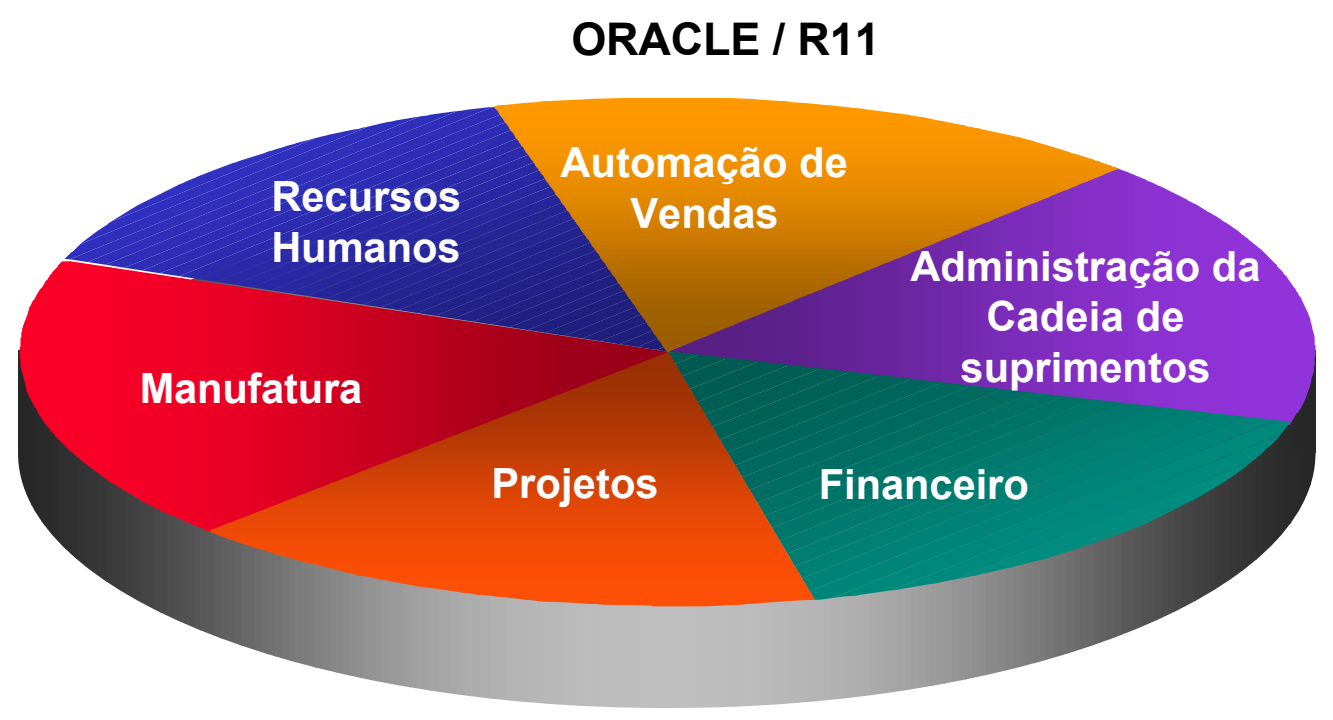

Figura 10 - Estrutura do Sistema Oracle R11.

(material fornecido pelo fabricante)

Como se pode observar na Figura 10, os módulos administrativos são em maior número que os de manufatura, o que nos leva a concluir que esses módulos possuem maior importância que os módulos de manufatura.

Aprofundando-se um pouco mais no sistema Oracle R11, percebe-se que esse software não dispensa a mesma atenção aos aplicativos básicos, largamente difundidos, como folha de pagamento e ordens de serviços, preferindo dar um tratamento especial e diferenciado a temas estratégicos, como a Cadeia de Fornecimento.

Apesar de ser possível utilizar esses módulos isoladamente, eles são desenvolvidos com a capacidade de serem agrupados de maneira a formar um único software.

Essa característica é observada em vários sistemas semelhantes e transmite a idéia de uma flexibilização/adequação do sistema às 
necessidades da empresa, trazendo à mente a imagem de um quebracabeça que pode ser modificado, segundo os interesses da companhia, conforme ilustra a Figura 11, a seguir.

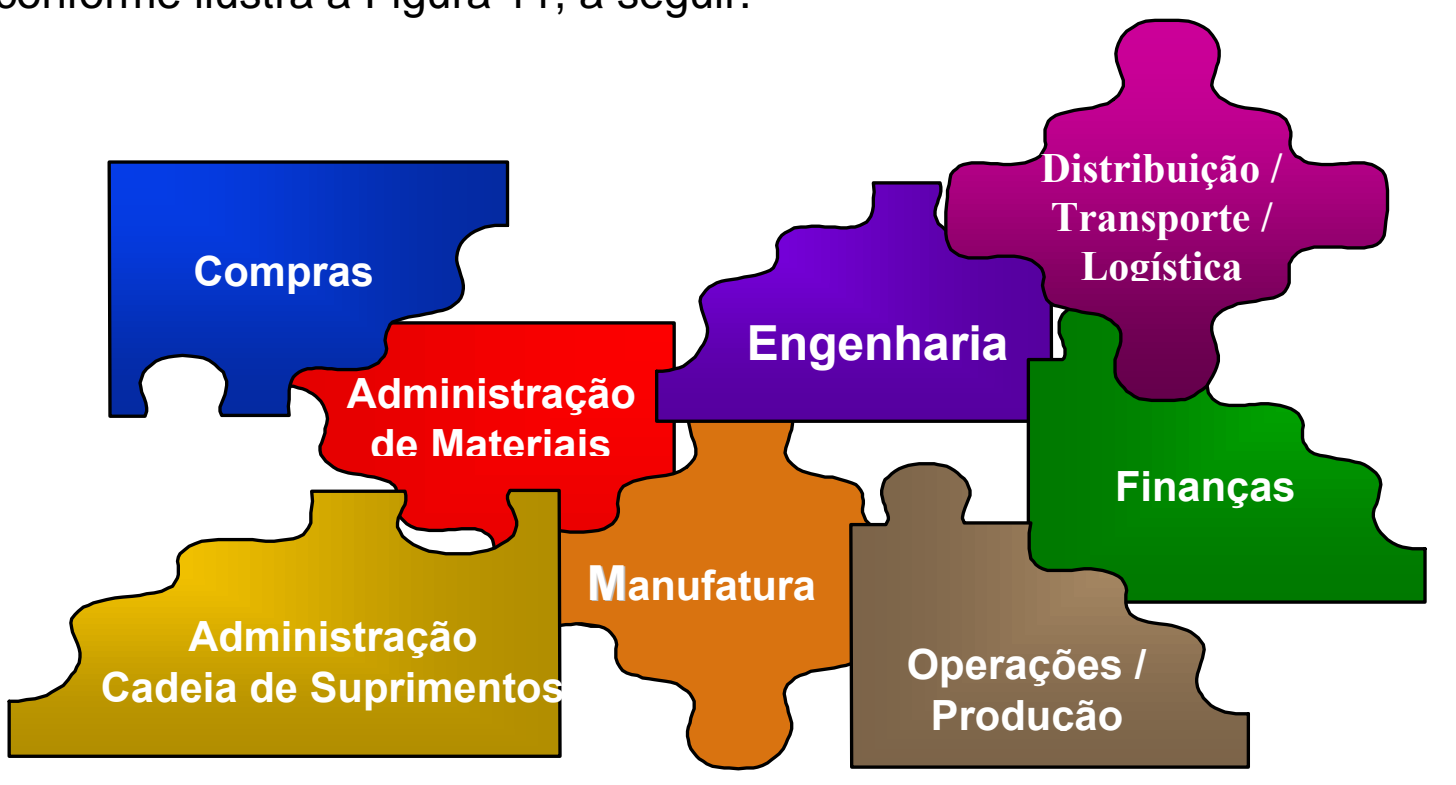

Figura 11 - Possibilidades de Flexibilização/Adequação do Sistema. (material fornecido pelo fabricante)

O módulo de manufatura possui várias características relevantes - como a tarefa de administrar e solucionar problemas relacionados a Administração da Qualidade, Administração de Custos, Produção, Cadeia de Fornecedores, Planejamento e Simulação e Desenvolvimento de Novos Produtos - conforme ilustra a Figura 12, a seguir:

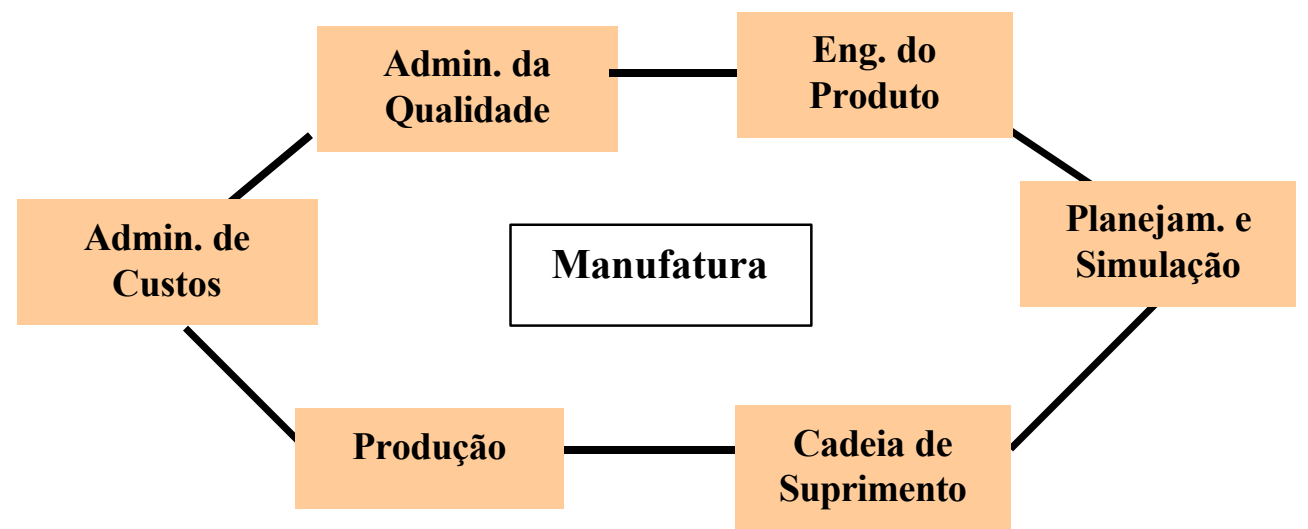

Figura 12 - Módulo de Manufatura.

(material fornecido pelo fabricante) 
Dessa forma, identifica-se que esse módulo se propõe a uma série de objetivos e metas, entre as quais destacam-se:

- redução de inventários;

- redução de trocas e preparações;

- redução de tempo de ciclo;

- redução de custos de material;

- otimização de recursos;

- redução de perdas; e

- evolução contínua.

Entre outros aspectos operacionais, esse módulo demonstra a preocupação em armazenar as folhas de processamento do produto e seus respectivos desenhos e dados técnicos, conforme ilustra a Figura 13, a seguir.

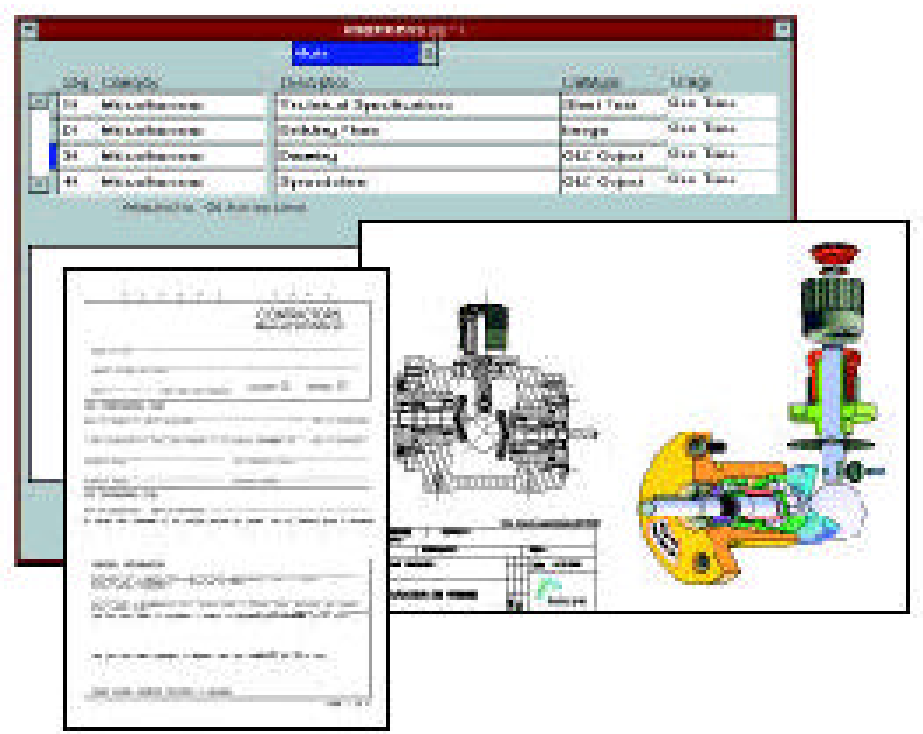

Figura 13 - Desenhos e Dados Técnicos. (material fornecido pelo fabricante) 
Também existe a preocupação com o armazenamento e a disponibilização do fluxo do processo, utilizado na manufatura dos produtos, como mostra a Figura 14.

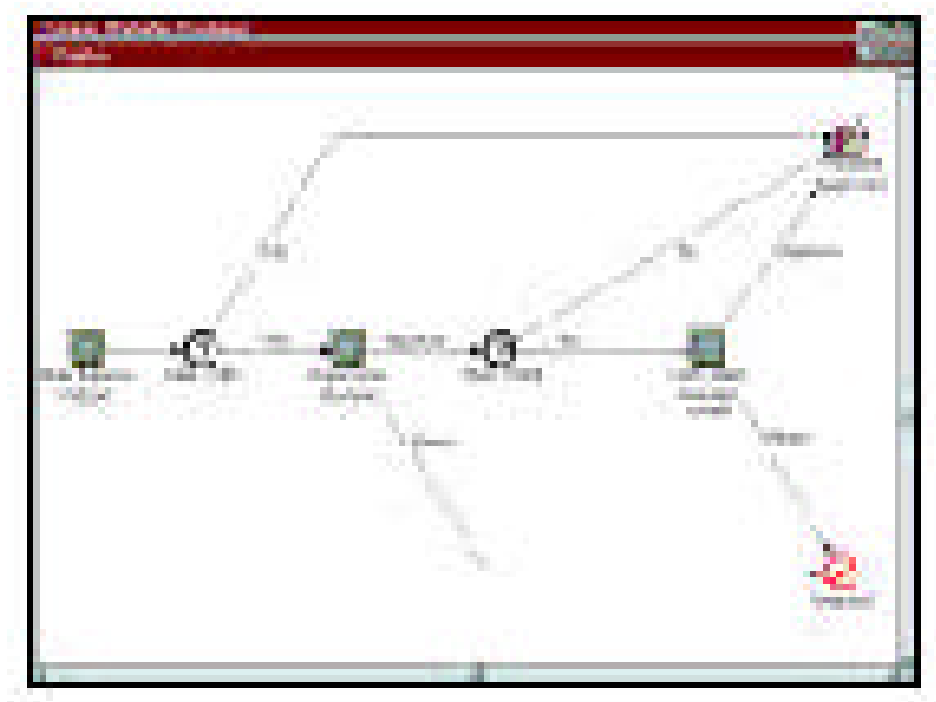

Figura 14 - Fluxo de Processo. (material fornecido pelo fabricante)

O módulo de projetos ocupa-se com a melhoria da eficiência operacional, implantando a administração de projeto que apoia o ciclo de vida de todo projeto, composto de:

- redução do tempo de ciclo;

- aumento da produtividade de laboratório;

- redução no inventário;

- redução na necessidade de espaço;

- redução nos custos de falhas; e

- aumento na capacidade do equipamento. 
Na Figura 15, a seguir, vê-se um exemplo de interfaces dos dados do projeto.

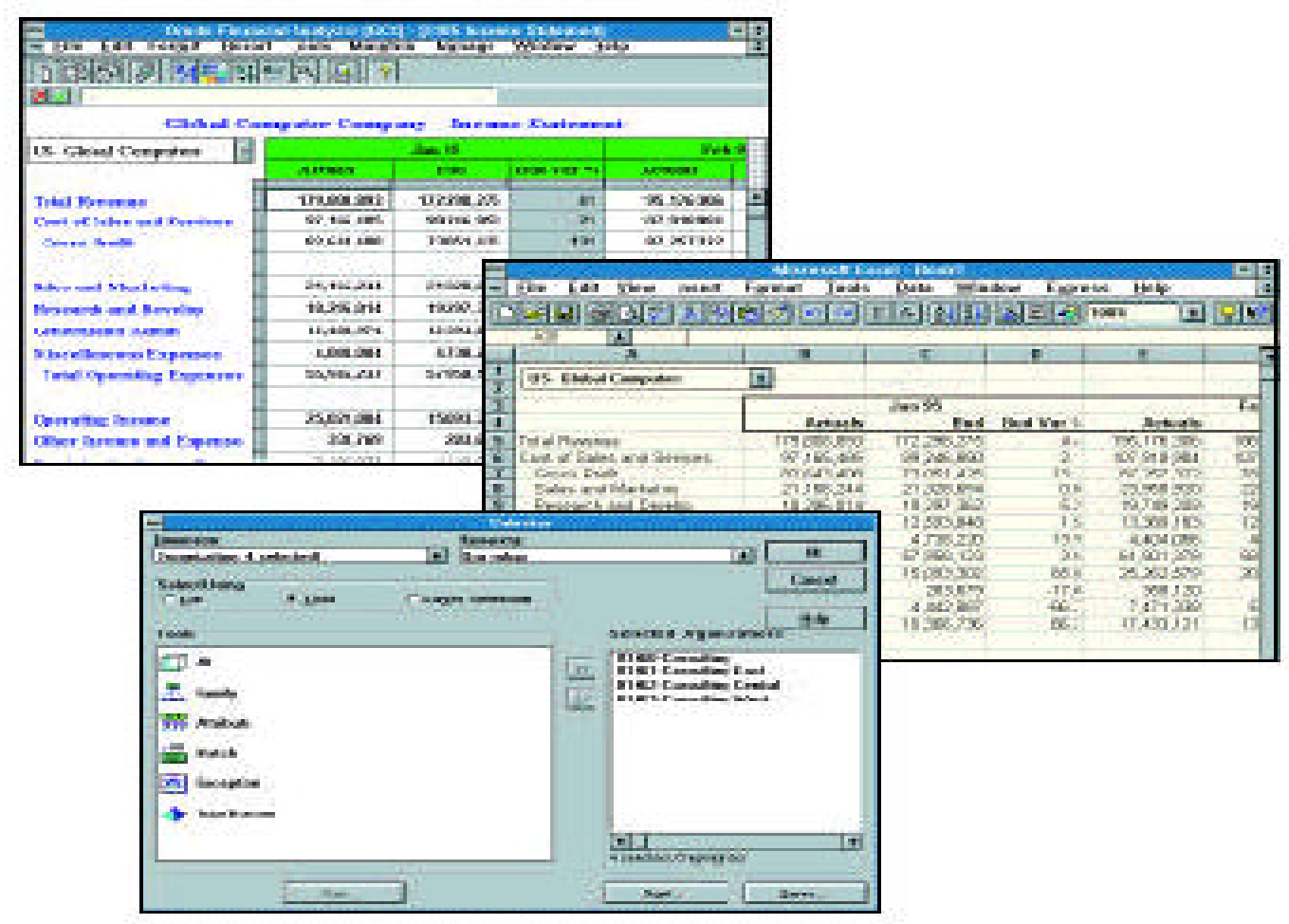

Figura 15 - Exemplo de Interfaces dos Dados do Projeto. (material fornecido pelo fabricante)

O módulo Financeiro procura transformar os aspectos econômicos da organização, através do acesso às funções estratégicas de administração, em uma força competitiva.

Esse módulo funciona como uma ponte entre sistemas de operações e corpo financeiro, utilizando um banco central com dados sobre o custo, faturas e desempenho associados às atividades empresariais ou a projetos. 


\section{Comentário:}

O sistema Oracle R11 demonstra dar prioridade ao desenvolvimento de um ambiente de trabalho menos rígido, através de: fluxos de trabalho flexíveis, estruturas da organização flexíveis e regras de negócios flexíveis.

Além disso, constata-se que as metodologias aplicadas na sua utilização são baseadas em: listas de tarefas, customização dos bancos de trabalho, pesquisas, fluxo de informações e interfaces com outros aplicativos. 


\section{3.a.3) BAAN}

O Sistema BAAN é um conjunto de aplicativos, voltados à gestão empresarial e desenvolvido pela empresa holandesa BAAN Company (fundada em 1978), cujas metodologias permitem mudanças nos limites de trabalho. Em outras palavras, trata-se de um sistema que administra, de forma flexível, as atividades da empresa.

Esse sistema integra vários programas baseados na arquitetura cliente/servidor que auxiliam as atividades de uma empresa (incluindo projeto, administração, vendas, manufatura, transporte e distribuição, serviços, manutenção e operações financeiras), através de soluções para a administração de produtos e documentos que integram e controlam o fluxo de informações do produto para toda organização.

Tal sistema utiliza um conceito de administração empresarial que, além de Planejamento de Recursos Empresariais (ERP), inclui o princípio de Modelagem Dinâmica de Empreendimento (DEM), que permite a conexão dos processos empresariais. Seu funcionamento é fundamentado numa estrutura básica de cinco elementos, que são:

- Orgware,

- Desktop,

- Ferramentas (Tools),

- Internet e

- Aplicações (módulos). 
A Figura 16, abaixo, ilustra a composição e a estrutura do sistema BAAN.

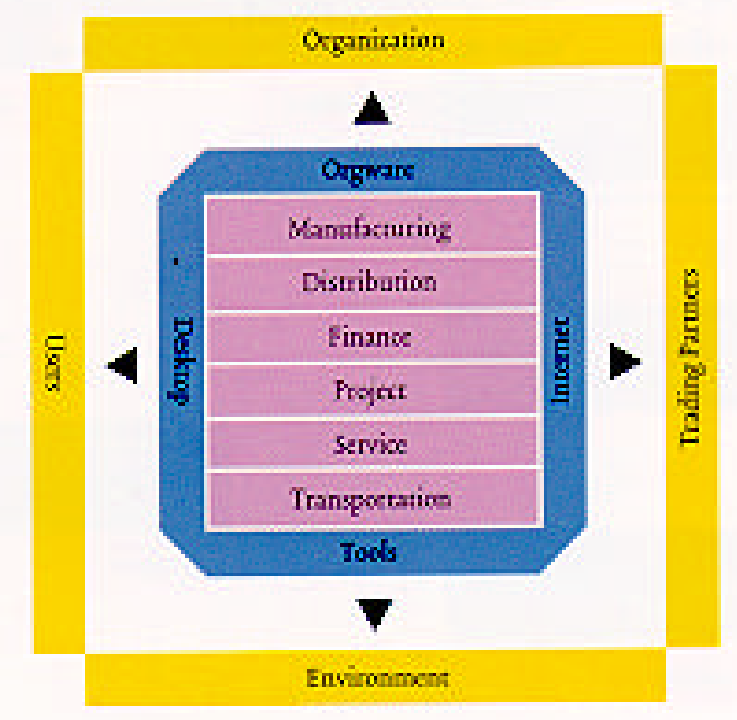

Figura 16 - Estrutura do Sistema BAAN. (material fornecido pelo fabricante)

\section{- ORGWARE}

O elemento Orgware possibilita a flexibilidade operacional da empresa, pois forma um conjunto de procedimentos e ferramentas de customização, que busca unir os processos empresariais e adaptar as suas estruturas organizacionais, em lugar de forçar a trabalhar com exigências de software pré-definidas. Nesse elemento, também está incluída a infra-estrutura para o desenvolvimento de menus individuais e procedimentos de workflow (com instruções) para cada usuário do sistema. 


\section{- DESKTOP BAAN}

Esse elemento permite a escolha da interface adequada para os vários usuários da empresa, por exemplo;

- $\quad$ para o escritório, escolhe-se o Windows95 ou WindowsNT;

- para engenheiros que usam UNIX, escolhe-se o X-Windows, - para o chão-de-fábrica, pode-se escolher uma interface ASCII (interface baseada em caracteres).

O DEM do Orgware possibilita a modelagem e a configuração do empreendimento, o que significa liberdade para criar menus exclusivos para cada usuário, baseado nas funções requeridas pelo seu trabalho. Além disso, o DEM também gera procedimentos de workflow e instruções para ajudar os usuários nas suas tarefas. Adicionalmente, para companhias e usuários que trabalham com o Windows, o BAAN possibilita a importação e a exportação de dados com outras aplicações e bibliotecas.

\section{- BAAN TOOLS}

O elemento TOOLS é usado para customizar telas, relatórios e lógica de processo, podendo criar suas próprias aplicações e interfaces. Também pode simplificar as tarefas de administração, além de permitir a conexão com outros ambientes e aplicações, por exemplo, bancos de dados de grande alcance, supply chain e sistemas operacionais, como UNIX, Windows95 e NT. 
Essa tecnologia proporciona uma melhor administração do sistema, além de outras características, como telas, relatórios e processamento lógico customizados, o que equivale a dizer que é possível a conexão com quase todos os tipos de arquitetura client/server, sem a modificação dos códigos da aplicação.

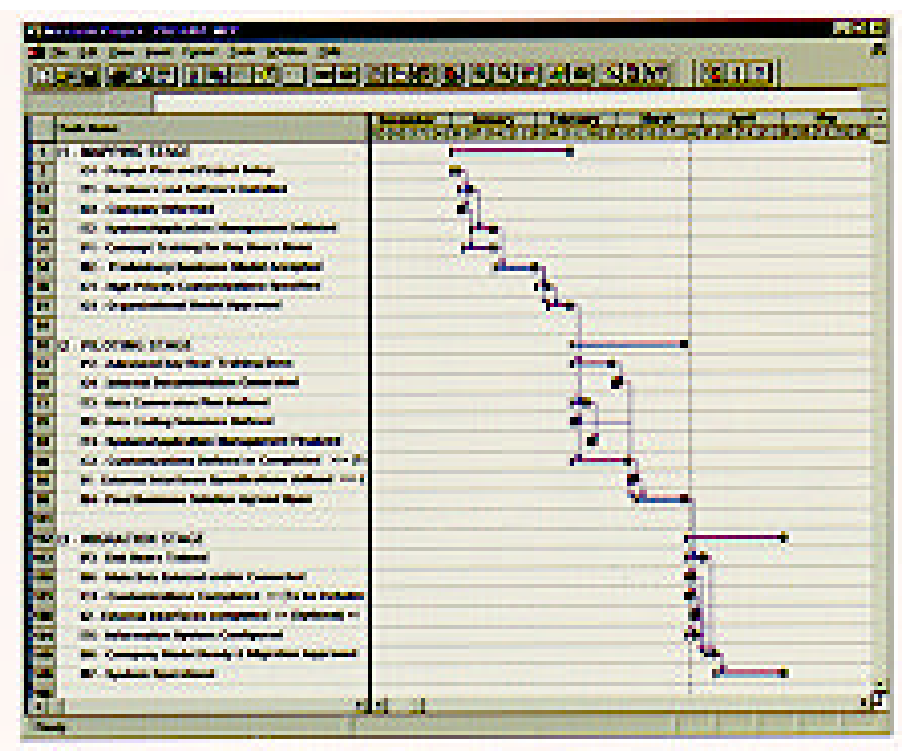

Figura 17 - Tipo de Formatação de Tela e Interface Gráfica. (material fornecido pelo fabricante)

\section{- INTERNET}

O sistema também pode suportar conexão com clientes e fornecedores através da Internet, a fim de agilizar e facilitar os processos comerciais. Os dados eletrônicos são trocados em alta velocidade com os parceiros (fornecedores e clientes), nutrindo relações comerciais mais próximas. 


\section{- APLICAÇÕES (Módulos)}

Com relação às aplicações (ou módulos de trabalho), destacam-se as seguintes:

- Manufatura - BAAN Manufacturing

- Finanças - BAAN Finance

- Projetos - BAAN Project

- Logística - BAAN Logistic and Distribution

- Serviços - BAAN Services

A Figura 18, a seguir, ilustra como pode ser a composição da tela e a respectiva distribuição dos módulos do sistema.

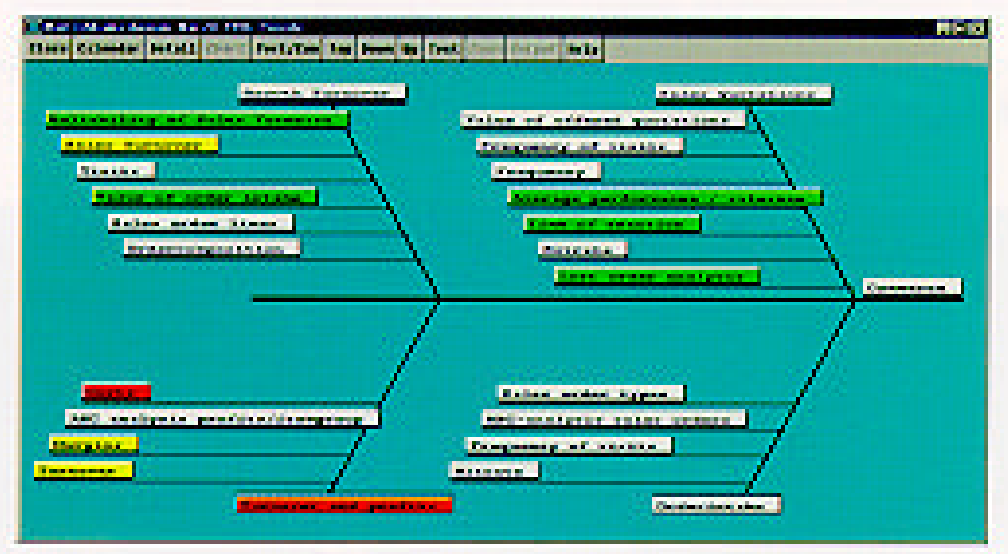

Figura 18 - Exemplo de Tela com Divisão de Módulos. (material fornecido pelo fabricante)

\section{Manufacturing}

O BAAN Manufacturing é projetado para suportar todos os tipos de estratégias de administração de produção e dar flexibilidade para a empresa, podendo até mesmo mudar a estratégia durante o ciclo de vida de um produto. 
Esse módulo trabalha com muitos tipos de estratégias de administração da produção, por exemplo, a filosofia do Programa Mestre de Produção (que ajuda a empresa no controle de produção do dia-a-dia e no planejamento de longo prazo). Também estão incluídos: Planejamento de Necessidades de Capacidade (CRP); Controle de Mudança; Administração de Dados; Plano Mestre de Produção; Planejamento de Necessidades de Material (MRP); Classificação de produto; ConFiguração de produto; Controle de Produção; Planejamento de Produção; Orçamento de Projeto; Controle de Projeto; Planejamento de Rede de Projeto.

\section{Finance}

Por entender que a integração de conhecimento por toda a empresa é crítico para o sucesso, o Finance possibilita o acesso instantâneo às informações financeiras e, com a evolução das necessidades corporativas, fornece soluções (opções) a serem trabalhadas com clientes, migrando para uma nova era de informação empresarial. Entre outros, destacam-se:

- acesso temporizado e preciso de informações financeiras;

- aplicações de consolidação e previsão orçamentária;

- sistemas de recursos humanos e folha; e

- aplicações de serviços corporativos. 
Essa aproximação com os processos industriais permite 0 acompanhamento das operações de manufatura e distribuição, fornecendo dados precisos e oportunos, necessários à otimização de calendário, redução de custos, de lead-time e da qualidade.

\section{Project}

Esse módulo controla vários aspectos dos projetos, inclusive suas rentabilidades. Com o controle, é possível acompanhar os objetivos, custos e datas de entrega prometida, até mesmo dos projetos mais complexos, administrando e fornecendo uma visão geral de todas as atividades do projeto.

\section{Transporte e Distribuição}

Essa aplicação inclui opções que vão desde a administração do warehousing público até o empacotamento, oferecendo a flexibilidade de ser configurada conforme as exigências específicas da companhia e de seus clientes. Esse módulo também fornece uma solução integrada, que permite administrar logísticas internas e externas.

\section{Service}

Para aumentar a eficiência, esse módulo procura manter um serviço de acompanhamento pós-venda, reduzindo o esforço 
administrativo através de um arquivo com informações detalhadas sobre serviço, contendo a história completa para referência.

Além dessas informações, mantém também outras, detalhadas sobre as garantias e os serviços contratados.

\section{Comentário:}

É interessante destacar que, esse sistema possui a opção de melhorar gradualmente os processos empresariais, ao invés de realizar uma reengenharia empresarial total, ou seja, o sistema BAAN poderá apoiar as atividades parciais e contínuas de reengenharia da empresa. 


\section{3.a.4) EMS}

A Datasul, empresa brasileira com mais de vinte anos no mercado, desenvolveu o EMS Framework, visando à integração de três tipos de sistemas dos processos básicos da cadeia de valor:

- apoio à decisão,

- comunicação, e

- funcionalidades.

Partindo da idéia de integração, o EMS incorpora vários conceitos que possibilitam aos usuários incluir novos processos padronizados ao sistema, complementando as soluções já oferecidas. Esse sistema procura fornecer ferramentas adequadas às peculiaridades dos negócios, agilizando a transmissão das informações para a tomada de decisões, buscando aumentar a produtividade e a competitividade. O sistema é constituído por três níveis de comunicação de dados (serviços, tecnologia e processamento), como se observa na Figura 19, a seguir.

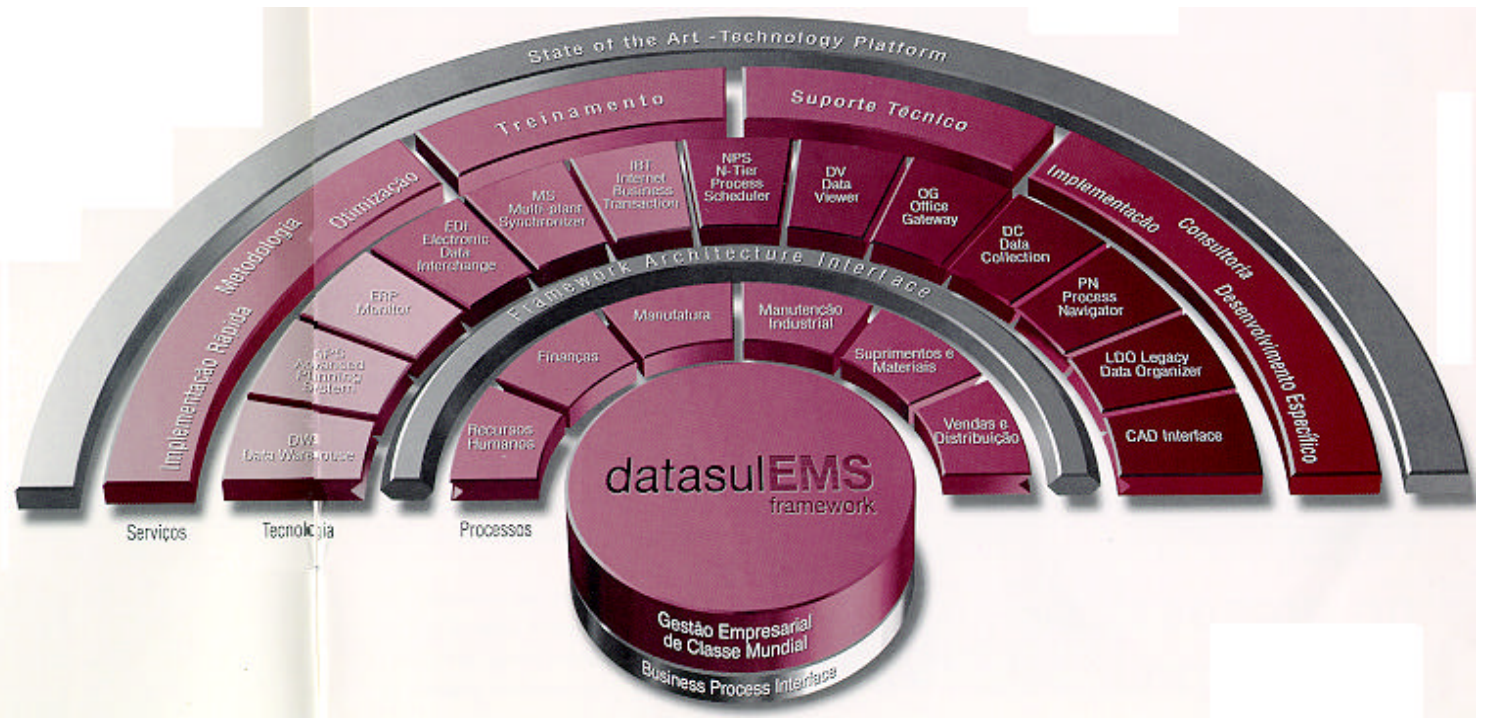

Figura 19 - Estrutura do sistema EMS.

(material fornecido pelo fabricante) 
Dentre os módulos ligados ao processamento e observados na Figura 19 (Manufatura, Manutenção Industrial, Suprimentos, Vendas, Finanças), entende-se que o módulo Manufatura seja o mais relevante para este trabalho.

Os aplicativos da manufatura, baseados na teoria das restrições, permitem o planejamento simultâneo das necessidades de material, capacidade e outros recursos. Têm-se assim, a análise de capacidade finita de produção e outras funções, como: simulações, estratégias de produção e consultas gráficas.

Dentro desse módulo, encontram-se funções ligadas ao produto e ao planejamento e controle de produção, por exemplo:

\section{PRODUTO}

Tratados inicialmente com protótipos, é possível simular estruturas de produtos, calcular seu custo e definir o processo de fabricação.

\section{PLANEJAMENTO}

\section{a) MRP}

Otimiza o gerenciamento das necessidades de material, fazendo com que os materiais necessários ao processo produtivo estejam disponíveis no momento e na quantidade certa. 


\section{b) MRPII - PLANO MESTRE DE PRODUÇÃO}

O Plano Mestre de Produção verifica os recursos críticos e interpreta vários cenários, apontando as medidas ideais a serem tomadas para se ter um plano de produção voltado às estratégias da empresa.

\section{c) CRP}

Destina-se a visualizar os gargalos de produção, através de gráficos e consultas, e executar os ajustes necessários para o dimensionamento correto da capacidade da fábrica, tornando os objetivos de produção compatíveis com as capacidades.

\section{CONTROLES}

\section{a) Controle de Produção}

Permite uma visão global dos processos envolvidos e, conseqüentemente, 0 acompanhamento das ordens de produção em todo o seu ciclo, mostrando de forma rápida e recursiva históricos completos sobre as ordens de produção.

\section{b) Controle Operacional}

Permite o planejamento detalhado das atividades relacionadas a cada centro de trabalho da fábrica, permitindo visualizar o estado das operações realizadas, em execução e a serem processadas. 


\section{c) Estatísticas}

Fornece indicadores sobre a performance do chão de fábrica, viabilizando decisões corretas sobre os assuntos mais críticos. A empresa escolhe os índices relacionados ao seu negócio, ou mesmo define os indicadores apropriados.

\section{d) Visualização Gráfica}

Fornece a visualização em tempo real do chão de fábrica, através de fotos, croquis e leds visuais, e ainda inúmeros indicadores de desempenho da produção e do faturamento, através de ferramenta própria para a geração de gráficos.

O módulo de finanças atende às funções de administração e controle do o fluxo administrativo e financeiro, com parâmetros flexíveis e completos, permitindo respostas rápidas às mudanças nas condições de negócios com alto grau de aderência a diversas formas de trabalho.

Com aplicativos ligados ao Sistema de Apoio à Decisão (DSS), Data Warehouse e ERP Monitor, é possível otimizar as análises e obter auxílio nas decisões das ações a serem tomadas. A integração com aplicativos de Comunicação, como o Multi-plant Synchronizer, permite que a empresa administre todas as plantas de maneira centralizada.

O Office Gateway permite a interface entre o EMS e seus aplicativos, como editores de texto, planilhas de cálculo, correios eletrônicos e outros. 
Além dos já citados o EMS também possui em seu nível de tecnologia, módulos facilitadores, tais como:

- Legacy Data Organizer - destinado à otimização da base de dados;

- Data Collection - para utilização de código de barras;

- Data Viewer - poderosa ferramenta para geração de relatórios;

- N-Tier Process - permite a criação de programação de eventos de acordo com horários e dias pré-programados;

- Process Navigator - provê a integração com sistemas agilizando o processo de transmissão de informações e reduzindo a burocracia e o fluxo de papel;

- CAD Interface - organiza as informações técnicas dos produtos e processos; uniformiza padrões de tratamento da informação, facilitando a comunicação entre as áreas ligadas à manufatura;

- Advanced Planning System (APS) - sistema de planejamento de atividades que utiliza a Teoria das Restrições, permitindo definir prioridades, políticas e metas, otimizando o fluxo de trabalho, os estoques e outros fatores que influenciam sua lucratividade;

- ERP Monitor - proporciona uma visão global dos negócios da empresa, agrupando informações dos aplicativos Contas a Receber, Contas a Pagar, Faturamento, Pedidos, Compras e Fluxo de Caixa;

- DV Data Viewer - ferramenta de extração de dados, voltada ao usuário final, que permite a elaboração de relatórios e gráficos. Relaciona várias tabelas, determinando critérios para classificação, criação de totais e outros cálculos, como: mínimo, máximo e média, utilizando fórmulas geradas automaticamente ou de forma livre, para que o usuário possa personalizar e fazer alterações no documento. 


\section{Comentário:}

De maneira geral, o EMS busca a resolução de problemas rotineiros, porém essa resolução é programada, ou seja, não se pode caracterizar esse sistema como um sistema inteligente ou especialista.

Também convém observar que o EMS é um conjunto de módulos desenvolvidos separadamente com integração posterior. Outra característica é que o módulo de manufatura não define os tipos de processamento e/ou organização industrial que são utilizados. 


\section{3.a.5) SIGA ADVANCED}

O Siga Advanced é um programa de Gestão Empresarial (ERP), desenvolvido com o intuito de ser um sistema aplicativo, com uma filosofia própria de gestão empresarial. Sua proposição é fornecer meios para que uma empresa utilize, de forma plena, os dados gerados a partir do processo operacional, agregando valor e facilidades no dia-a-dia, garantindo o retorno do investimento efetuado na informatização.

Esse sistema é dividido em vários módulos (que visam a distribuir as atividades específicas de cada setor) mais uma ferramenta de análise gerencial (SIGAEIS), o que mantém a integração e a integridade dos dados e disponibiliza a ferramenta, que permite a apresentação das informações diárias no momento das decisões.

O SIGA Advanced permite flexibilidade e adequação da solução oferecida à realidade de custo suportada pela empresa.

O conjunto de módulos é formado por: Administrativo, Contábil, Financeiro, Ativo Fixo, Livros Fiscais, Manufatura, Planejamento e Controle da Produção, Estoque e Custos, Compras, Distribuição, Faturamento, Telemarketing, Pessoal, Recursos Humanos (incluindo o Terminal do Funcionário), Controle de Ponto e Folha de Pagamento. 
Esses módulos são acessíveis através de uma tela de interface, conforme demonstra Figura 20, abaixo.

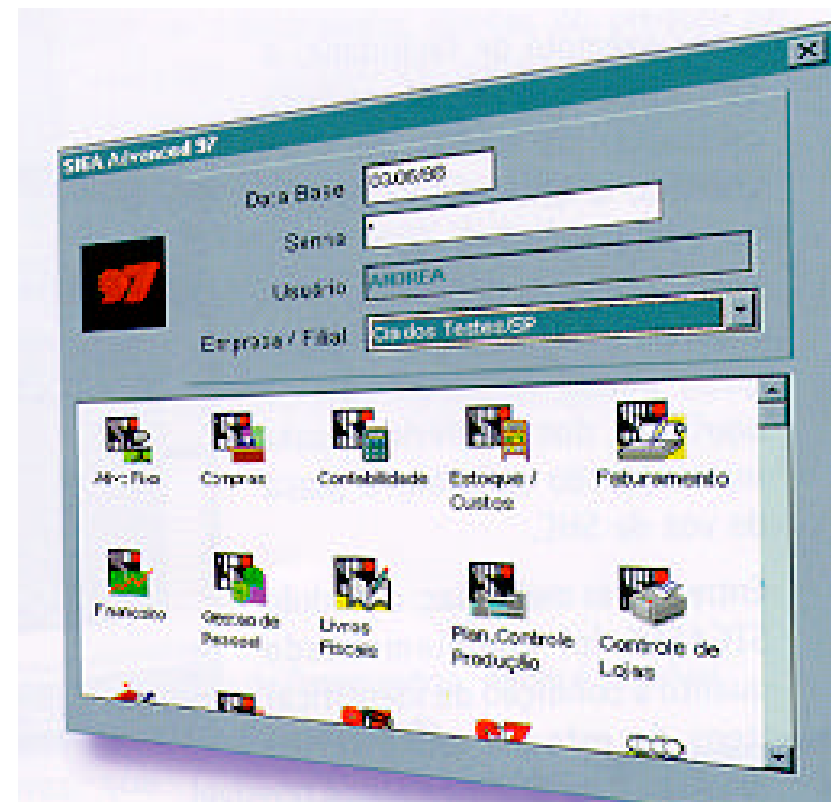

Figura 20 - Tela de Interface Sistema x Usuário. (material fornecido pelo fabricante) 
Na Figura 21, abaixo, pode-se observar como está constituída a estrutura desse sistema e como seus elementos se relacionam.

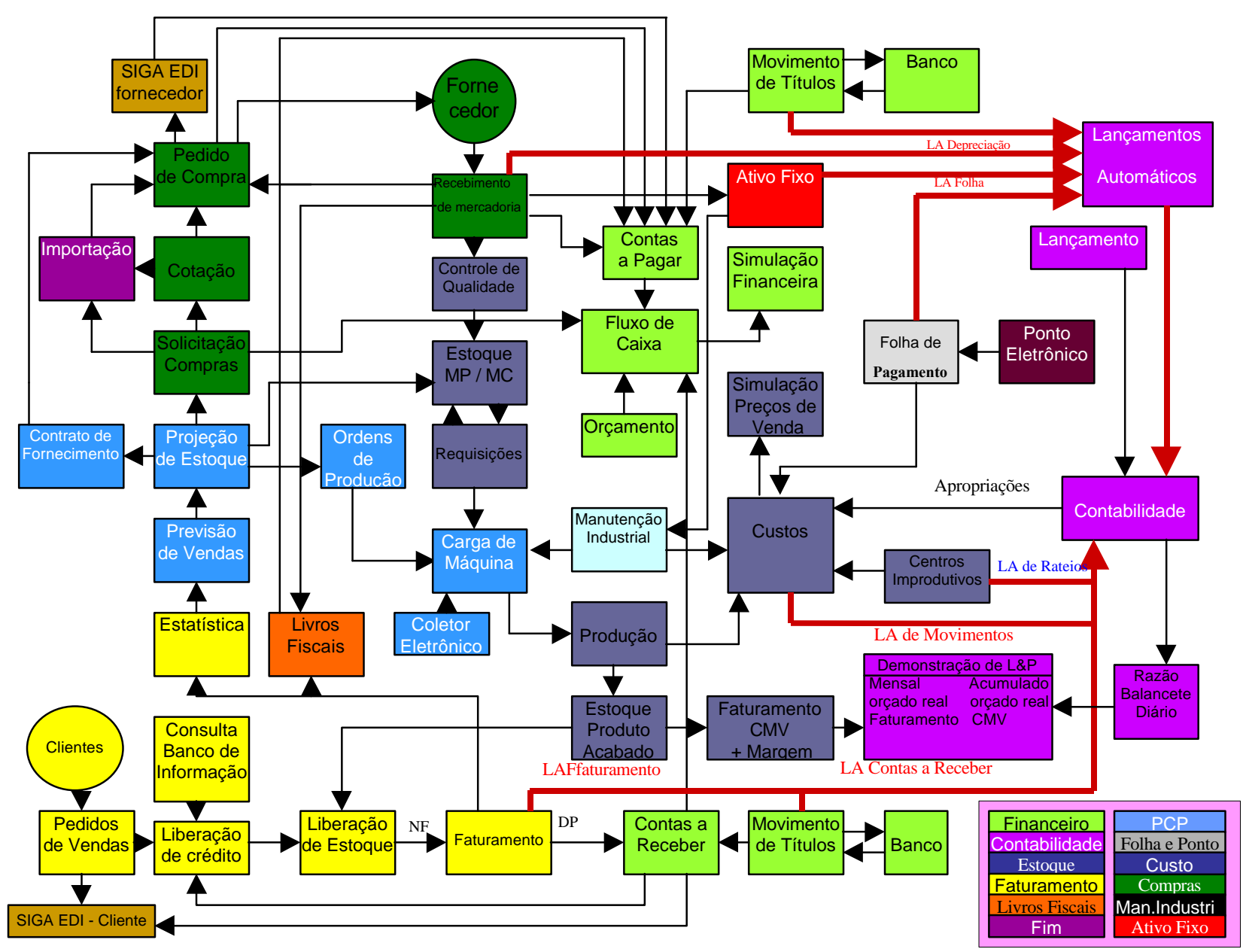

Figura 21 - Esquema de Fluxo de Informações do Sistema Micro-Siga. (material fornecido pelo fabricante)

O sistema Advanced possui uma estrutura orientada a objetos e é dotado de um dicionário de dados ativo, que permite um alto grau de adaptabilidade às características peculiares da maioria das empresas. 


\section{SIGAEIS}

A ferramenta SIGAEIS permite a análise gerencial dos dados armazenados, paralelamente à realização das operações do sistema, entre as quais destacam-se as seguintes:

- Carga de máquinas visualizável em tela;

- Planejamento das necessidades;

- Recursos alternativos;

- Engenharia do Produto/Processos (Processo de Fabricação, Ciclo, Fórmula);

- Tempo mínimo na operação antes de processar outra;

- Tratamento de conjuntos fictícios,

- Previsão de necessidades de materiais auxiliares a partir da curva de estoque, baseada em lote econômico, estoques mínimos e de segurança e consumo médio histórico;

- Geração automática das Ordens de Produção e Compra (Requisições automáticas de materiais);

- Comparativos, entre quantidade de material prevista e realmente gasta; $\mathrm{e}$

- Integração com Contabilidade.

As principais características e facilidades técnicas do sistema são:

- Integridade Referencial na versão ADS, SQL Server, AS400, Oracle, UDB, Informix e Sybase;

- Capacidade de processamento de múltiplas empresas, filiais e almoxarifados;

- Help on-line em diversos níveis: programas, campos, erros e soluções; 
- Acesso a rotinas, programas e determinados campos controlado pela senha do usuário;

- Menus configuráveis por usuário; e

- Gatilhos em nível de campo que permitem a atualização de outros, sempre que uma informação for inserida/alterada.

\section{Comentário:}

Ao se analisar o MS Advanced, nota-se que sua forma e apresentação são derivados do seu desenvolvimento segmentado, ou seja, seus módulos foram desenvolvidos e implementados sem uma filosofia estruturada, mas sim, pela necessidade expressa de um grupo de usuários.

Assim como os sistemas anteriores, esse também não pode ser considerado um sistema inteligente e não oferece igualmente alternativas de sistema de organização industrial e de métodos de processamento. 


\section{3.b) Comentários Gerais}

De maneira geral, os provedores de soluções integradas são muito parecidos e sempre vendem a idéia de que seus produtos se ajustam a qualquer empresa, independentemente do tamanho, da natureza do negócio e da disponibilidade de recursos para investir.

A aderência do produto ao modus operandi das organizações, assim como as funcionalidades de solução, abrangência, custo total de propriedade, grau de comprometimento do fornecedor e do implementador do projeto, são apenas alguns dos vários fatores que devem ser levados em consideração na escolha de um sistema ERP. (http://www.uol.com.br/computerworld/computerworld/280/gcapa2.htm 22/07/99)

Além disso, para efetuar a mensuração de desempenho, deveriam realizar-se dois tipos de análises. A primeira é relativa ao próprio produto, para saber se o sistema é capaz de atender às necessidades da empresa.

A segunda análise deve comparar os vários sistemas entre si, a fim de estabelecer qual deles possui o melhor desempenho na execução das atividades de gestão da empresa.

Porém, realizar a comparação dos vários sistemas existentes em condições semelhantes e frente aos seus altos valores, tempo e demais recursos que devem ser disponibilizados (ex: mão-de-obra, equipamentos, aprendizado) torna-se economicamente inviável. 
Entende-se também que a realização de uma comparação entre as principais características dos sistemas integrados de gestão constitui um trabalho tão relevante que justifica sua execução em forma de tese ou dissertação, e não apenas um assunto dentro desta pesquisa.

Mas, apesar de todas as dificuldades, é possível e desejável preparar um quadro comparativo que coloque lado a lado as principais características (políticas de cálculos e funções) dos diversos sistemas, o que pode, ao menos, direcionar o processo de seleção do sistema.

Deve-se, porém, considerar o fato de que, normalmente as empresas optam por diferentes métodos e estratégias de trabalho, o que equivale a dizer que um determinado sistema dificilmente será considerado o melhor por unanimidade.

Todos os sistemas analisados possuem virtudes e problemas específicos na arquitetura lógica, no sistema operacional e na linguagem de programação utilizada. Das características gerais de todos os sistemas, destacam-se que:

a) pelas definições dadas anteriormente (Capítulo 2), os sistemas não devem ser considerados inteligentes, uma vez que não há aprendizado durante sua utilização;

b) os sistemas dão maior importância às áreas financeira e administrativa;

c) todos são desenvolvidos a partir da área financeira, ao invés de iniciar pela área de manufatura; 
d) os sistemas financeiros são diferentes de empresa para empresa; e

e) a maioria não oferece alternativa (flexibilidade) entre as formas de administração industrial, os processamentos, os parâmetros, os critérios etc.

Ao se analisarem essas caraterísticas, percebe-se que, muitas vezes, as classificações são extremamente subjetivas e que, em determinadas situações ou condições, elas se invertem de qualidade para falha e viceversa, conforme ilustra a Tabela 2, abaixo.

\begin{tabular}{|c|c|c|c|c|c|}
\hline & SAP / R3 & ORACLE & BAAN & EMS & M-SIGA \\
\hline Estrutura & modular & modular & modular & modular & modular \\
\hline Banco de Dados & relacional & relacional & relacional & relacional & relacional \\
\hline Interface & gráfica / fixa & gráfica / fixa & $\begin{array}{c}\text { gráfica I } \\
\text { customizável }\end{array}$ & $\begin{array}{c}\text { gráfica I } \\
\text { customizável }\end{array}$ & gráfica / fixa \\
\hline Internet & $\begin{array}{c}\text { fins } \\
\text { comerciais }\end{array}$ & $\begin{array}{c}\text { fins } \\
\text { comerciais }\end{array}$ & $\begin{array}{c}\text { fins } \\
\text { comerciais }\end{array}$ & $\begin{array}{c}\text { fins } \\
\text { comerciais }\end{array}$ & $\begin{array}{c}\text { fins } \\
\text { comerciais }\end{array}$ \\
\hline $\begin{array}{l}\text { Integração cl } \\
\text { Manufatura }\end{array}$ & não & não & não & não & não \\
\hline Hardware & $\begin{array}{c}\mathrm{pc} / \\
\text { mainframe }\end{array}$ & $\begin{array}{c}\mathrm{pc} / \\
\text { mainframe }\end{array}$ & $\begin{array}{c}\mathrm{pc} / \\
\text { mainframe }\end{array}$ & $\begin{array}{c}\mathrm{pc} / \\
\text { mainframe }\end{array}$ & $\begin{array}{c}\mathrm{pcl} \\
\text { mainframe }\end{array}$ \\
\hline Plataforma & todas & todas & Unix / NT & todas & NT / Novell \\
\hline$\%$ de mercado & $29 \% / 10,7 \%$ & $10 \% /-\%$ & $5 \% /-\%$ & $-\% / 39,3 \%$ & $-\% / 8,3 \%$ \\
\hline Simulação & $\begin{array}{c}\text { parte } \\
\text { financeira }\end{array}$ & $\begin{array}{c}\text { parte } \\
\text { financeira }\end{array}$ & $\begin{array}{c}\text { s/ } \\
\text { informação }\end{array}$ & manufatura & $\begin{array}{c}s / \\
\text { informação }\end{array}$ \\
\hline $\begin{array}{l}\text { Variedade de } \\
\text { critérios }\end{array}$ & $\begin{array}{c}\text { s/ } \\
\text { informação }\end{array}$ & $\begin{array}{c}\text { administra- } \\
\text { tiva }\end{array}$ & $\begin{array}{l}\text { administrat. } \\
\text { e manufatura }\end{array}$ & manufatura & $\begin{array}{c}\text { sl } \\
\text { informação }\end{array}$ \\
\hline $\begin{array}{l}\text { Porte dos } \\
\text { clientes }\end{array}$ & $\begin{array}{l}\text { grande e } \\
\text { médio porte }\end{array}$ & grande porte & grande porte & médio porte & $\begin{array}{l}\text { médio, } \\
\text { pequeno }\end{array}$ \\
\hline
\end{tabular}

Tabela 2 - Resumo das Características dos Sistemas Analisados.

(Fonte: http://ourinhos.com.br/perin/interest.html) 
Em relação ao mercado-alvo dos sistemas e considerando os altos valores cobrados, tanto pelas licenças de uso dos sistemas integrados como pelos serviços de implementação e manutenção (aproximadamente US\$ 5.000 por licença e US\$ 3.000 em implantação, por usuário), tornase fácil entender porque as instituições que já os utilizam são as empresas de grande porte.

Porém, no atual momento, em que o mercado das grandes corporações começa se esgotar, os grandes provedores de sistemas de apoio à gestão de negócios começam cortejar os clientes de médio porte, cujo faturamento está entre US\$ 5 e US\$200 milhões. (GIURLANI, 1999)

Como já fora comentado anteriormente, não se pretende tirar o valor dos sistemas aqui citados, simplesmente pelo fato de serem desenvolvidos empiricamente, ao contrário, reconhece-se que tais sistemas possuem inúmeros méritos, que devem ser exaltados. Mas é importante destacar que a maioria dos sistemas apresentados está capacitada a realizar apenas cálculos comuns, ou seja, não conseguem fazer simulações e/ou orientações.

Nos capítulos seguintes são discutidos os princípios de uma teoria que deve orientar a elaboração de um sistema completo de gestão empresarial, em que serão mantidas as qualidades e eliminadas as falhas dos sistemas comentados, procurando melhorar ou desenvolver alguns pontos básicos desses sistemas e acrescentar uma estrutura baseada em análises acadêmicas. 


\section{4) MODELO DE SISTEMA PROPOSTO PARA GERENCIAMENTO DE EMPRESAS}

Observando os SIGs citados no capítulo anterior constata-se que, embora esses sistemas representem avanços no modus operandi das empresas, eles, na maioria, acabam por tirar a flexibilidade das empresas.

Em conseqüência disso, surgiu a necessidade de um sistema que realizasse as tarefas administrativas, sem tirar a liberdade de escolha dos usuários e das empresas. Para dar início ao desenvolvimento do sistema são consideradas três fases distintas de pesquisa, que são;
A) O que fazer?
B) Como fazer?
C) Para quem fazer?

Deve-se ter em mente, em cada uma dessas fases que a proposta deste trabalho é estruturar um sistema especialista e/ou inteligente que possibilite o gerenciamento de uma empresa através da integração -via computador- da administração com a manufatura.

Ressalta-se uma vez mais que a presente pesquisa constitui um esforço para a evolução lógica dos sistemas administrativos elevando-os ao estágio de especialistas e/ou inteligentes, dentro da filosofia ERP. 


\section{A) O que fazer?}

Levando-se em conta as considerações anteriores, decidiu-se estipular um conjunto de diretrizes conceituais que, quando seguidas, resultam num grupo de módulos aplicativos. Quando agrupados, esses módulos funcionam como um sistema integrado especialista, flexível e aberto, podendo ser adaptado a vários tipos de empresa na sua administração.

Esse sistema é considerado uma evolução dos sistemas ERP, passando ao estágio denominado Expert Enterprise Resources Planning (E-ERP) e posteriormente ao Intelligent Enterprise Resources Planning (I-ERP). Sendo assim, a escolha do formato a seguir descrito visou a eliminação das falhas de comunicação entre os vários setores abrangidos, buscando a otimização de recursos através de Sistemas Especialistas e da consolidação dos dados da empresa.

Destaca-se ainda que a integração desejada implica um ajuste na estrutura gerencial das empresas, em que se percebe que há uma troca constante de dados e informações entre as áreas administrativa e produtiva. Para facilitar o entendimento do objetivo deste trabalho, convém esclarecer que o ajuste acima citado é realizado com a utilização de sistemas integrados e banco de dados compartilhados, interligados por uma rede computadorizada, como ilustra a figura 22 a seguir. 

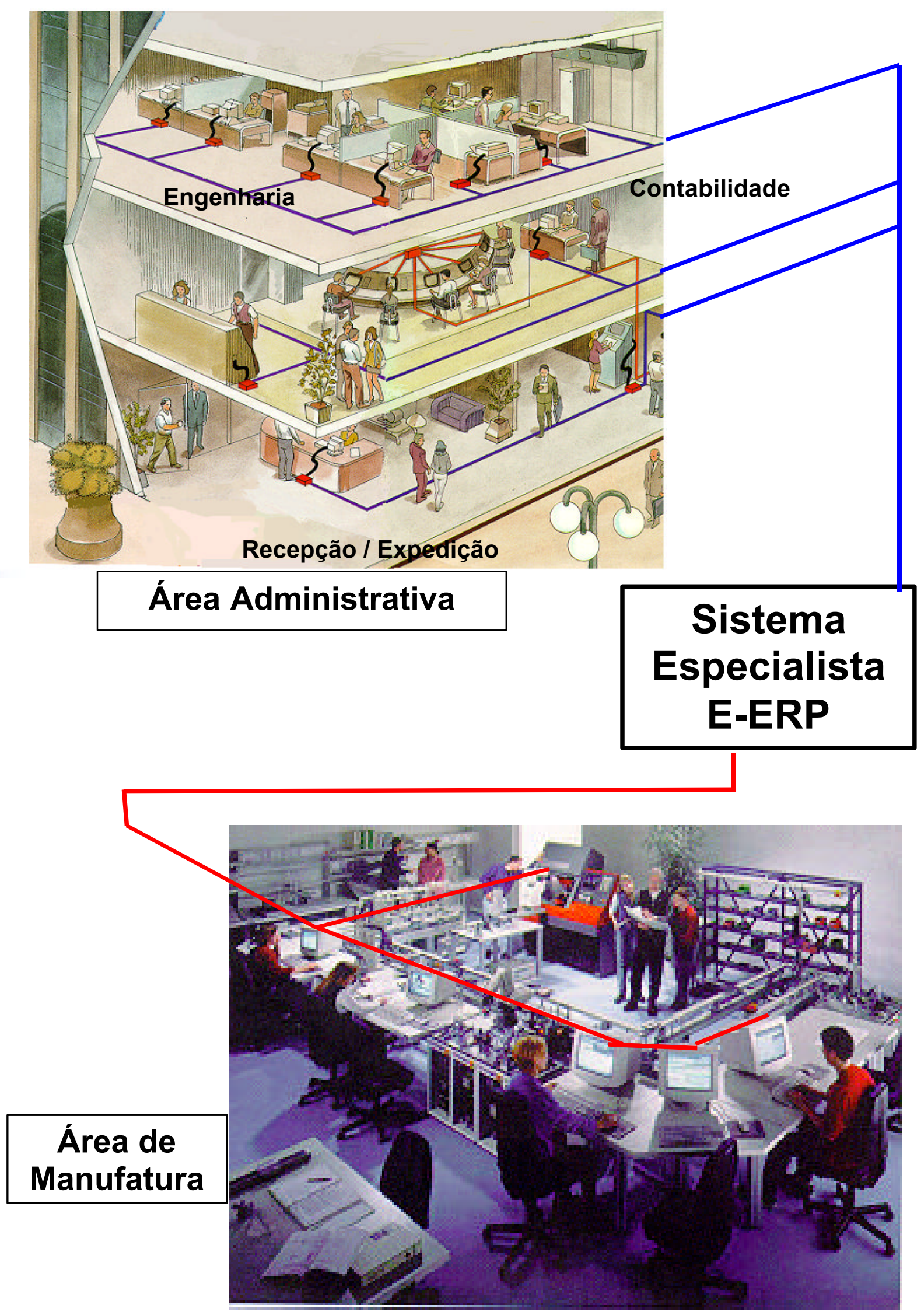

Figura 22 - Estrutura de Integração entre Áreas Administrativa e Produtiva. 
No modelo proposto, o aumento de velocidade e a precisão no processo decisório devem ser conseguidos eliminando-se o uso de aplicativos específicos para solucionar problemas isolados.

Devido às incompatibilidades de programas e tecnologias, a utilização de softwares origina, em muitas empresas, um número ainda maior de tarefas, por exemplo, as transcrições manuais de resultados que, por sua vez, fornecerão subsídios a um processo decisório da empresa.

Sendo assim, há uma preocupação em elaborar uma nova ferramenta, livre de incompatibilidades que gerem redundância de trabalho, permitindo que a área de planejamento industrial programe e controle melhor e mais rapidamente, a utilização dos seus recursos.

É importante destacar o fato que, o aplicativo deve ser capaz de ser operado em qualquer das várias plataformas operacionais (Windows, UNIX, etc.) e ser compatível com os principais bancos de dados e programas comerciais. Essas condições possibilitam a resolução de diferentes, porém comuns, problemas da Engenharia de Produção. Novamente ressalta-se que não se trata da elaboração de um novo software de MRP, mas sim da orientação ao desenvolvimento (evolução) de programas de gestão integrada, onde se destacam as filosofias de ERP (Enterprise Resource Planing).

Conforme fora citado anteriormente, os modernos programas de gestão possuem uma arquitetura modular baseada num banco de dados único e 
que busca, desse modo garantir a integridade e exatidão das informações distribuídas na empresa. (CORRÊA, 1997)

Ainda segundo CORRÊA (1997) essa arquitetura de sistema será usada como base dos sistemas de informação nas empresas.

Conforme observam ROZENFELD e ZANCUL (1998), o avanço tecnológico tem permitido às empresas utilizarem sistemas computacionais para apoiar suas atividades. Entre os principais problemas decorrentes dessa aplicação destacam-se a dificuldade na obtenção de informações consolidadas e a inconsistência de dados redundantes, armazenados em mais de um sistema. (ROZENFELD, \& ZANCUL, http://www.numa.org.br/conhecimen-tos/ERP_v2.html- 9/10/99) Esse conceito já havia sido utilizado por outros estudiosos do assunto, conforme se pode observar na figura 23 , a seguir.

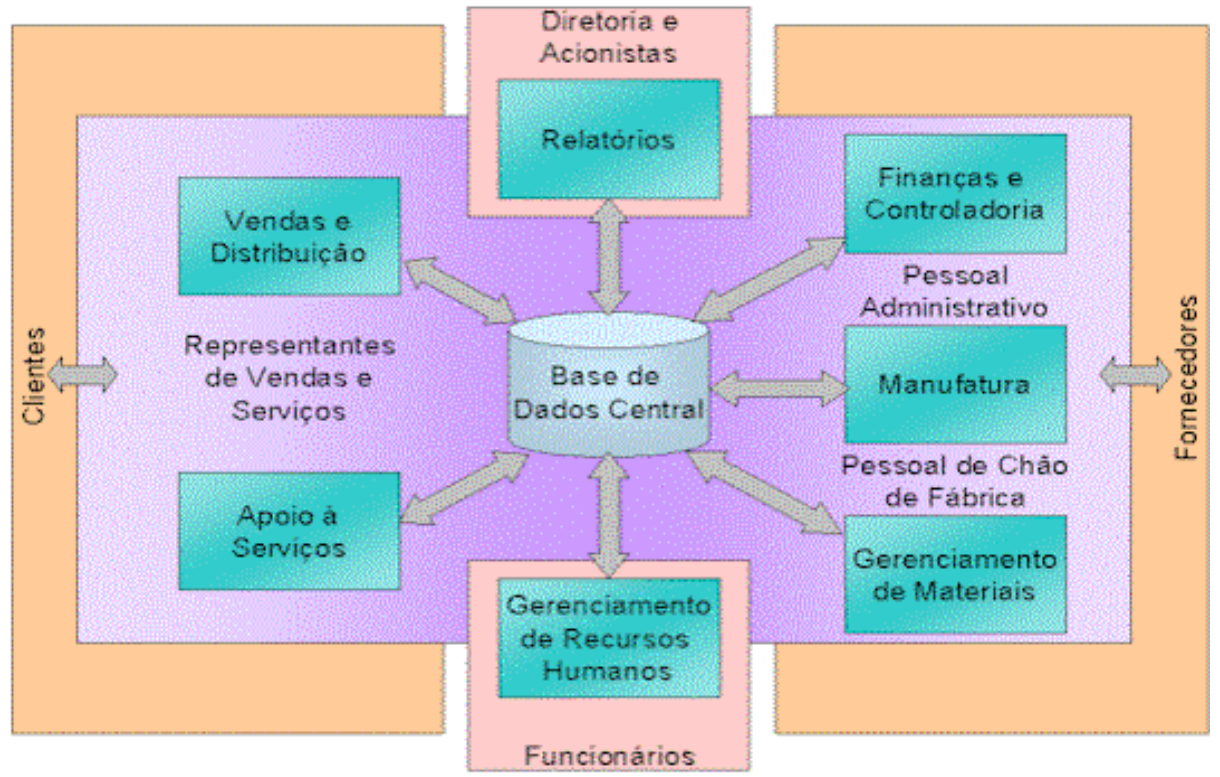

Figura 23 - Arquitetura ERP - (Adaptada de DAVENPORT, 1998). 


\section{B) Como fazer?}

Este é um trabalho que requer esforços científicos multidisciplinares (computacionais e comportamentais), trabalhando juntos em sinergia. Por esse motivo, optou-se por dividir as aplicações de atuação e diversificar as áreas que compõem o projeto.

No primeiro momento, foi adotada uma filosofia básica a ser seguida, em que se consideraram a estrutura do sistema especialista e a forma de aplicação que esse programa seguirá.

Assumindo que o programa deve ser flexível, escolheu-se utilizar a forma modular (em módulos) que, além de permitir ser complementada aos poucos, também possibilita variações de aplicação. Conforme comentado anteriormente, esse formato tem se constituído em uma das características principais dos softwares modernos. (CORRÊA, 1997) A forma escolhida está ilustrada na figura 24 abaixo.

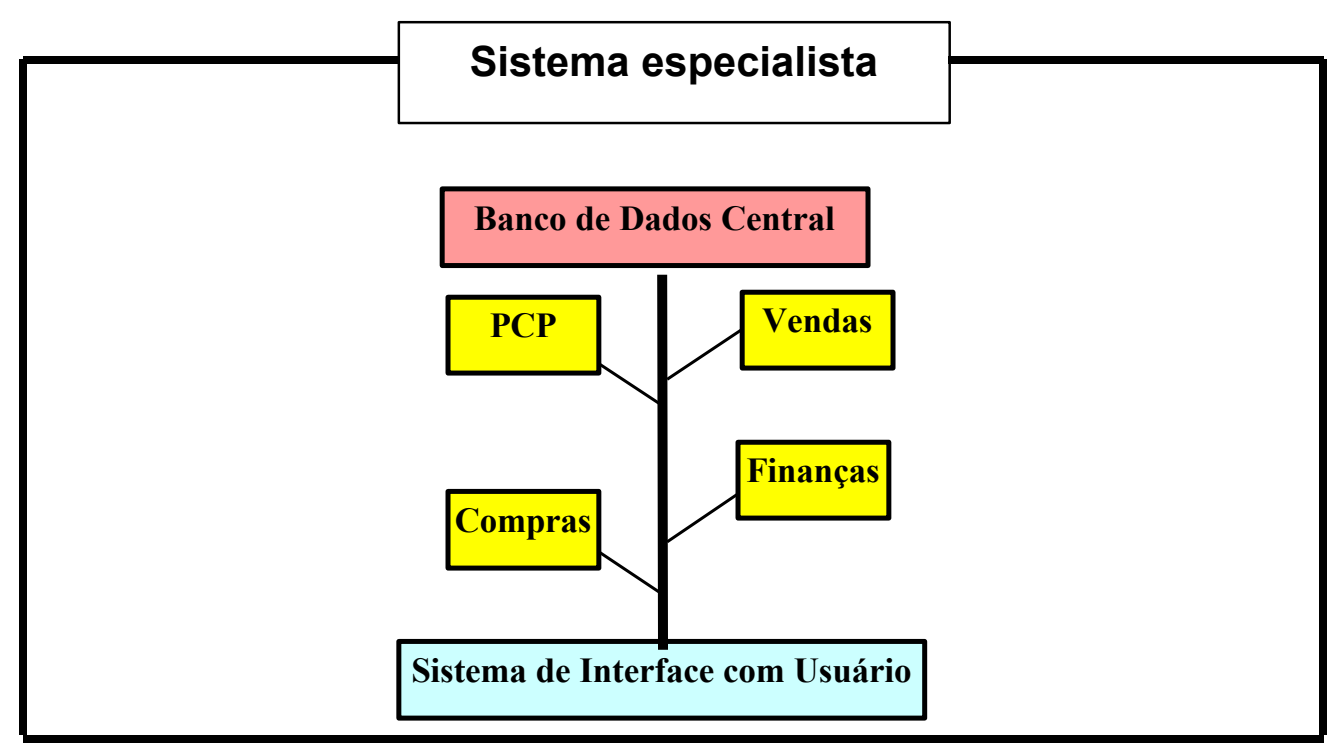

Figura 24 - Estrutura Modular do Sistema Especialista 
Sendo assim, utilizando a proposta de Sistema Especialista desenvolvida por BELHOT (1991), o E-ERP deve ser constituído por:

1) um programa mestre (shell) que administrará todos os módulos e suas compatibilidades, e será composto por uma interface gráfica amigável e um controlador de bancos de dados.

2) módulos especialistas (incluindo sistemas de inferências), independentes e customizáveis.

O shell atuará como gerenciador de módulos, ou seja, através dele, todos os módulos poderão interagir entre si. Ou seja, o controle de entrada e saída de dados, a manipulação de elementos no banco de dados, a interface com o usuário, inclusão ou remoção de módulos e modelamento da fábrica são da responsabilidade do shell.

Os módulos devem estar aptos a realizar os cálculos administrativos (e suas variações) e possuir um sistema de inferência que coordene esses cálculos, verificando as restrições impostas pelo mercado e pela empresa. Além disso, também deve ser possível fazer a introdução e a modificação de parâmetros utilizados nas análises.

Conseqüentemente, a procura de uma estrutura dinâmica, com alta capacidade de adaptação é, portanto, essencial para o desenvolvimento 
dos sistemas de apoio à gestão de empresas que pretendam se enquadrar nesta nova realidade.

Outra característica merecedora de destaque é a sugestão de realizar a integração do Sistema E-ERP com o sistema que controla a manufatura (CAM/CIM), seguindo as orientações de automação total, conforme ilustra a figura 25 a seguir.

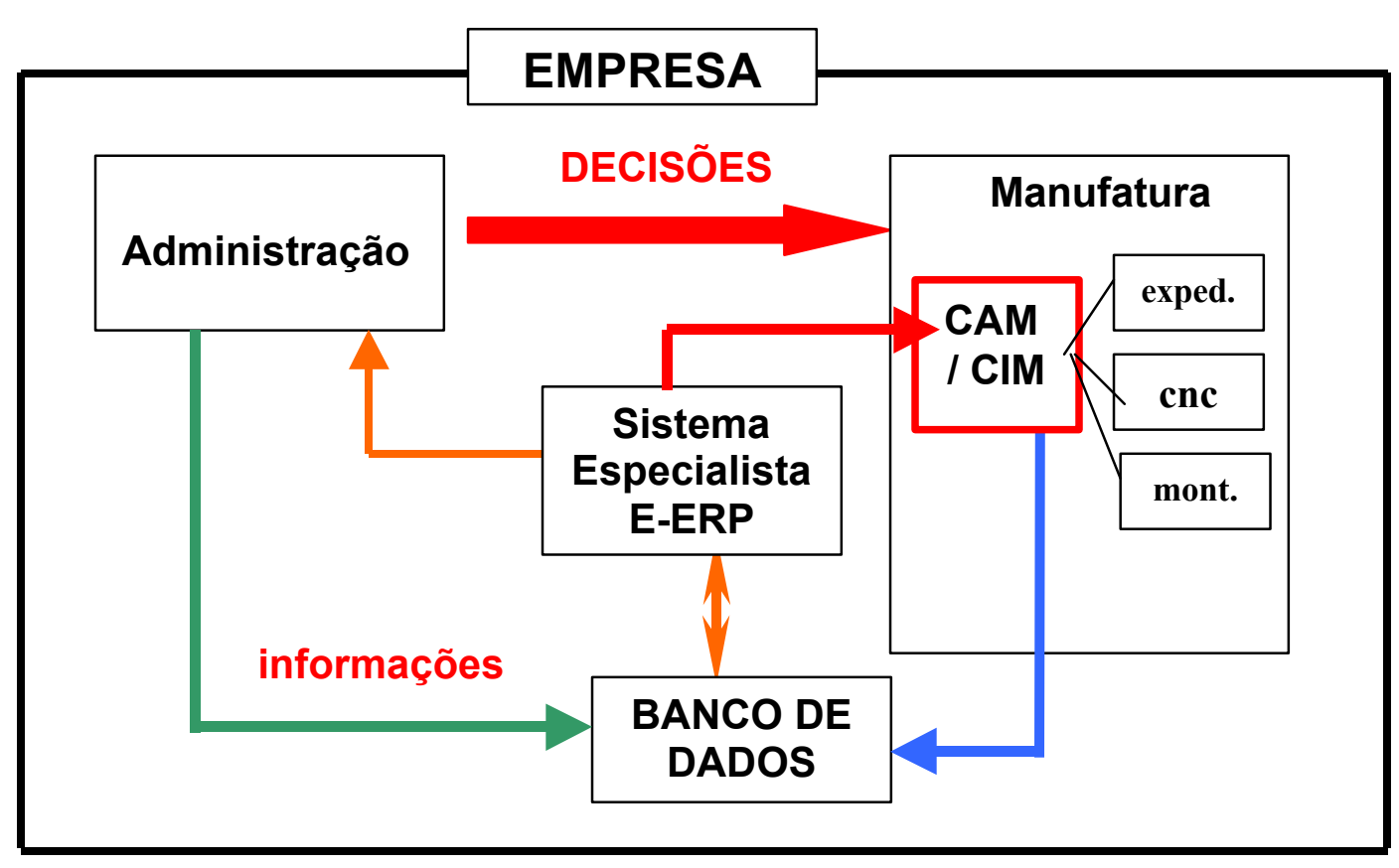

Figura 25 - Integração Manufatura Administração.

Entretanto, é preciso lembrar que os avanços tecnológicos na área de informática e o dinamismo decorrente do uso da Internet possibilitam que as empresas hoje possam ser gerenciadas a distância. 
Essa possibilidade impulsiona a empresa na direção da empresa virtual, ao mesmo tempo em que o E-ERP vai adquirindo característica de integrador de áreas (administrativa e produtiva).

Dessa forma, aproveitando as proposições mais modernas, disponibiliza a conexão remota (via internet) da matriz com outras unidades da empresa, permitindo que a matriz possa auxiliar ou influenciar as decisões da empresa.

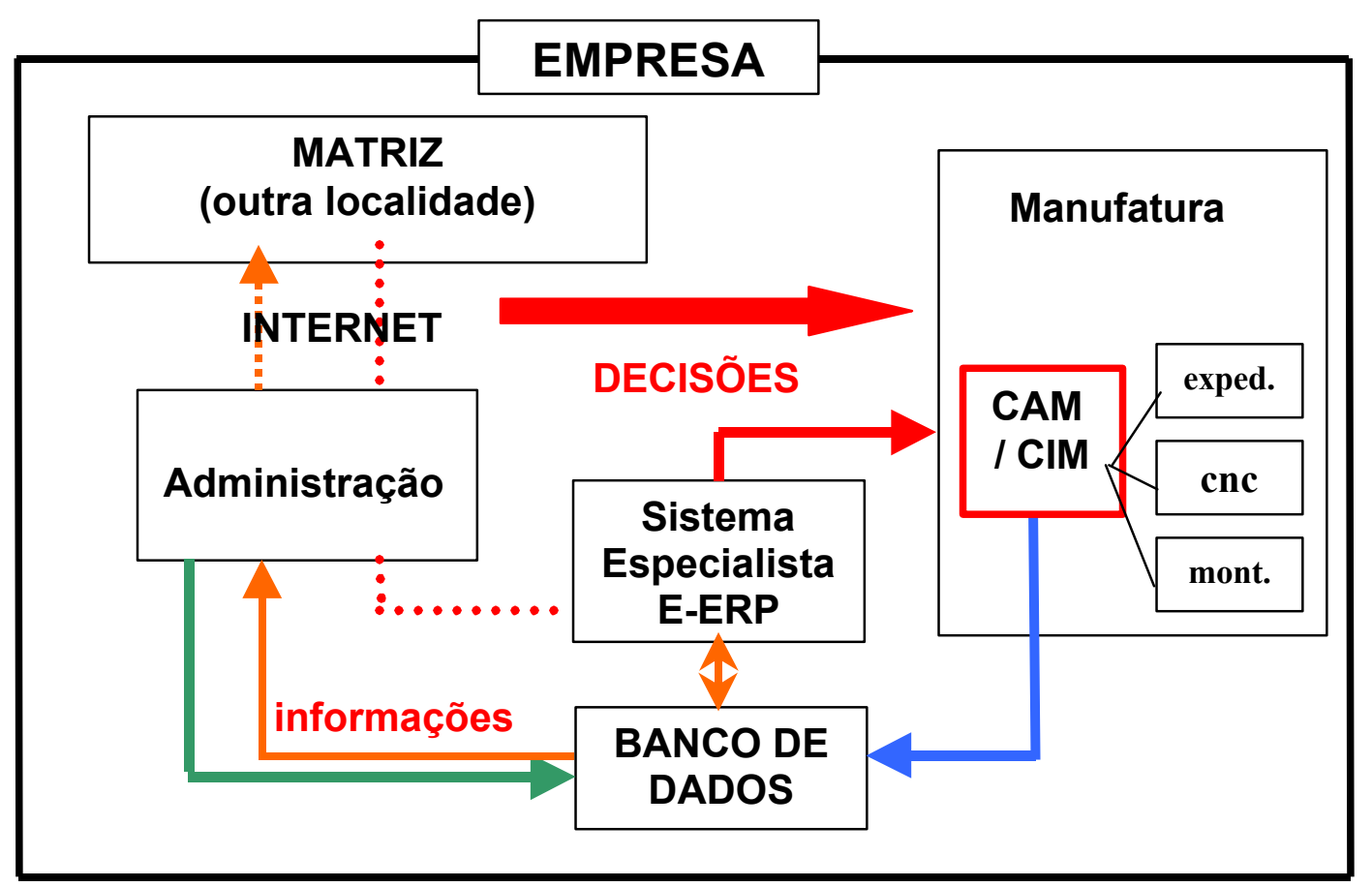

Figura 26 - Administração através de Conexão Remota.

Tendo esses preceitos básicos em mente, partiu-se para a estruturação do Sistema E-ERP propriamente dito, que realizará os diversos cálculos necessários e oferecerá opções nas ações que as empresas devem tomar. 
Como se pode verificar, existe uma diversificação de temas, que conduz a uma variedade de análises e interpretações de diferentes aspectos ou de problemas a serem solucionados.

A diversidade da natureza destas análises, assim como sua multidisciplinariedade, torna necessária a freqüente reavaliação, conforme sugere BELHOT (1991), possibilitando a correção de qualquer distorção ou insatisfação.

Ainda nessa mesma linha de pensamento, estipulou-se uma seqüência de análise e desenvolvimento que deve reforçar, não só a retroanálise, como também os procedimentos de validação do aplicativo, conforme ilustra a figura 27.

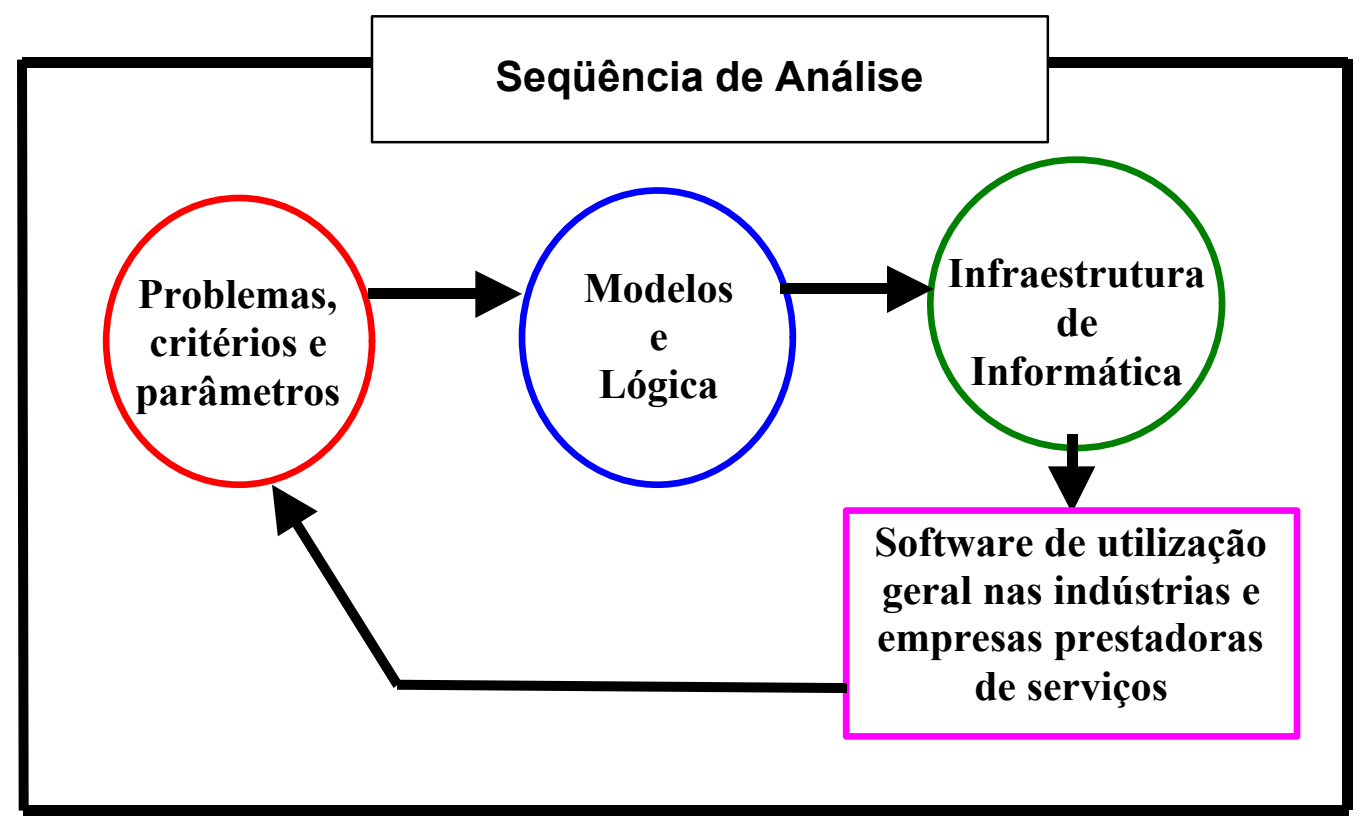

Figura 27 - Seqüência de Desenvolvimento de Análises. 
Lembrando-se de que o Sistema E-ERP proposto ainda se encontra no estado da arte, considerou-se inadequado, nesse momento, tentar mensurar seu desempenho, ou compará-lo com os outros sistemas já conhecidos.

Entretanto, mesmo entendendo que tal mensuração não pertence ao escopo do trabalho, apresenta-se a seguir uma lista das características que diferenciam o sistema proposto dos demais sistemas atualmente utilizados:

- sistema de inferência, caracterizando o sistema especialista e contendo diferentes alternativas para a realização das tarefas;

- utilização de sistemas de comunicação à distância, para permitir a comunicação remota entre as diversas unidades (matriz e filiais);

- conexão do sistema administrativo com o computador que comanda a execução da manufatura, transmitindo informações referentes a quantidades, setups, mix de produção, seqüência de processos e todas outras informações relevantes à área da manufatura;

- simulações e comparações de resultados de maneira mais confortável; e

- disponibilização de interfaces mais amigáveis com o usuário.

Os módulos de cálculo, idealizados por este trabalho, devem contemplar inicialmente as atividades básicas da empresa (tais como: Compra, Venda, Manufatura, Financeiro, Expedição e outros) e, conforme a necessidade ou planejamento, expandir para as funções diferenciais. 
Porém, tais módulos devem possuir os sistemas de inferência (que farão as verificações e análises dos resultados), um método que permita alterar os critérios de cálculos, alternando entre as diferentes metodologias (ex: MRP e CRP, ou Custeio Padrão e ABC) e um conjunto de parâmetros que servirão para as análises do sistema de inferência (como: crescimento de mercado de $5 \%$ ou $10 \%$, atendimento integral dos maiores clientes ou proporcional, entre outros).

\section{C) Para quem fazer?}

A esta altura cabe lembrar que o sistema E-ERP só alcançará o sucesso desejado se os usuários conseguirem manejá-lo adequadamente. Para isso, é vital que as interfaces sejam bem feitas e principalmente amigáveis.

Isso indica a relevância da Ergonomia e da Ciência Cognitiva no projeto, ou seja, é imprescindível recordar as principais relações de interface, consideradas na preparação de softwares institucionais, posteriormente usados pelos funcionários das empresas.

1) Programador $x$ Usuário

2) Organização x Usuário

3) Programa x Organização

4) Usuário x Programa 
Sendo assim, aconselha-se a realização de várias análises para chegar à eliminação de uma série de conflitos e desconfortos nas interfaces existentes, principalmente naquelas que relacionam o usuário com 0 sistema.

\section{Comentário:}

Adiante, será realizada uma análise mais completa sobre o assunto. Também será realizado, nos próximos capítulos, um detalhamento das funções e estruturas do sistema integrado proposto. 


\section{5) DESENVOLVIMENTO}

Como já citado anteriormente, o sistema proposto seguirá as tendências atuais de flexibilização e modularização do programa e da administração da empresa. Isso possibilitará que os funcionários de diferentes setores da empresa possam acessar os programas específicos (módulos) e realizar os cálculos administrativos. Dessa forma, o desenvolvimento do sistema é orientado tanto para o produto (programa) quanto para a sua aplicação (lógica).

\section{1) METODOLOGIAS}

Algumas metodologias vêm sendo utilizadas a fim de alcançar esses objetivos, entre as quais, podem-se destacar:

\section{1.a) Capability Maturity Model (CMM)}

O Capability Maturity Model (CMM), criado pelo Software Engineering Institute (SEI), descreve os princípios e as práticas inerentes ao processo de desenvolvimento de software, visando à organização e à melhoria na maturidade de seus processos, guiando-os num trajeto evolutivo de um ambiente ad-hoc e caótico para processos maduros e disciplinados, beneficiando os grupos de engenharia de software, gerente de softwares e indivíduos do programa de melhoria de qualidade.

(http://jacques.ic.cti.br/ic/pqps/cmm.htm - 01/10/99).

O CMM é uma metodologia de desenvolvimento de sistemas de difícil implantação, pois é necessário preparar o ambiente através de uma 
capacitação tecnológica (conhecimento e habilidades). É também conhecido por ser o modelo de gerenciamento do processo de software mais respeitado. A idéia é criar uma infra-estrutura que permita a elaboração de um software melhor, mais rápido, mais barato e com menos falhas, visando a dar uma metodologia de desenvolvimento e classificação de software às Software-Houses. (BELLOQUIM, 1999).

A maior diferença entre os estudos da ISO 9000 e os do CMM está nas suas ênfases. Enquanto o MMC se preocupa com o melhoramento contínuo de processos, a ISO 9000 está interessada em dar critérios mínimos para que um sistema de qualidade seja aceitável.

Outro aspecto importante é que o CMM está focado estritamente no software, enquanto a ISO 9000 tem maior alcance englobando hardware, software, processos de materiais e serviços.

(http://www.les.inf.puc-rio/socinfo/nestor/Cuerpo.htm - 01/10/99)

\section{1.b) Personal Software Process (PSP)}

O Personal Software Process (PSP) é uma nova tecnologia do Software Engineering Institute, que traz disciplina à prática individual de engenheiros de software. Isso faz com que eles melhorem drasticamente a qualidade, a previsibilidade e o ciclo de tempo de seus produtos. (http://www.campus.fortunecity.com/princeton/117/psp/psp.htm $-01 / 10 / 99)$ 
O PSP consegue, através de um curso, treinar o engenheiro de software para ser mais eficiente. As melhorias conseguidas variam para cada engenheiro, mas todos recebem condições para melhorar nos seguintes aspectos:
a) criatividade;
b) fazer planos;
c) gerenciar planos; e
d) reduzir defeitos.

Essas duas metodologias são, sem dúvida, extremamente relevantes para empresas e engenheiros de software. Porém tais técnicas não se aplicam a este estudo, uma vez que, antes de projetar o sistema integrado proposto, é necessário, primeiramente, compreender as suas funções e formas para, numa fase posterior, escolher as melhores técnicas de programação, de gerenciamento e avaliação.

\section{2) ATIVIDADES DE PESQUISA}

Como já fora citado anteriormente, considerou-se a idéia de avaliação e medição de desempenho não adequada para esta pesquisa, pois ela ainda se encontra no estado da arte.

Sendo assim, partindo-se para a que foi denominada fase de compreensão e definição, decidiu-se subdividir as atividades de pesquisa em quatro áreas distintas, interligadas entre si, a saber: 


\section{2.a) Gerência da Produção;}

\section{2.b) Matemática (métodos matemáticos empregados);}

5.2.c) Informática (plataformas e linguagem de programação); e 5.2.d) Interfaces e Ergonomia.

Em função dessa subdivisão, faz-se necessária uma breve descrição das atribuições de cada área, onde se encontram alguns breves comentários sobre suas atividades e características:

\section{2.a) GERÊNCIA DA PRODUÇÃO}

Essa área recebeu o nome de Gerência da Produção (GP) em conseqüência da forte associação das pesquisas com as atividades rotineiras da Engenharia de Produção.

Paralelamente as várias atividades realizadas nessa área, três princípios devem orientar às pesquisas e, portanto, serem mantidos sempre em mente, que são:

$>$ identificação das características, dos pontos de controle e dos problemas existentes nas empresas;

procura dos critérios de administração industrial que permitam uma melhor avaliação da situação encontrada; e

> desenvolvimento dos parâmetros e indicadores que tornem possível uma decisão eficaz e adequada às características da empresa. 
Assim, entre as principais atividades de pesquisa que devem ser orientadas a atender os princípios acima citados, destacam-se as seguintes:

\section{2.a.1) Processos de Manufatura}

Detalhar as formas de manufatura possíveis de serem usadas pela empresa e quais delas melhor se adaptam; escolher quais serão os processos colocados à disposição do usuário; e quais são os dados que cada processo necessita que sejam registrados.

Por exemplo: célula de manufatura, produção em série, produção sob encomenda, tempos de processamento, capacidades e mãode-obra.

\section{2.a.2) Planejamento, Programação e Controle da Produção}

Definir as formas de Planejamento, Programação e Controle da Produção que podem ser usadas posteriormente no sistema. Como exemplo, citam-se: Plano Mestre de Produção, Previsão de Demanda, MRP, Controle de Estoques, Controle de Custos, Lote de Produção, CPM, PERT, lead-time, setups, delay.

\section{2.a.3) Critérios e Métodos para a Resolução dos Problemas}

Estabelecer as metodologias empregadas na resolução de conflitos e os critérios que os regem. Por exemplo, restrições comerciais ou tecnológicas; Margem Bruta de Contribuição 
Máxima; Receita Máxima; Grau de Alavancagem Operacional; Margem de Segurança; Taxa Interna de Retorno, Market share. Entre as diversas áreas de aplicação destacam-se a Estratégica, a Econômica Financeira e a Produtiva.

\section{2.a.4) Critérios e parâmetros de análises de produtividade}

Determinação dos critérios adotados e de seus respectivos parâmetros utilizados nas análises de produtividade. Por exemplo, quantidade de entradas/quantidade de saídas, quantidade de material re-processado, receita/matéria prima.

\section{2.a.5) Layout de Fábrica}

Baseado no processo de manufatura escolhido, deve-se estruturar o layout do setor produtivo, seguindo as determinações das normas vigentes (segurança, ISO etc.). Por exemplo: manufatura em forma de $\mathrm{U}, \mathrm{T}, \mathrm{L}, \mathrm{M}$ ou $\mathrm{W}$, com entrada de material simples ou múltipla e saída de produto acabado (ou semi-acabado).

\section{2.a.6) Qualidade do Produto e Processo}

Verificar quais são os procedimentos e as determinações recomendados pelas normas ISO e se comprometer a seguir tais recomendações, repassando esse compromisso também aos demais níveis de manufatura da empresa. 


\section{2.a.7) Escolha dos Dados Introduzidos no Banco de Dados}

Compartilhamento de dados implica o registro de conjuntos de dados no Banco Central de Dados, possibilitando que os diferentes setores possam usá-los. Essa atividade deve ser revista freqüentemente e, se necessário, incrementar novos tipos de dados. Os conjuntos de dados escolhidos devem ser suficientes para o gerenciamento da empresa, por exemplo: cadastros de fornecedores e clientes, custos, receitas e pagamentos, características de processos e produtos, tolerâncias e limites.

\section{2.a.8) Simulações}

Aproveitando a natureza dessa pesquisa, é recomendada a preparação de testes que possibilitem a execução de simulações de diferentes alternativas, que podem acabar economizando tempo e recursos financeiros.

\section{2.b) MATEMÁTICA}

A segunda área foi denominada Matemática (MA), por se tratar do desenvolvimento de algoritmos e de outras atividades de cálculo. Essa área se preocupa com a definição dos modelos matemáticos e com ferramentas e atividades auxiliares, incluindo: 


\section{2.b.1) Desenvolvimento e Análise de Algoritmos}

Baseado nas informações fornecidas pelo setor de GP, o setor MA deve elaborar o algoritmo aritmético que irá solucionar o problema. É preciso enfatizar que esses algoritmos podem utilizar funções matemáticas de complexidades variadas, ou seja, utiliza-se desde a simples adição até equações diferenciais, matrizes e outros.

\section{2.b.2) Ferramentas Matemáticas (Redes Neurais, Constraint- Nets, Qualitative and Quantitative Dates).}

Já considerando as ferramentas matemáticas como instrumentos auxiliares, avalia-se que o setor MA deve possuir liberdade para utilizar diferentes concepções relacionadas às árvores de decisões.

\section{2.b.3) Pesquisa Operacional e Métodos Quantitativos}

Aqui também são consideradas outras categorias de ferramentas matemáticas. Essas, porém, estão relacionadas com procedimentos de logística, tais como: simplex; método do canto noroeste; mix de produção; distribuição de materiais e outros.

\section{2.b.4) Análise Estatística de Dados}

Por fim, porém não menos importante, deve disponibilizar as ferramentas estatísticas que auxiliam nos controles de processos e da qualidade. 


\section{2.c) INFORMÁTICA}

O terceiro setor, aqui denominado Informática (IN), está incumbido de tornar os algoritmos e a lógica desenvolvida pelo setor MA em programa de computador, utilizando linguagens de programação modernas e de fácil utilização.

Ressalta-se que essa tarefa deve utilizar os conceitos de qualidade de software, o que implica o trabalho conjunto com o setor GP, que será posteriormente o usuário do sistema desenvolvido, ou seja, é preciso a aprovação posterior pelo usuário final do sistema desenvolvido.

O aplicativo segue algumas políticas de independência modular na linha de programação orientada a objetos, onde os diversos módulos do programa são projetados para funcionar isoladamente.

Porém, é preciso ressaltar que, mesmo para a instalação parcial do sistema, é necessário que seja instalado um conjunto mínimo de módulos aplicativos, caso contrário, não será possível constituir um sistema integrado de gestão.

As principais atividades de pesquisa incluem:

\section{2.c.1) Elaboração de Algoritmos}

É necessária, para que os módulos estejam de acordo com as linguagens de alto nível modernas e de maior aceitação comercial, e sejam compatíveis com o mercado, tais como: LISP, $\mathrm{C}_{++}$, Smalltalk etc.. 


\section{2.c.2) Qualidade de Software}

deve-se seguir as orientações ISO para se obter um sistema já aprovado internacionalmente, o que facilitará sua aceitação pelo mercado.

\section{2.c.3) Redes de Computadores}

Recomenda-se que o sistema tenha opções de conexões para diferentes sistemas operacionais. Além disso, o sistema deve possuir uma arquitetura lógica que possibilite o acesso de diferentes pontos da rede e, logicamente, deve-se ser dotado de uma política de perfil de usuário que habilite o acesso a diferentes arquivos, respeitando-se as necessidades e permissões configuradas.

\section{2.c.4) Sistemas Flexíveis de Informação e Banco de Dados \\ O sistema deve utilizar os conceitos de flexibilidade para sistemas e banco de dados compartilhados, já comentados anteriormente.}

\section{2.c.5) Sistemas de Introdução de Dados}

A fácil introdução de dados será um dos fatores que irá diferenciar o sistema. A idéia de possibilitar a entrada de dados por meios ainda não rotineiros (voz, leitura de código de barras etc.) já deve ser prevista. 


\section{2.c.6) Possibilidade de alternativas}

Outra tarefa a ser destacada é o desenvolvimento da função de oferecimento de alternativas (critérios, parâmetros, apresentação de resultados), que devem ser configurados (escolhidos) e utilizados pelos usuários.

\section{2.d) INTERFACES E ERGONOMIA}

Por se tratar de um trabalho multidisciplinar - e havendo uma superposição de áreas de interesse - acredita-se que, paralelamente às tarefas citadas anteriormente, o sistema deve dar uma ênfase especial à aplicação de conceitos de ergonomia na informática, principalmente no que tange à melhoria da amigabilidade do software.

Essa ênfase tem o objetivo de eliminar qualquer problema ou dificuldade que os usuários possam encontrar na sua utilização, por exemplo: conceitos de estrutura organizacional; distribuição lógica e física de atividades; utilização de ícones adequados, de cores de fundo de tela; sistemas auxiliares de ajuda.

Faz-se, a seguir, uma breve descrição das relações consideradas principais, a serem analisadas e utilizadas no desenvolvimento do sistema. 


\section{2.d.1) Programador $x$ Usuário}

Deve-se imaginar que o programador é um agente que tenta entender a empresa e seus procedimentos, ao mesmo tempo que deve fazer uma análise da visão do usuário, procurando entender como esse interpreta os mesmos procedimentos.

O programador deve preparar esses aplicativos baseando-se nessas duas visões, de maneira que o usuário não boicote o uso do aplicativo.

Ou seja, o programador deve entender os desejos/anseios do usuário e dar flexibilidade ao software, para que atenda aos usuários que atuem na mesma função, porém que expressem anseios distintos.

\section{2.d.2) Organização x Usuário}

Um estudo mais profundo nessa relação irá fornecer aos programadores e analistas informações úteis sobre:

- como os usuários entendem a organização;

- o que os usuários conhecem dos processos da empresa e como eles os interpretam; e

- como os usuários interagem com outros setores e departamentos da empresa. 


\section{2.d.3) Programa x Organização}

O programa deve ter várias funções, com o objetivo de auxiliar as atividades setoriais da empresa. Para que assim aconteça, é preciso que o programa esteja baseado nos processos da empresa e no modo como os futuros usuários compreendem esses processos. O programador deve enfrentar duas situações distintas de análise, a saber:

- estrutura organizacional e estrutura funcional; e

- o modo como o usuário entende que a Organização está estruturada e como ele (usuário) está disposto a agir.

\section{2.d.4) Usuário x Programa}

A experiência tem mostrado que uma boa interface entre o usuário e o aplicativo é alcançada quando o programa é de fácil entendimento (auto-explicativo), sendo complementado por um conjunto de dispositivos, tais como: código de cores ou sinais externos (sons, mensagens, cores) que auxiliem o usuário na sua utilização. Em geral, as soluções apontam para a melhoria de interfaces, tais como: apresentações em modelo gráfico e gerenciamento automático de diálogos.

A adição de algumas capacidades funcionais (menus, espaços para serem completados, entradas parametrizadas, comandos interativos) a um sistema computacional, além de vantajosa para o 
usuário, normalmente contribui de maneira significativa para a construção mais eficiente de programas em linguagem de alto nível.

Outra característica relevante na busca de uma boa manipulação do aplicativo é que as interfaces sejam projetadas com um bom componente visual, ou seja, que as tarefas (funções) possam ser rápida e facilmente identificadas pelo usuário.

Esse componente visual procura, através de um bom desenho de tela, fazer com que o usuário manuseie o programa baseando-se apenas nas suas interpretações visuais da tela, tentando eliminar a necessidade de outras leituras, ex: ajuda on-line (help). 


\section{TABELA 3 - Aspectos da Interface Homem x Sistema}

\section{(Fonte: EHRICH \& WILIGES, 1986)}

1. Organização de dados

1.1 Codificando informação

1.1.1 Código de cores

1.1.2 Código de formas

1.1.3 Código de blink

1.1.4 Código de luminosidade

1.1.5 Códigos alfanuméricos

\subsection{Densidade da informação \\ 1.3 Rotulação \\ 1.4 Formato \\ 1.4.1 Prompt \\ 1.4.2 Dados tabulares \\ 1.4.3 Gráficos \\ 1.4.4 Dados textuais \\ 1.4.5 Dados numéricos \\ 1.4.6 Dados alfanuméricos \\ 1.5 Layout da tela}

2. Módulo de diálogos

2.0 Escolha do módulo de diálogos

2.1 Preenchimento de formulários

2.1.1 Valores default

2.1.2 Feedback

2.1.3 Layout de telas

2.1.4 Entrada de dados

2.1.5 Movimento de cursor

2.2 Busca no computador

2.3 Seleção de menu

2.3.1 Ordem de opções

2.3.2 Seleção de códigos

2.3.3 Layout do menu

2.3.4 Conteúdo do menu

2.3.5 Controle de seqüência

2.4 Linguagens de comando

2.4.1 Organização de comando

2.4.2 Nomenclatura de comando

2.4.3 Defaults

2.4.4 Orientação de editores

2.4.5 Controle do usuário

2.4.6 Operação de comando

2.4.7 Dispensa do sistema

2.4.8 Operações especiais

2.5 Linguagem interrogatória formal

2.6 Linguagem natural restrita
3. Dispositivo de entrada dos usuários

3.0 Procedimento de entrada de dados

3.1 Dispositivo de seleção de entrada

3.2 Teclados

3.2.1 Funções chaves especiais

3.2.2 Controle do cursor

3.3 Controles pontuais diretos

3.4 Controles contínuos

3.5 Tabelas gráficas

3.6 Analisadores de vozes

4. Feedback e Administração de erros

4.1 Feedback

4.1.1 Mensagens de status

4.1.2 Mensagens de erro

4.1.3 Saídas de cópias rígidas

4.2 Recuperação de erros

4.2.1 Correção pelo usuário

4.2.2 Procedimentos de correção

4.2.3 Checagem automática de erros

4.2.4 Correção automática

4.2.5 Comandos amontoados

4.3 Controle do usuário

4.4 Ajuda e documentação

4.4.1 Documentação offline

4.4.2 Documentação online

4.5 Ajudas do computador

4.5.1 Ajuda na correção

4.5.2 Ajuda na decisão

4.5.3 Ajuda na entrada gráfica

5. Segurança e prevenção de desastres

5.1 Comandos de cancelamento 5.2 Verificação de ambigüidade ou ações destrutivas

5.3 Controle de seqüência

5.4 Falhas de sistema

6. Usuários múltiplos

6.1 Separando mensagens / entradas

6.2 Separando áreas de trabalho

6.3 Registro de comunicações 
Finalizando este capítulo, destaca-se que a metodologia de desenvolvimento do projeto também propõe a seqüenciação dos esforços distribuídos entre três áreas citadas (Engenharia de Produção, Matemática e Informática), conforme ilustra a Figura 28, a seguir.

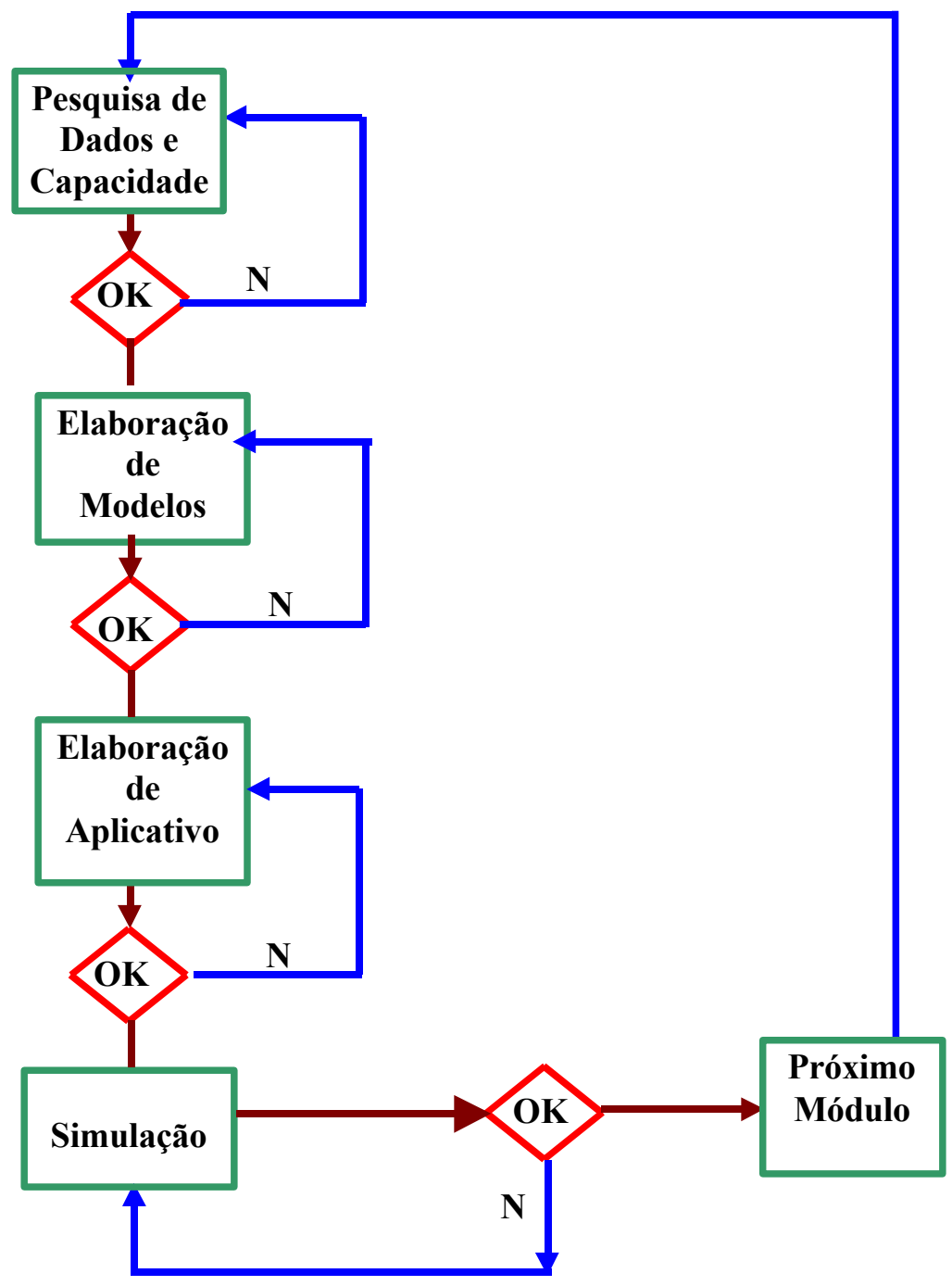

Figura 28 - Diagrama de fluxo (simplificado). 


\section{6) ESTRUTURAS}

Para a aplicação das idéias desenvolvidas neste trabalho, é necessário que haja uma troca da estrutura organizacional hierárquica atualmente utilizada para uma estrutura compatível das idéias aqui expostas.

\section{1) Estrutura Hierárquica}

Tomando a Figura 29 como exemplo típico de estrutura atual, observa-se que não há um relacionamento horizontal entre os vários setores da empresa. Isso significa que, para viabilizar a troca oficial de dados e informações entre setores subordinados a diferentes áreas, normalmente, há uma atuação (intervenção) dos níveis hierárquicos mais altos.

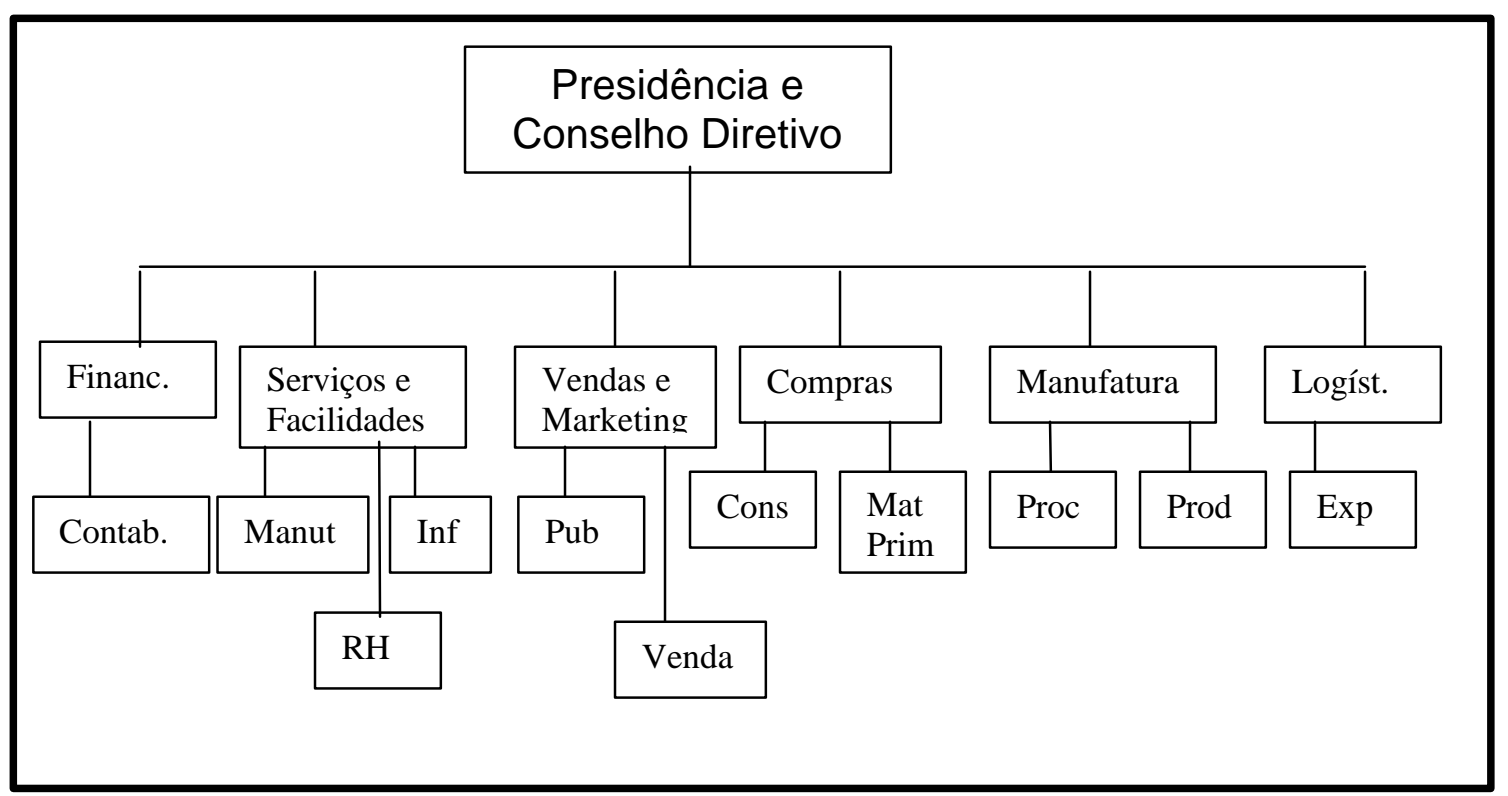

Figura 29 - Exemplo de Estrutura Organizacional Hierárquica Atual. 
Esse arranjo organizacional quase impossibilita a visualização das influências advindas de outros setores. Em outras palavras, a forma tradicional de organização operacional não permite a observação da influência das atividades e dos resultados de outros setores, com os quais não estejam diretamente relacionados, por exemplo: as decisões e atuações do setor de Compras nas atividades do setor de Logística e assim por diante.

Sendo assim, optou-se pela utilização de um formato mais adequado, as relações atualmente existentes nas empresas, denominada estrutura de malha ou rede, descrito em BARRELLA (1995).

Esse formato, cujo princípio de relacionamento - reconhecidamente utilizado em alguns sistemas de gestão (por exemplo, no formato de diamante usado pela SAP) - permite não só a observação das influências entre setores, mas também, a verificação da centralização de um banco de dados, que irá alimentar e ser alimentado por vários setores da empresa.

Ao contrário do que possa parecer, a centralização num banco único de dados irá facilitar o acesso a seu conteúdo, uma vez que, dada permissão de acesso, não será mais necessária a intervenção de instâncias superiores (diretoria), na obtenção de dados necessários para seus cálculos. Além de que, essa metodologia também irá garantir a consolidação dos dados. 
Outra vantagem da estrutura proposta é possibilitar a elaboração da estratégia da empresa como um todo, ou seja, trocar a alta performance de um único departamento por um melhor resultado geral da empresa.

A Figura 30, abaixo, ilustra a estrutura proposta e possibilita o entendimento das relações acima-citadas, inclusive do Banco Central de Dados.

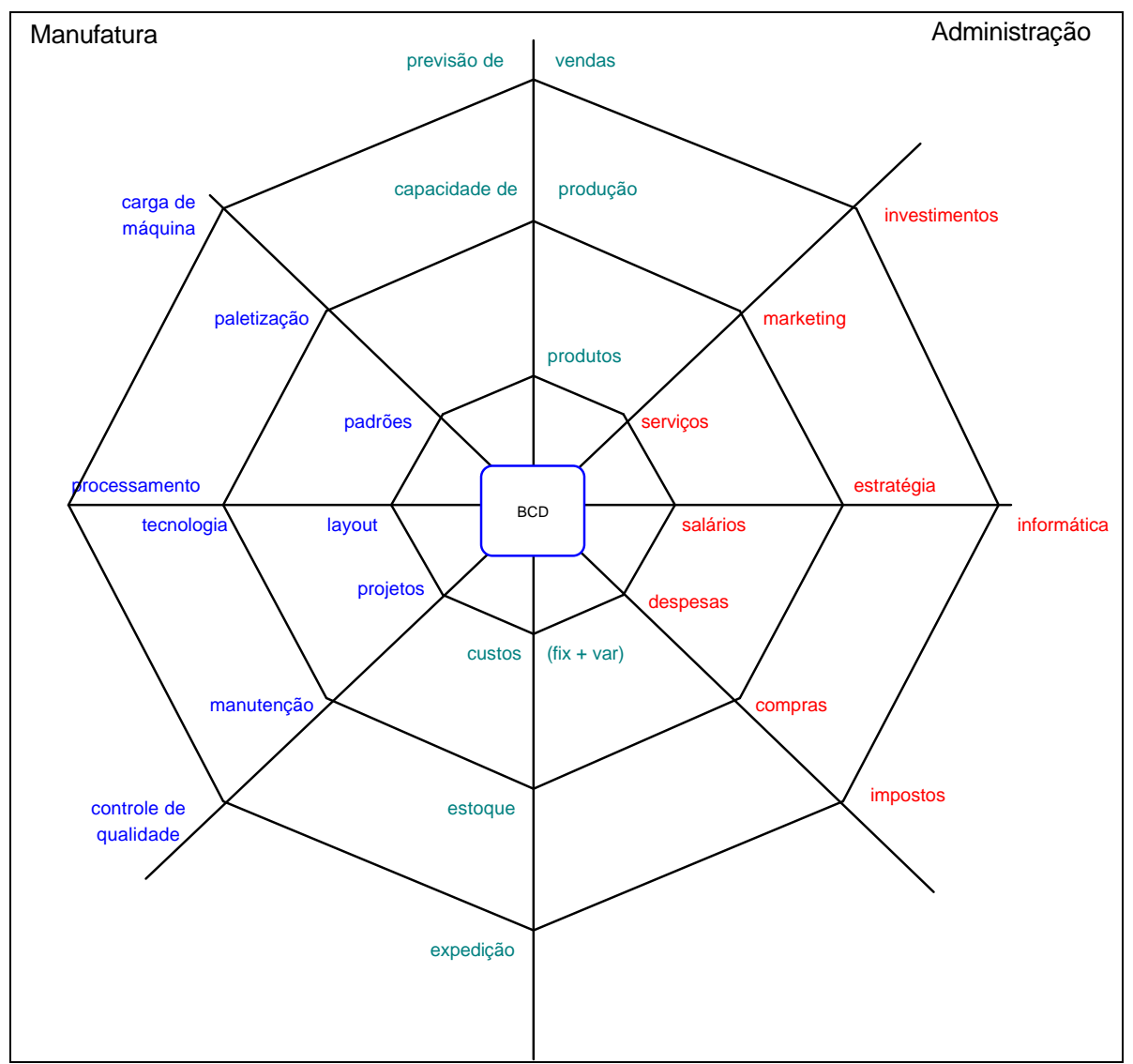

Figura 30 - Estrutura Organizacional Proposta.

(Fonte: BARRELLA, 1995) 


\section{2) Estrutura de Processamento}

Ao mesmo tempo em que é discutida a utilização de um novo formato na estrutura relacional da empresa, sugere-se uma estrutura de processos mais ajustada às operações realizadas nas empresas e mais adequada a automação que deve ser alcançada.

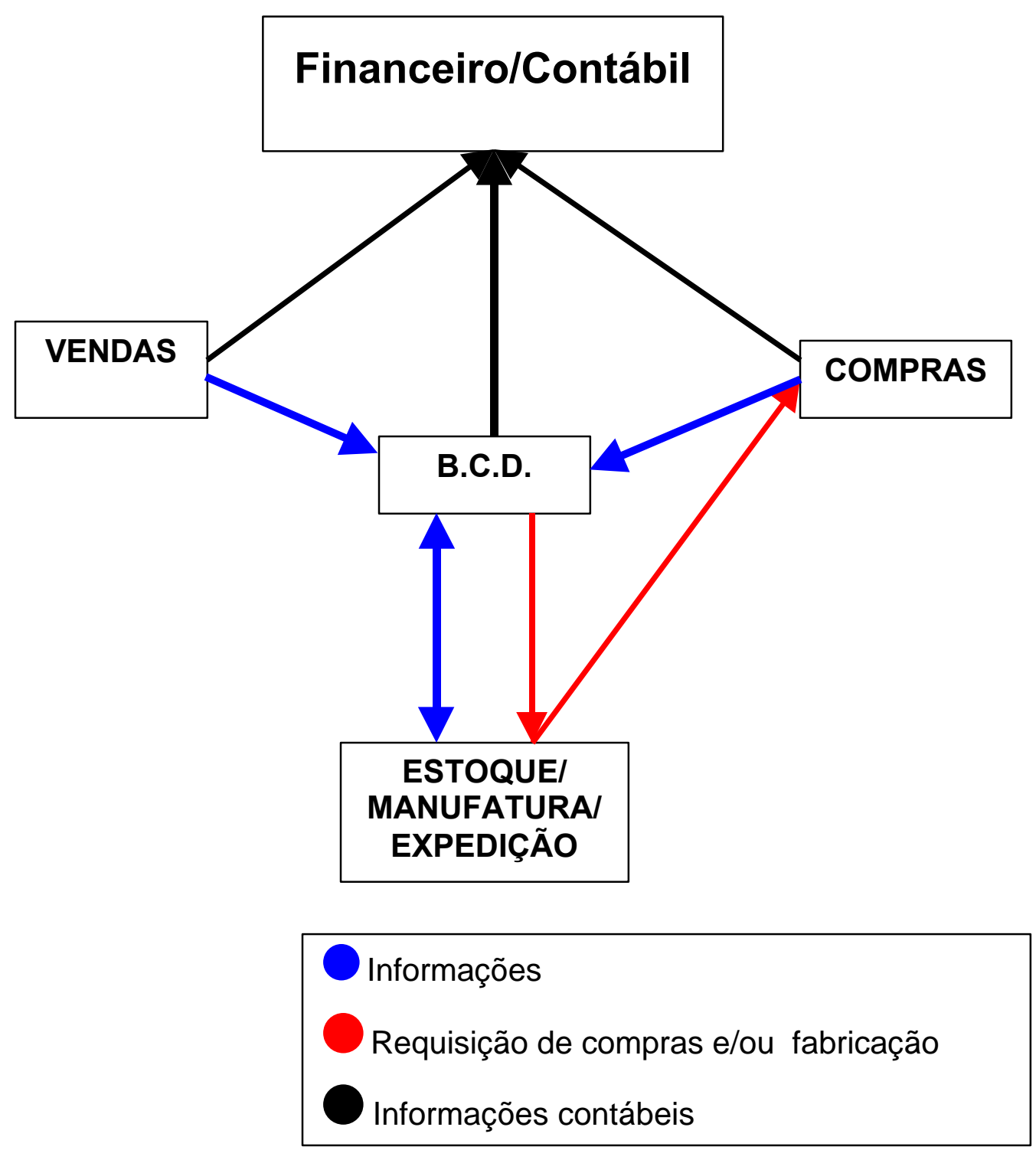

Figura 31 - Estrutura de Processamento Proposta. 
Para uma melhor compreensão do esquema simplificado da Figura 31, pode-se imaginar que uma empresa que esteja inserida no segmento de produção de bens duráveis e inicie seu planejamento empresarial para os próximos períodos. Uma das várias possibilidades para iniciar esse planejamento é a utilização da previsão de vendas nos próximos períodos, normalmente fornecida pela área de Marketing. Outra possibilidade é a de que a Alta Administração coloque suas metas de ocupação de mercado e de estratégias de produção.

Entretanto, o importante é que, com base nessas previsões e/ou metas, devidamente registradas no banco de dados central - BCD - da empresa, o departamento de Engenharia de Produção comece a traçar seus planos, para cumprir as metas estabelecidas. Nessa ocasião, é feita na primeira análise de recursos necessários e disponíveis para a produção, dentre os quais, incluem-se: mão-de-obra, equipamentos e matériaprima. O departamento de Engenharia busca no BCD os dados relativos aos estoques (de produto acabado) disponíveis e verifica quais produtos devem ser manufaturados e suas respectivas quantidades.

Tendo essas informações em mãos, o departamento de Engenharia Industrial dá início ao processo de manufatura (planejamento, programação e execução) de produtos, que será encerrado quando a programação for totalmente cumprida e o estoque de produto acabado atingir o nível capaz de atender às vendas e aos prazos exigidos pelos clientes. 
Se for constatada durante o planejamento a falta de matéria-prima para o processamento dos produtos necessários, o departamento de Engenharia deverá emitir uma requisição de compras, que será transformada em pedido de compras de matéria-prima que, por sua vez, proverá o respectivo estoque com o material necessário.

\section{3) Estrutura de Comunicações}

Com as teorias de Sistemas Integrados, descritas por DAVENPORT (1998), HABERKORN (1999) e CORREA (1997), o SIG proposto deve possibilitar as ações descritas no item 6.2, ao mesmo tempo em que envia várias comunicações a diferentes setores da companhia.

Essa ação significa que, paralelamente aos processos de planejamento e manufatura, deve haver uma comunicação (sobre vendas, produções e compras) para a área financeira, uma vez que essa é a responsável pela contabilização dos custos.

Para ilustrar essa visão mais detalhada da estrutura de processos proposta, utiliza-se a Figura 32, a seguir, que pode também ser considerada como o Diagrama de Fluxo de Dados do Sistema. 


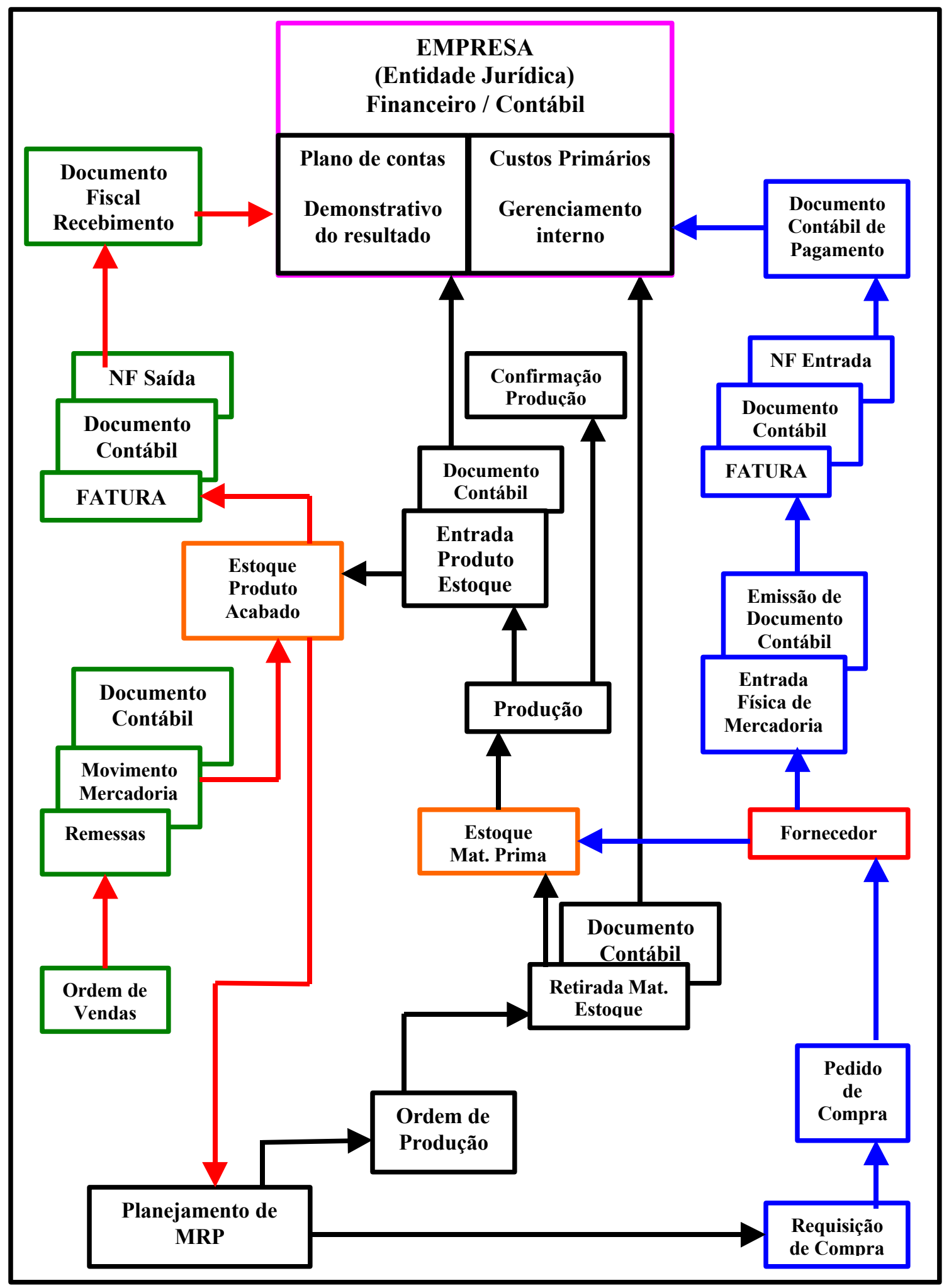

Figura 32 - Estrutura de processos proposta. 
Como se nota na figura anterior, as comunicações citadas ocorrem junto com as operações (movimentação e transformação de material) e são feitas através de documentos fiscais, emissão de notas, faturas, boletos de pagamento, recebimento de material e outros. Essa documentação (eletrônica ou não) é enviada ao departamento Financeiro, que é encarregado de registrar as contas (receitas, custos e despesas) e seus respectivos responsáveis.

\section{4) Seqüência Lógica do Programa}

A maneira escolhida para dar início à elaboração do programa está baseada nas atividades realizadas pela empresa num processo rotineiro. Descrevendo a utilização passo a passo, tem-se uma seqüência próxima a esta descrita a seguir:

1) ligar o computador e conectá-lo a rede principal da empresa;

2) fornecer o usuário e a respectiva senha;

3) preencher os dados dos cadastros necessários;

4) verificar (definir, se necessário) a estrutura do plano de contas;

5) verificar a projeção de vendas ou dos pedidos em carteira;

6) escolher um critério e fazer a programação da manufatura;

7) se necessário, efetuar compra de matéria prima;

8) liberar e efetuar a manufatura;

9) determinar os detalhes sobre a entrega aos clientes; $e$

10) determinar os custos e calcular os resultados da empresa. 
O início do desenvolvimento do aplicativo é independente da filosofia de manufatura (make-to-order, make-to-stock ou outros).

Embora a filosofia empregada seja um elemento diferencial para a utilização do sistema, pois é preciso em qualquer caso calcular a quantidade de produtos e os respectivos recursos necessários.

Conforme citado anteriormente, optou-se por tomar a seqüência de utilização do sistema, mostrada na Figura 33, como linha mestra na criação do aplicativo.

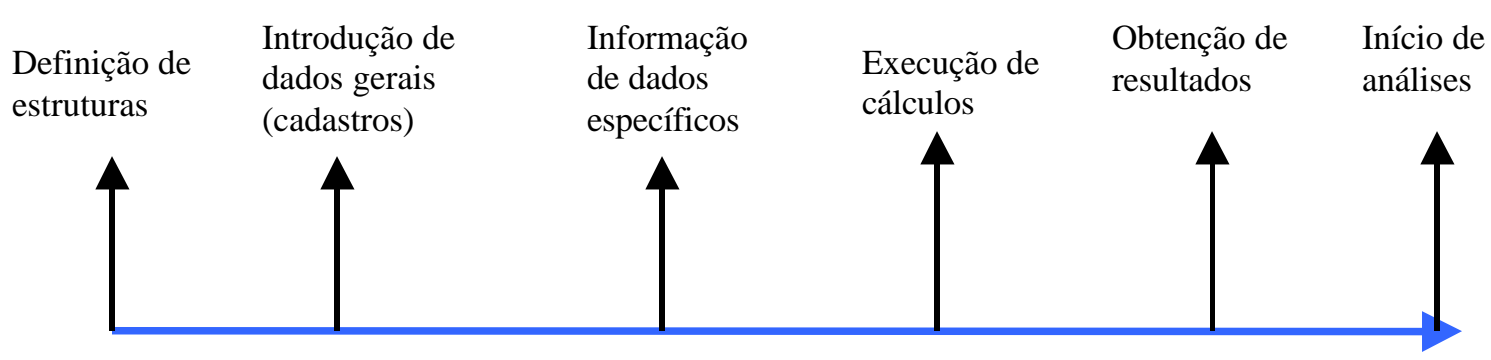

Figura 33 - Linha Mestra da Criação do Programa.

Numa segunda fase de desenvolvimento, serão consideradas as alternativas de filosofias de cálculos, assim como, as comunicações com os computadores da manufatura e com os servidores situados em outras localidades geográficas.

Iniciou-se a preparação do sistema pela definição das estruturas e pela introdução dos dados necessários para a empresa calcular as quantidades e os valores inerentes a sua manufatura. 
Escolheu-se a esta seqüência de definição e preenchimento dos seguintes formulários:

1) Registro de Cadastros: Matéria Prima, Produto Acabado, Fornecedores, Clientes, Processo, Funcionários.

2) Registro de Atividades: Compra, Venda, Manufatura, Logística, Serviços, Contabilidade.

3) Cálculos: Manufatura, Análises, Relatórios, Simulações, Comunicações.

4) Customização das telas e dados.

Quando esses formulários estiverem devidamente definidos e programados, pode-se passar à fase de introdução de dados e testes.

\section{5) Componentes do Sistema}

O SIG sugerido é composto por vários elementos, definidos e conectados em um sistema único. Entre os principais elementos, destacam-se:

6.5.a) Banco de Dados: é um sistema informatizado onde são registrados os cadastros, conhecimentos e outros dados relevantes para a execução dos cálculos efetuados nos módulos. 
6.5.b) Dispositivo de Inferências: é o conjunto de regras que controla os conhecimentos pertencentes à solução do problema colocado, tornando-o sistema capaz de tomar decisões num dado domínio.

6.5.c) Cadastros: são as tabelas do banco de dados, onde são registrados os atributos relativos aos elementos da empresa, onde se destacam:

6.5.c.1) Matéria-prima - código, descrição, unidade, produtos, armazenagem, fornecedores, preço de compra.

6.5.c.2) Produto acabado - código, descrição, unidade de medida, árvore de subprodutos, local de armazenagem, compradores, preço de venda.

6.5.c.3) Fornecedores - nome comercial, nome fantasia, código, CNPJ, endereço, material que fornece (preço, quantidade, prazo), ICMS, condições de pagamento.

6.5.c.4) Clientes - nome comercial, nome fantasia, código de cliente, CNPJ, endereço, produtos que compra (preço, quantidade, prazo), ICMS, condições de pagamento.

6.5.c.5) Processos - nome do processo, código, equipamentos, descrição, velocidade de trabalho (unidades/hora), tempo, funcionários, horas trabalhadas por turno, energia elétrica, outros insumos. 
6.5.c.6) Funcionários: nome, endereço, estado civil, nascimento, escolaridade, número de dependentes, cargo, número de funcionário, salário nominal.

6.5.d) Atividades: são todas as tarefas realizadas no dia-a-dia da empresa e utilizadas na administração da companhia. As atividades básicas do sistema são:

6.5.d.1) Compra - código do pedido, material, quantidade, fornecedor, data de entrega, fator de qualidade, local de entrega, condições de pagamento, responsável, tipo (reposição de estoque, consumo, produção), fator ICMS, outros impostos.

6.5.d.2) Venda - código da ordem, produto, quantidade, comprador, data de entrega, fator de qualidade, condições de pagamento, responsável, local de entrega, fator ICMS, outros impostos.

6.5.d.3) Manufatura - código de manufatura, material, quantidade, data de entrega, processos envolvidos, responsável.

6.5.d.4) Logística - código de movimentação, material, quantidade, data e local de entrega, armazém de origem, via de expedição (aérea, rodovia, ferrovia), responsável. 
6.5.d.5) Serviços - código do serviço, tipo do serviço (manutenção, reposição, re-trabalho etc.), data do serviço, local do serviço, centro de custo responsável pelo pagamento do serviço.

6.5.e) Customização: é um artifício que possibilita a adaptação do sistema às características da empresa, do mercado, do país e qualquer outro detalhe que particularize a companhia.

6.5.f) Módulos: programas que executam cálculos utilizados na administração da companhia. Os módulos confundem-se com as atividades, porém nem toda atividade constitui um módulo, por exemplo: contabilidade, análises, relatórios e comunicações.

6.5.f.1) Vendas: elabora a projeção de vendas dos próximos períodos; estipula preços mínimos; recebe encomendas; informa os produtos negociados, quantidades, datas, valores, clientes e forma de cobrança ao BCD.

6.5.f.2) Compras: recebe informação sobre: falta de materiais, custos, quantidades, datas, fornecedores; informa custos e despesas relacionados a materiais e serviços, quantidades, datas, fornecedores, locais, forma de pagamento ao BCD. 
6.5.f.3) Logística: verifica a disponibilidade de produto acabado no BCD; informa locais, datas, quantidades, produtos, meio de transporte, custos e armazém de origem para entrega aos clientes; informa locais, datas, quantidades, produtos, meio de transporte, armazém de destino para entrega dos fornecedores.

6.5.f.4) Contabilidade: determina e atribui os centro de custos; distribui os custos e receitas para seus respectivos centros; determina a estrutura das contas contábeis; consolida as contas; rateia custos, realiza provisão de verbas; informa ao BCD os valores disponíveis em todas as contas.

6.5.f.5) Manufatura: recebe informação sobre a manufatura dos produtos; verifica a disponibilidade da matéria-prima e dos subconjuntos; emite pedido de compras de matéria-prima e informa ao BCD; calcula o mix de produção e a carga de máquina; informa o BCD os lead times, os setups, e os custos associados à produção.

6.5.f.6) Análises: busca os dados no BCD e disponibiliza cálculos (MBC, Custos fixos e variáveis, Taxa Interna de Retorno, Grau de Alavancagem Operacional, Elasticidade, Resultado da Empresa), para estudos posteriores. 
6.5.f.7) Relatórios: realiza a interface com o usuário e disponibiliza vários tipos de relatórios; busca os dados no BCD e calcula os valores solicitados, apresentando-os conforme preferência do usuário.

6.5.f.8) Simulações: verifica os dados no BCD; executa os cálculos de determinado módulo (realizando simulações e obtendo seus resultados, podendo salvá-los), apresentandoos de maneira agradável e tornando possível a comparação entre eles.

6.5.f.9) Comunicações: permite a conexão com o servidor principal, onde se encontra o BCD (acessando/atualizando os dados); permite a conexão com o computador que comanda a produção (comunicando dados da manufatura).

\section{6) Estrutura do Plano de Contas}

É fundamental que a empresa, através do módulo de contabilidade, possa definir a estrutura do seu plano de contas, pois a opção de elaborar a estrutura de controle monetário utilizada na companhia, além de flexibilizar a utilização do software permite que sejam feitos os controles de custos. Essa estrutura é analisada sob as óticas Financeira e Contábil. 


\section{6.a) Financeira}

A parte financeira realiza os controles econômicos em função dos aspectos legais e jurídicos, tendo, no Brasil, toda uma legislação específica. As tabelas a seguir exemplificam os tipos de controle realizados.

\begin{tabular}{|l|l|}
\hline \multicolumn{2}{|c|}{ BALANÇO PATRIMONIAL } \\
\hline \multicolumn{1}{|c|}{ ATIVO } & \multicolumn{1}{|c|}{ PASSIVO } \\
200.000 - Bancos & 160.000 - Fornecedores \\
140.000 - Clientes & 315.000 - EM / EF \\
250.000 - Imposto a Receber & 260.000 - Imposto a Pagar \\
340.000 - Estoque & \\
360.000 - Produto Acabado & \\
370.000 - Material em Processo & \\
\hline & PATRIMÔNIO LíQUIDO \\
\hline
\end{tabular}

Tabela 4 - Exemplo de Controle Financeiro de Contas.

\begin{tabular}{|c|}
\hline \multicolumn{1}{|c|}{ DEMONSTRATIVO DE RESULTADO } \\
800.000 - Receitas \\
453.000 - CPV Lucro Bruto \\
400.000 - Suprimentos \\
410.000 - Serviços \\
420.000 - Salários \\
430.000 - Eletricidade \\
Lucro Líquido \\
\hline
\end{tabular}

Tabela 5 - Exemplo de Controle Financeiro de Contas. 


\section{6.b) Contábil}

Por sua vez, a visão contábil, que possui um "espelho" das contas da empresa, realiza suas análises levando em consideração os aspectos gerenciais internos da empresa, por exemplo, a utilização de diferentes sistemas (custos padrão, rateio de custos, sistema $A B C$ ou ainda unidade de esforços de produção - UEP), para determinação e análise dos seus custos internos.

Sendo essa análise uma atividade cujos resultados servem apenas para orientação interna das ações e decisões dos administradores da empresa, pode-se ter a estrutura de subordinação, ou agregação, de custos conforme disposto na Figura 34, a seguir.

Destaca-se, entretanto, que essa organização de sistemas de custos da companhia, deve ser elaborada conforme o desejo e o interesse dos seus administradores.

Para que seja possível definir a organização das estruturas de custos, é preciso que o SIG preveja a possibilidade de o usuário (administrador) alterar essa estrutura conforme the convenha. Em outras palavras, a definição da estrutura e da hierarquia dos custos pode ser elaborada e alterada através do próprio sistema.

Também deve ser previsto que os dados já alocados não sejam perdidos, quando houver qualquer alteração. 
Ressalta-se apenas o fato de que se deve evitar a realização freqüente de alterações nas estruturas, fato, em geral, conseguido através de um planejamento inicial adequado.

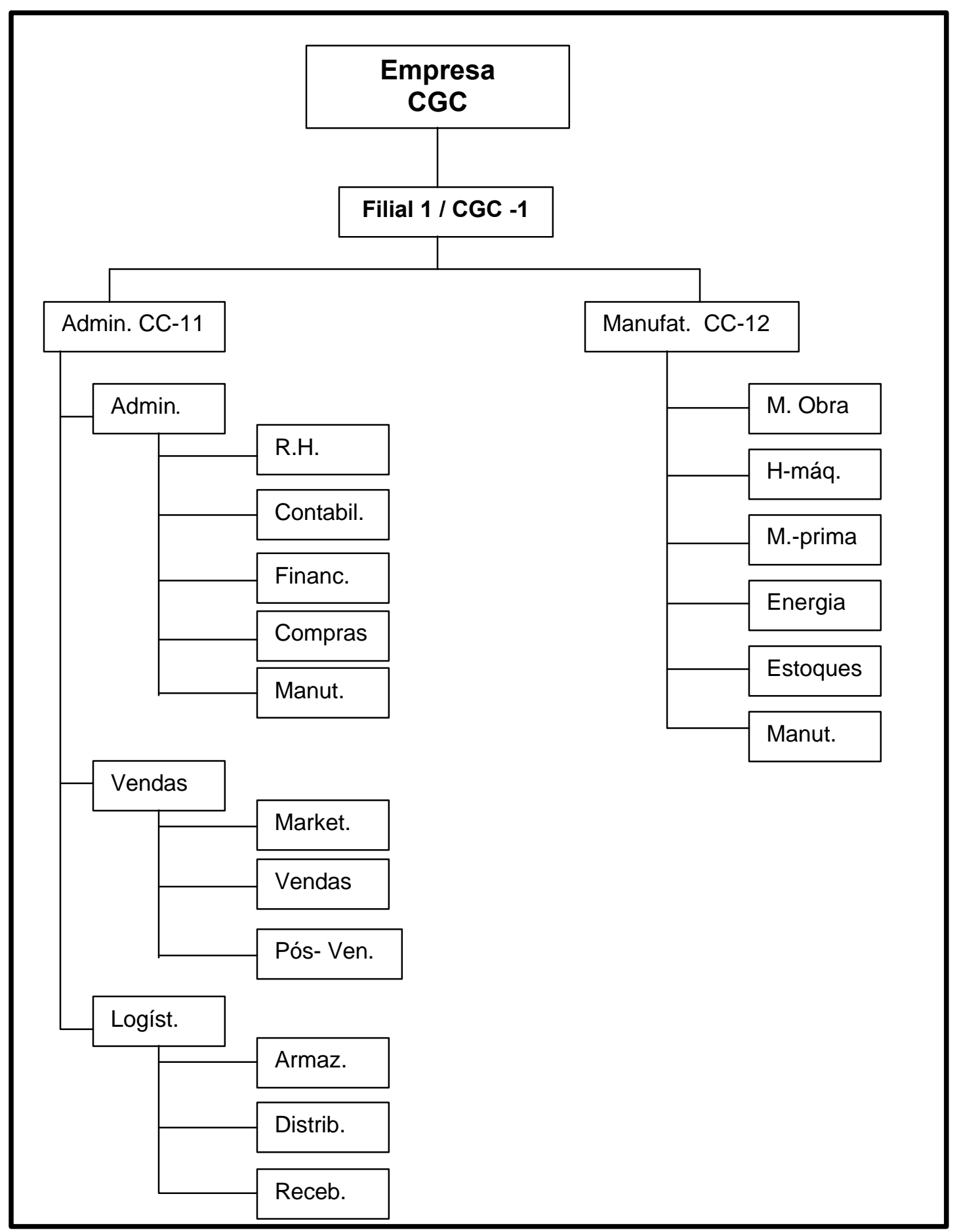

Figura 34 - Ilustração da Estrutura do Plano de Contas. 
Entendendo que as estruturas apresentadas representam inovações, conclui-se que a seqüência completa para a utilização desse sistema é composta de quatro fases distintas e subseqüentes, que podem ser classificadas como a sugestão abaixo:

fase 1) Entendimento do sistema integrado, seus reflexos em outras áreas da empresa; elaboração das estruturas adequadas e preparação da seqüência de processos; e emissão de documentos contábeis.

fase 2) Implementação do sistema proposto em paralelo ao sistema utilizado; validação do sistema proposto; treinamento e capacitação de pessoal; start-up do novo sistema como sistema oficial.

fase 3) Inserção de dados relativos às atividades (cadastros, processos etc.) e eventuais testes e auditorias que garantam sua utilização correta.

fase 4) Entendimento das análises dos dados e das informações obtidas e verificação se tais informações foram conseguidas através de métodos e cálculos adequados, o que irá orientar as ações da empresa para o futuro. 


\section{7) PROTÓTIPO}

Tendo já definido, nos capítulos anteriores, elementos, formatos estruturas e relações que compõem o aplicativo proposto, será feita a seguir uma rápida ilustração das telas do sistema para a realização das atividades rotineiras da empresa.

Ao se executar o comando de inicialização do sistema, o usuário terá a sua frente a tela inicial e será obrigado a fornecer seu login e sua senha, através dos quais será possível ao administrador do sistema, permitir e/ou controlar os acessos do usuário. É sempre interessante recordar que o acesso é validado por um servidor central. Passado esse controle inicial, passa-se à utilização efetiva do sistema.

A primeira tela exibida, a Figura 35, é um lembrete/sugestão para que o usuário utilize o menu de opções que o sistema possui. Através desse menu, o usuário terá acesso a todas as atividades que compõem sua rotina de tarefas.

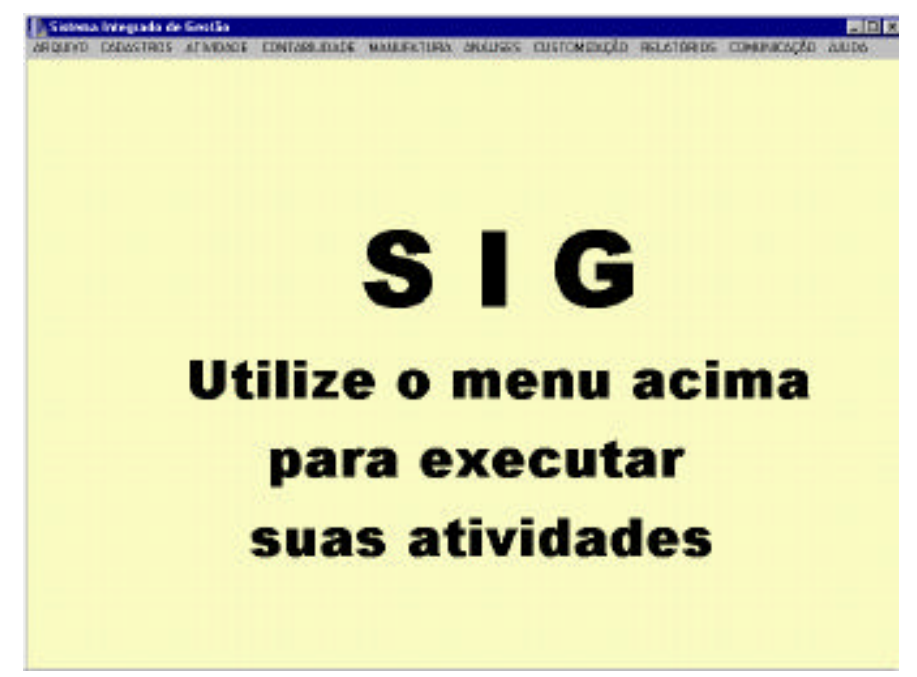

Figura 35 - Tela Inicial do Protótipo. 


\section{1) Cadastros}

As telas referentes aos cadastros (dados) utilizados pelo programa devem ser preenchidas em uma fase inicial, de preferência na implementação do software. Dessa forma, serão registradas as informações sobre produtos, fornecedores, compradores, processos e o que mais for necessário. É interessante destacar que tais registros são atualizados com pouca freqüência. As figuras a seguir ilustram o formato e as informações contidas nos citados cadastros.
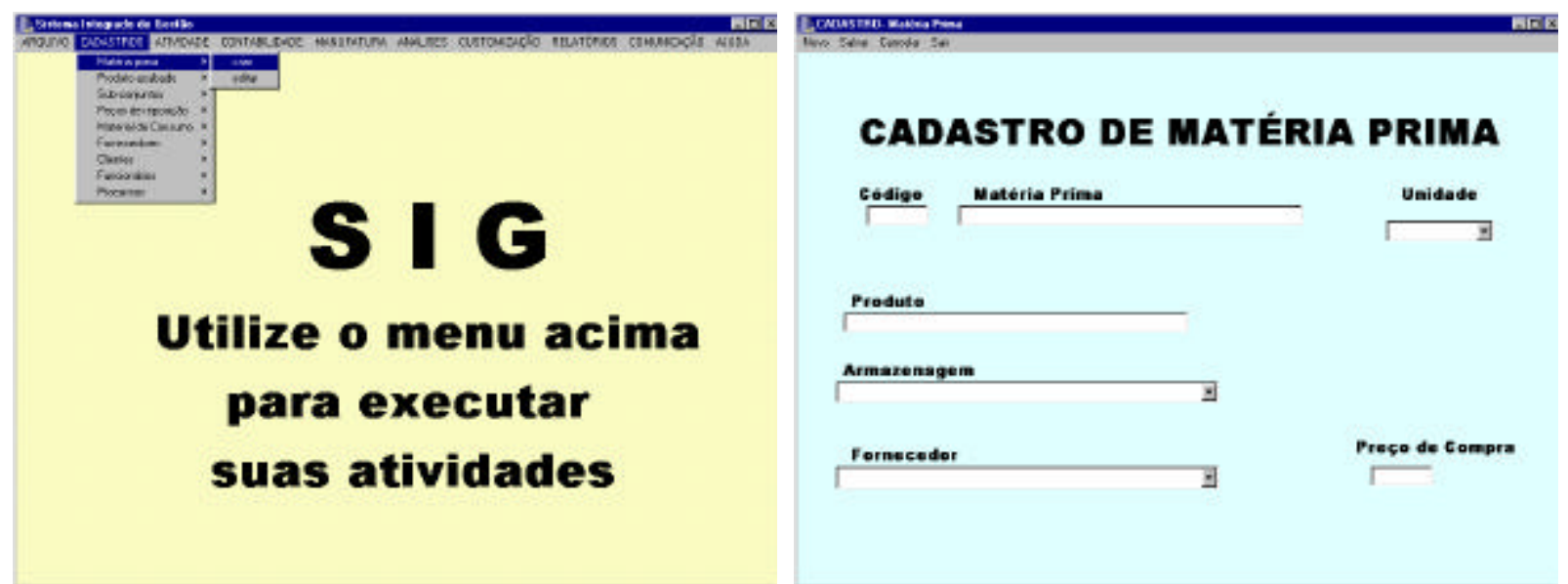

Figura 36 - Exemplo de Tela do Protótipo.
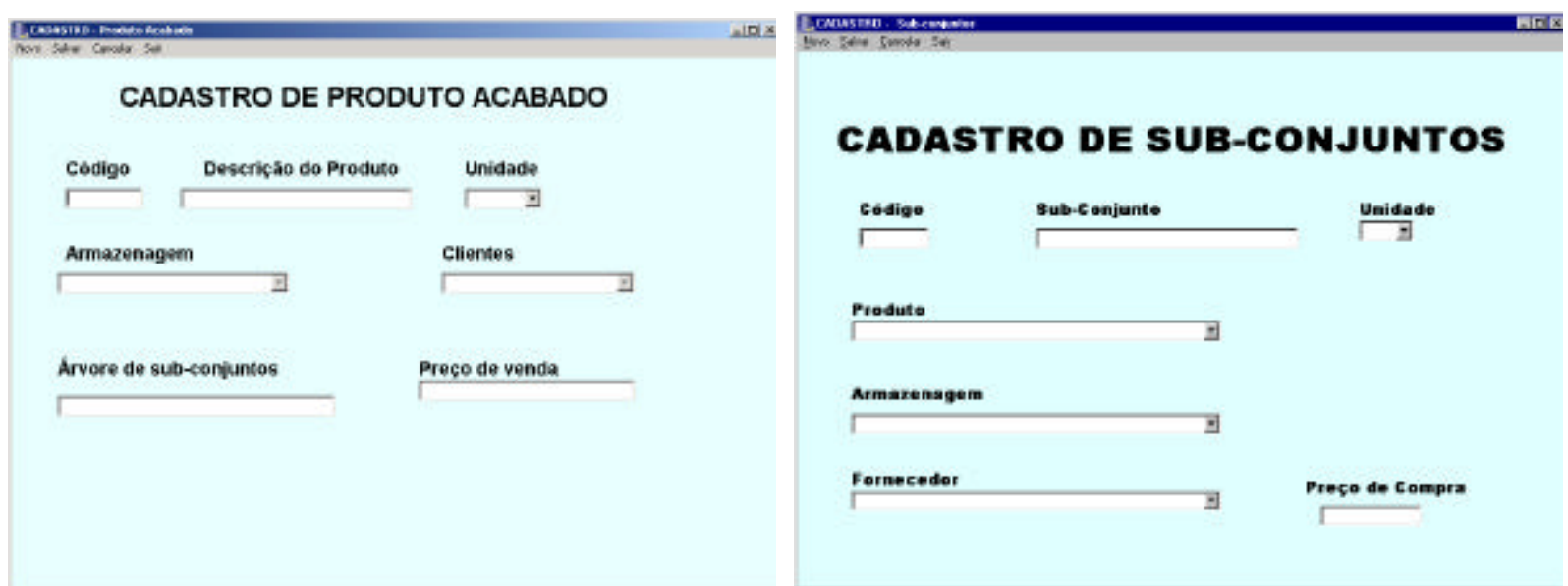

Figura 37 - Exemplo de Tela do Protótipo. 

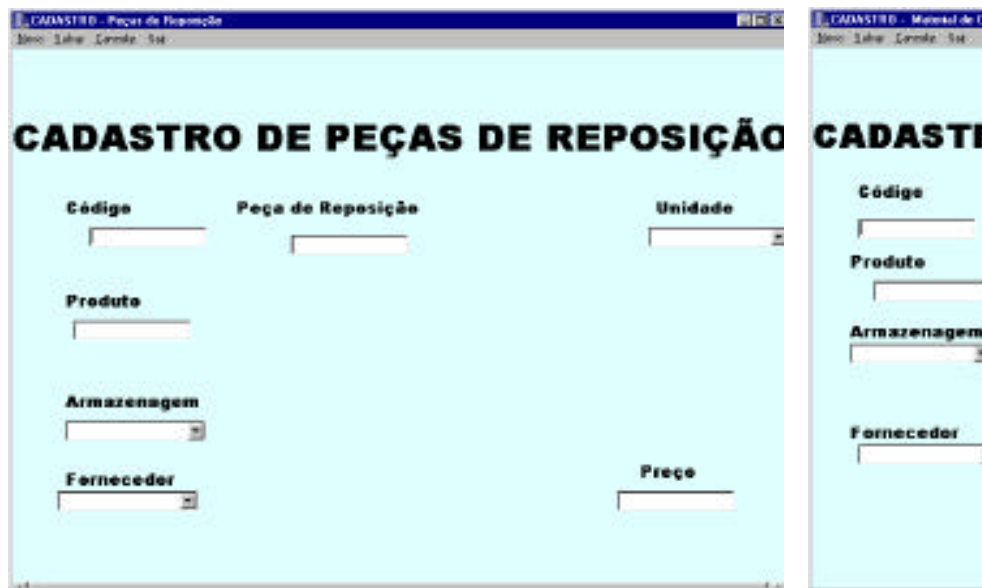

Figura 38 - Exemplo de Tela do Protótipo.
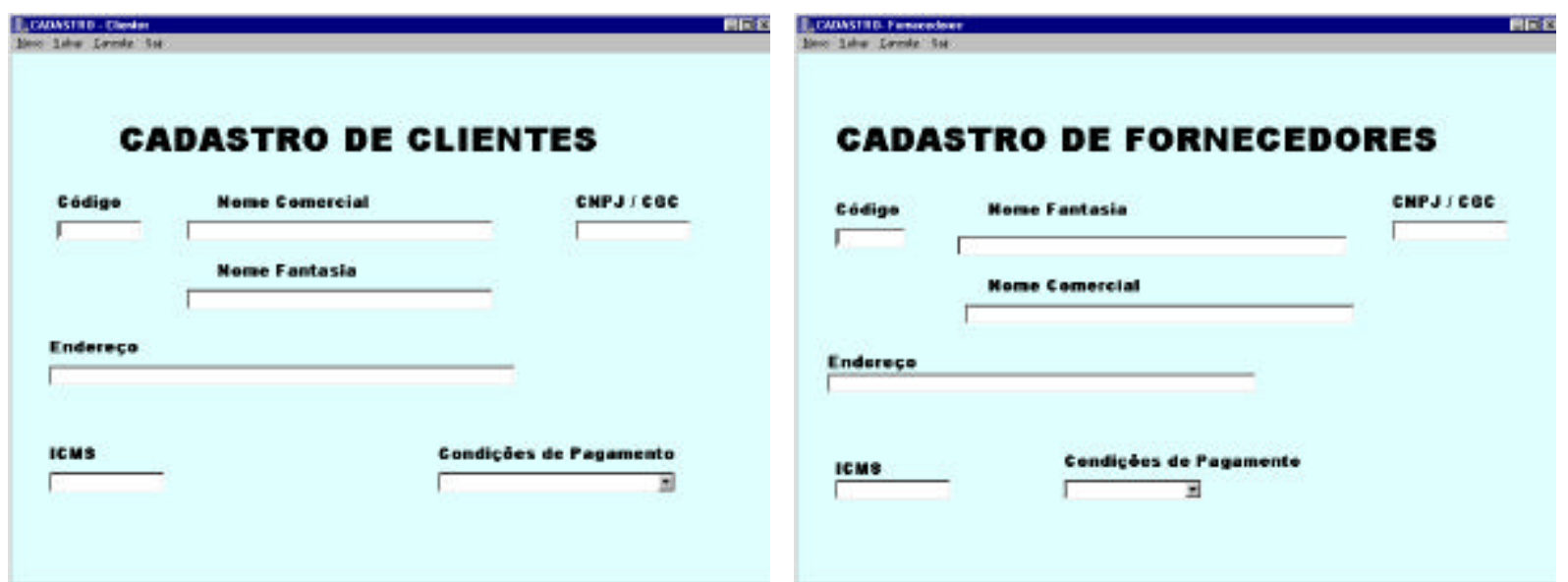

Figura 39 - Exemplo de Tela do Protótipo.
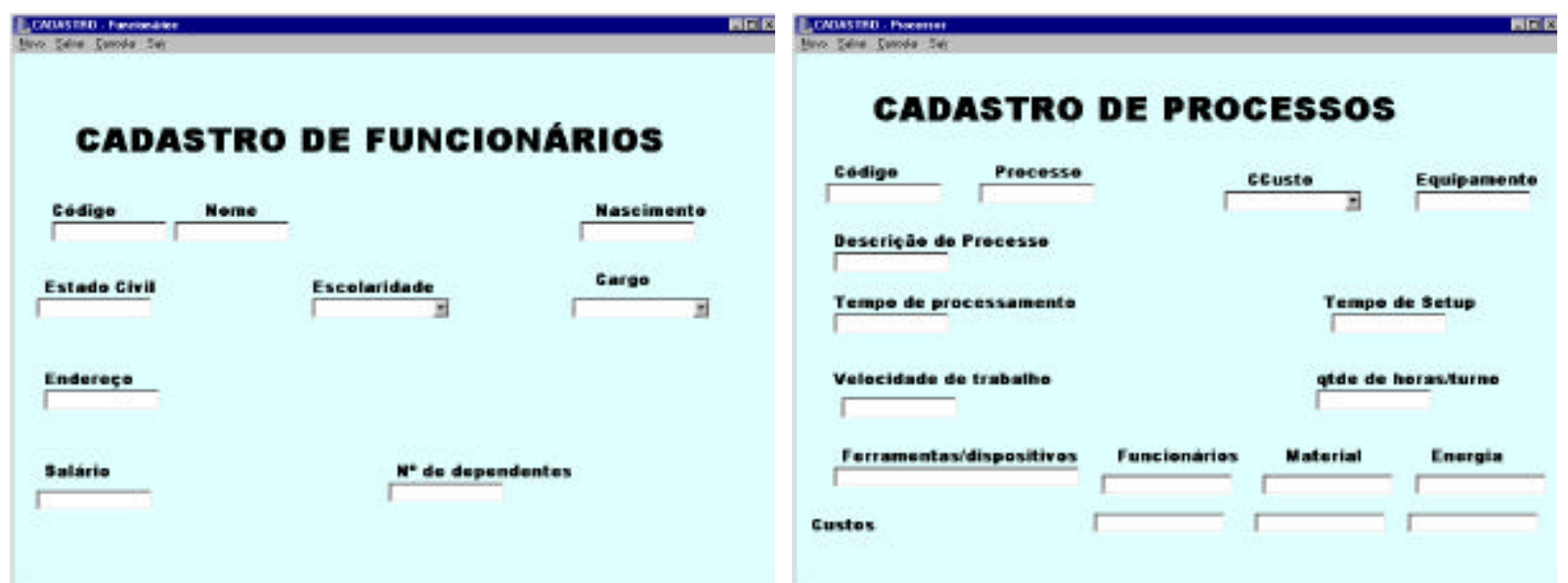

Figura 40 - Exemplo de Tela do Protótipo. 


\section{2) ATIVIDADES}

As interfaces referentes às atividades realizadas na empresa devem ser preenchidas já na fase de utilização, registrando as informações sobre compra, venda, manufatura, estocagem e outros. Destaca-se que os registros das atividades são incrementados ou atualizados conforme as atividades da empresa. O conjunto de figuras a seguir ilustra o formato e tipos de informações contidas nessas atividades.
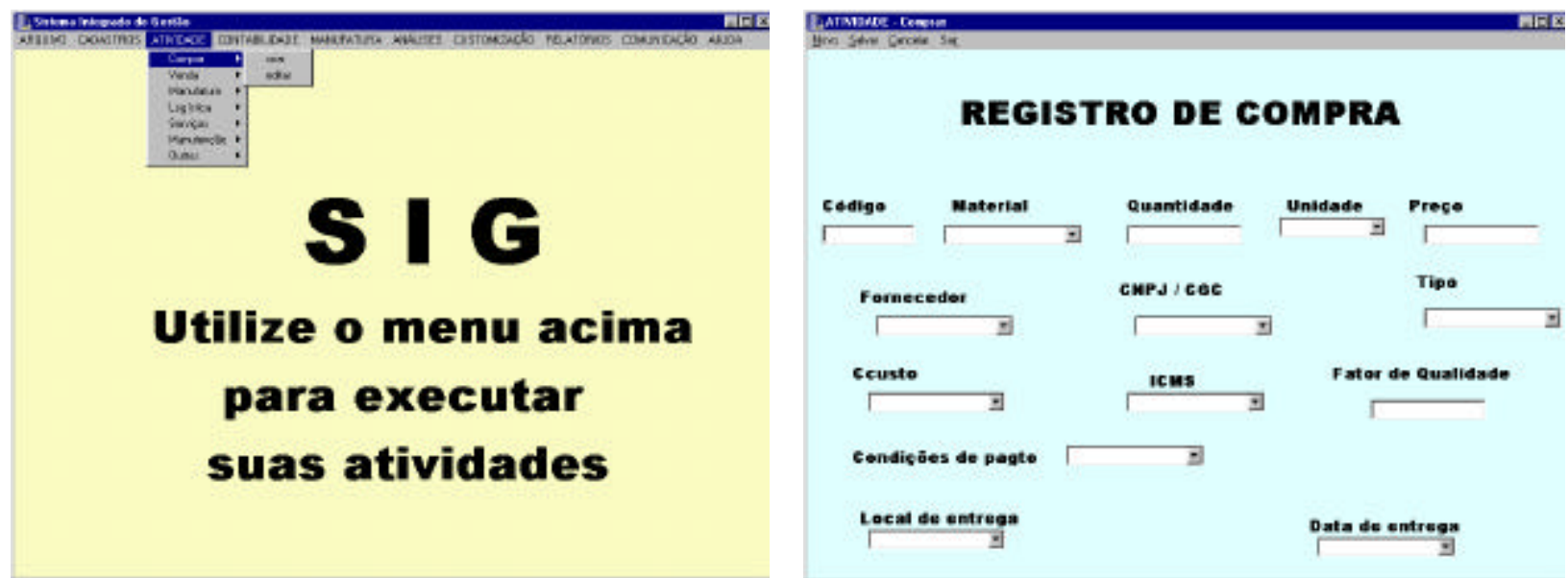

Figura 41 - Exemplo de Tela do Protótipo.
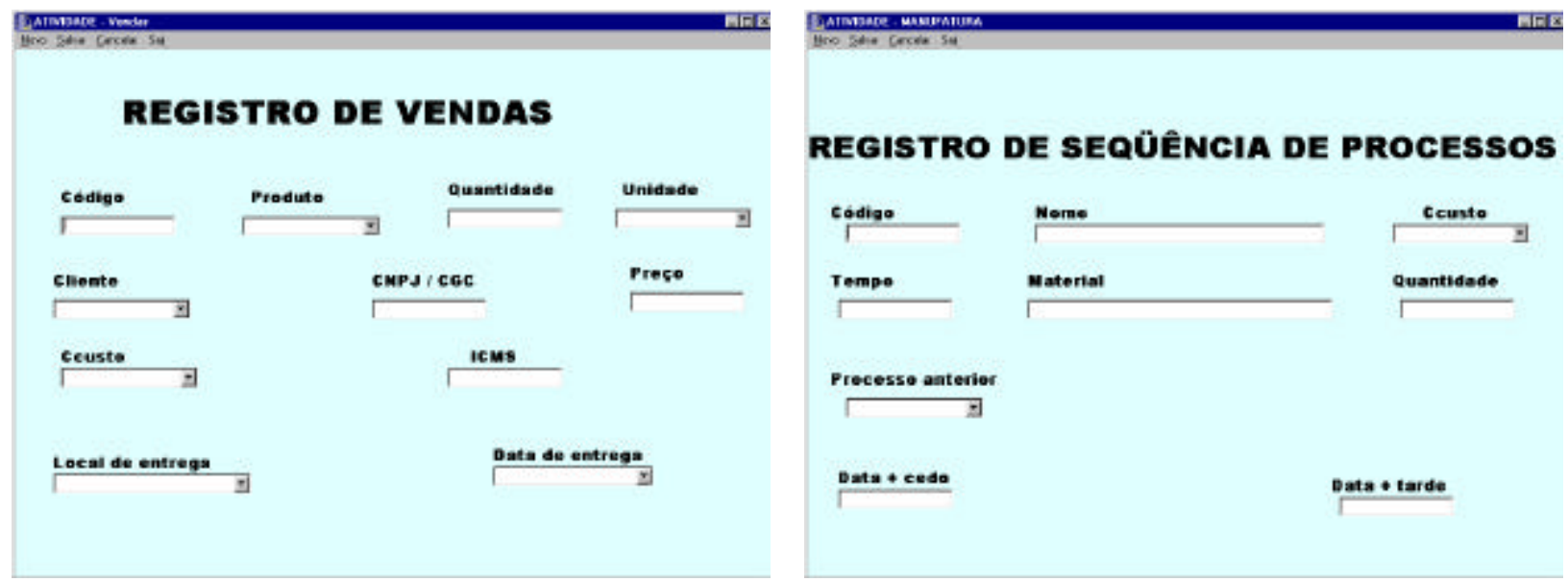

Figura 42 - Exemplo de Tela do Protótipo. 

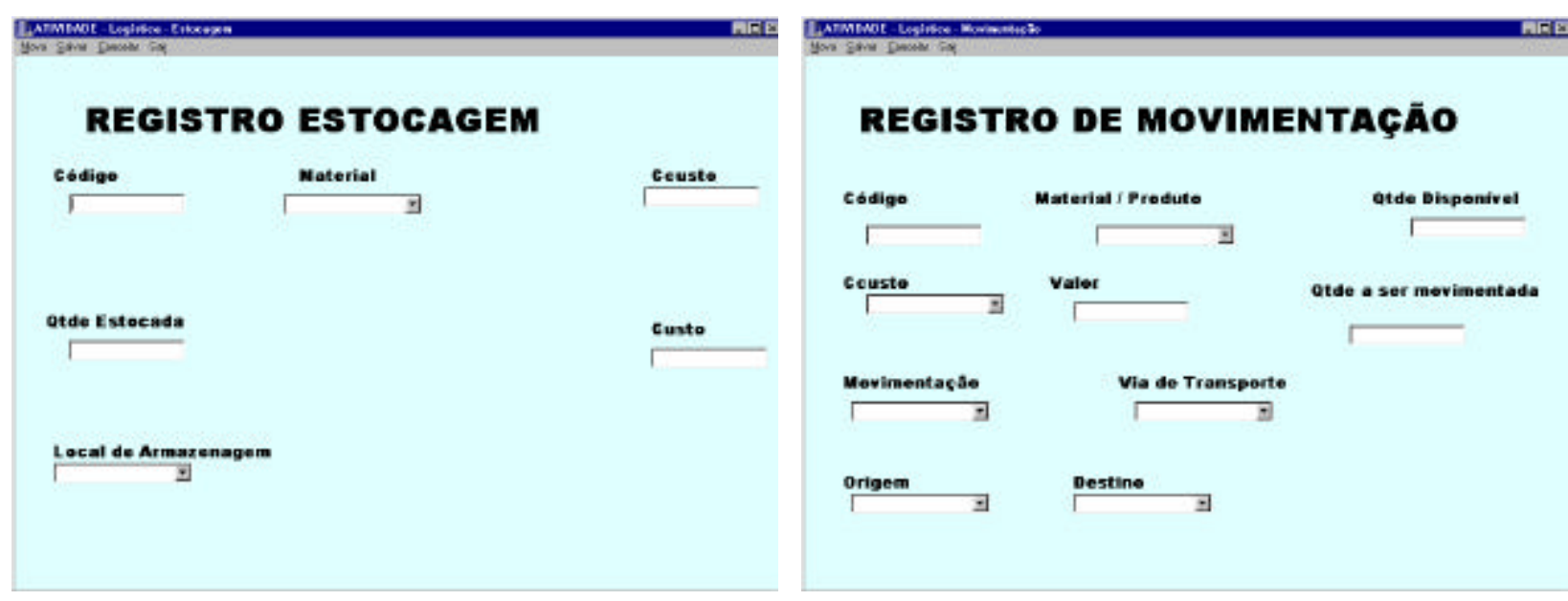

Figura 43 - Exemplo de Tela do Protótipo.

\section{3) CONTABILIDADE}

As telas de contabilidade são as primeiras relativas à escolha de políticas e filosofias de trabalho. Elas são também preenchidas na fase de utilização, registrando as opções da empresa (E-ERP) sobre estrutura do plano de contas, centros de custos, filosofias de custeio, além de emissão de notas fiscais e faturas. Alguns desses registros (ex: estrutura de plano de contas) raramente são atualizados ou modificados, enquanto algumas aplicações são freqüentemente utilizadas (ex: relatórios). As figuras, a seguir, mostram como podem ser essas telas.

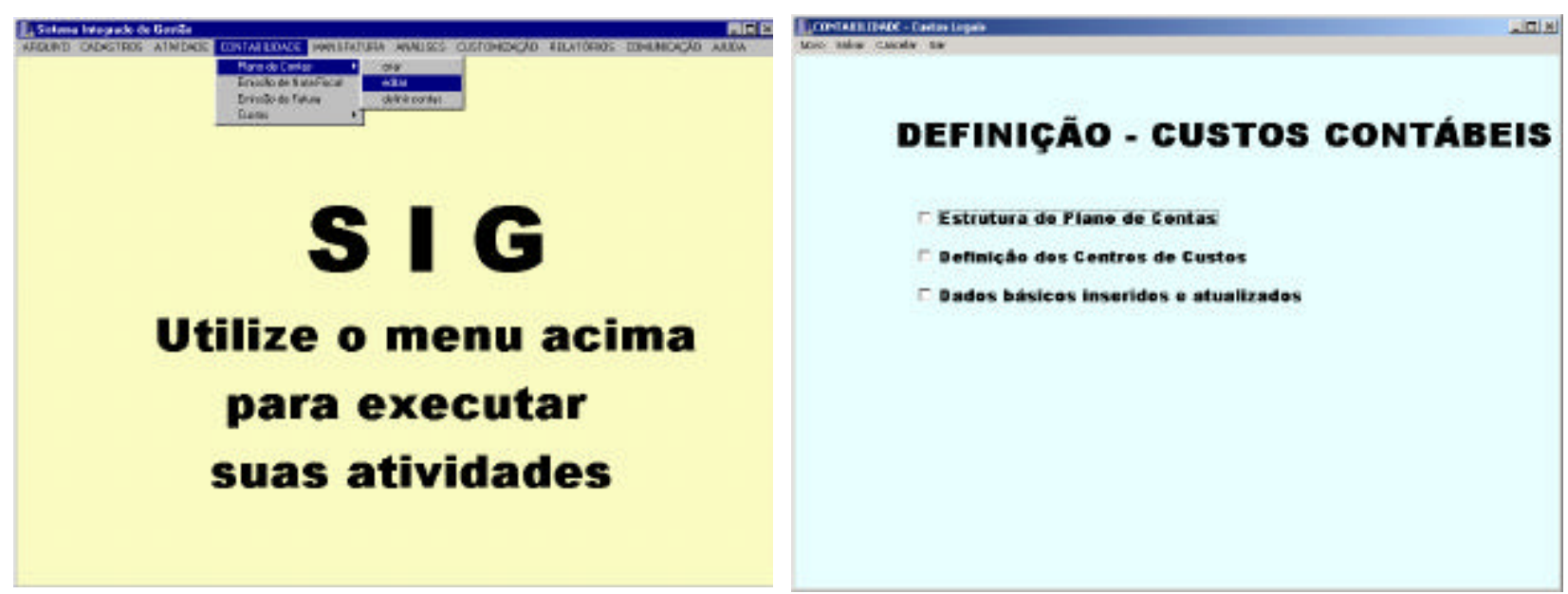

Figura 44 - Exemplo de Tela do Protótipo. 

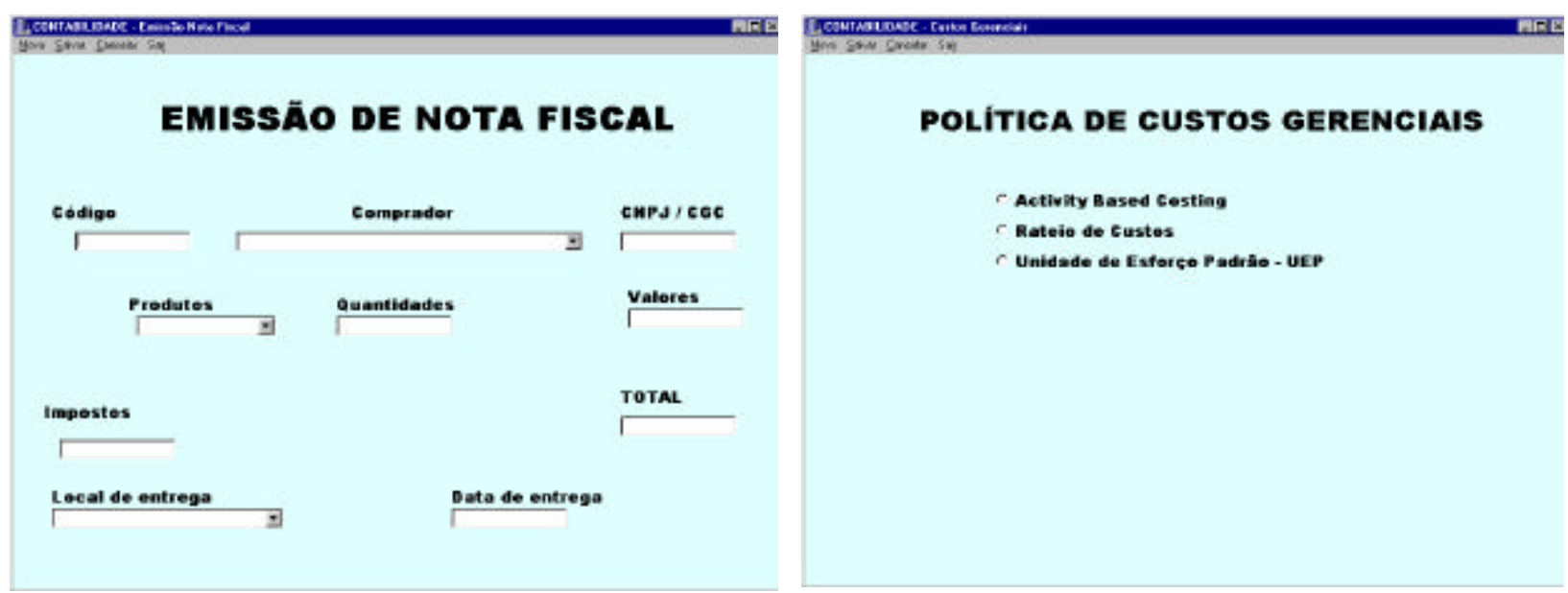

Figura 45 - Exemplo de Tela do Protótipo.

\section{4) MANUFATURA}

Com relação às telas de manufatura, pode-se notar a preocupação em calcular o mix de produção e as estatísticas, porém tais cálculos são efetuados com base em critérios e restrições informados (E-ERP). Esses cálculos podem, e devem, ser realizados várias vezes ao dia, permitindo inclusive a simulação de alternativas. Abaixo são apresentados alguns exemplos de como podem ser as telas desse módulo.
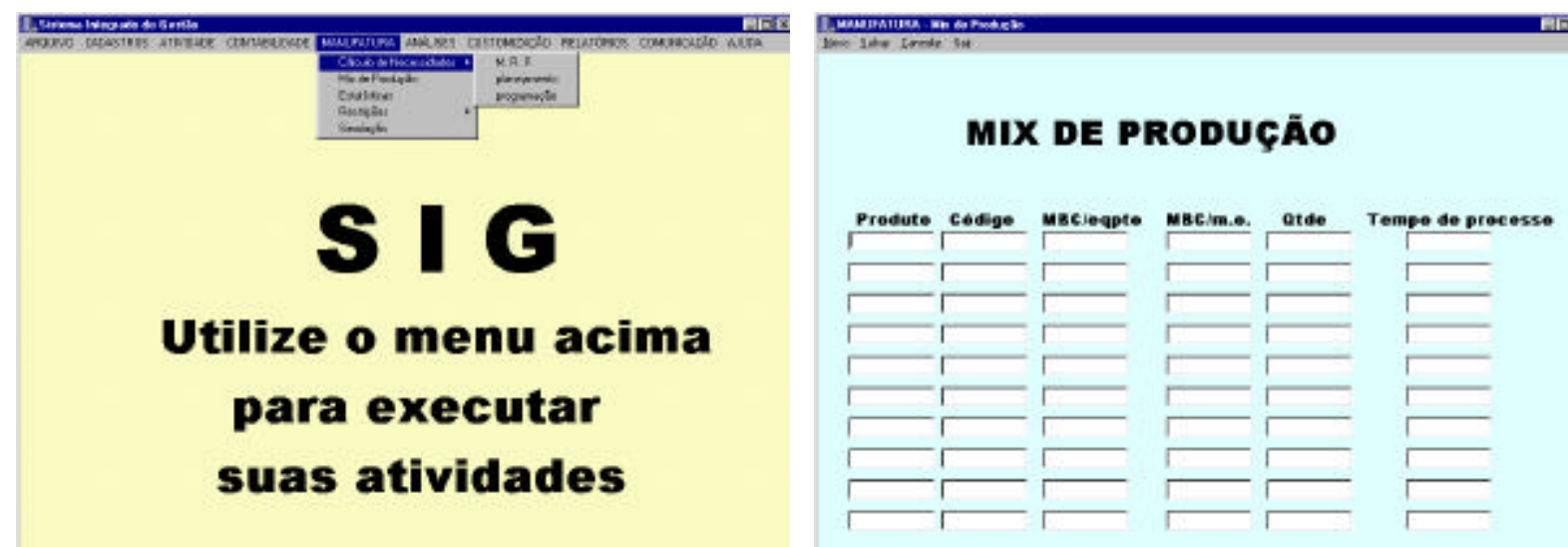

Figura 46 - Exemplo de Tela do Protótipo. 

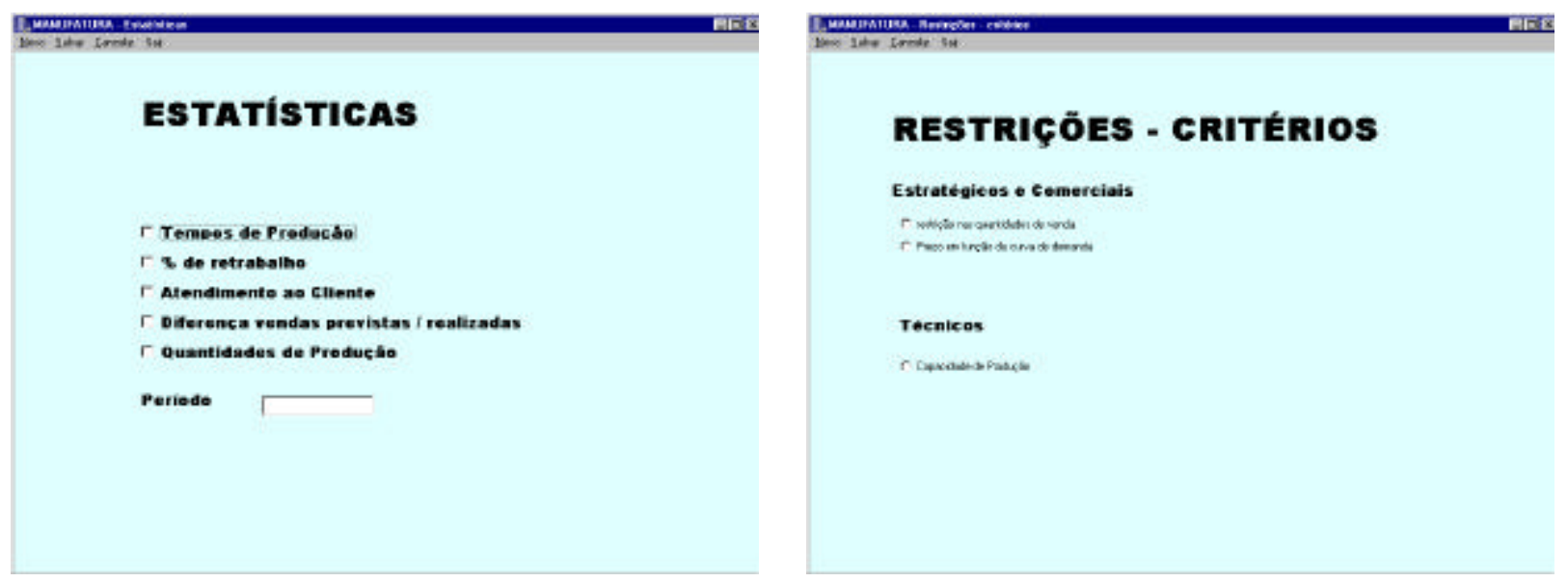

Figura 47 - Exemplo de Tela do Protótipo.

\section{5) ANÁLISES}

Esse módulo merece um destaque especial, pois nele começa a ser embutido o conceito de sistema inteligente (I-ERP). Nesse módulo estão inseridas as idéias de análises, comparações e sugestão de alternativas para a empresa/usuário. Esse, sem dúvida, é um aspecto diferencial com relação aos sistemas comerciais existentes atualmente. A seguir, alguns exemplos de telas utilizadas.
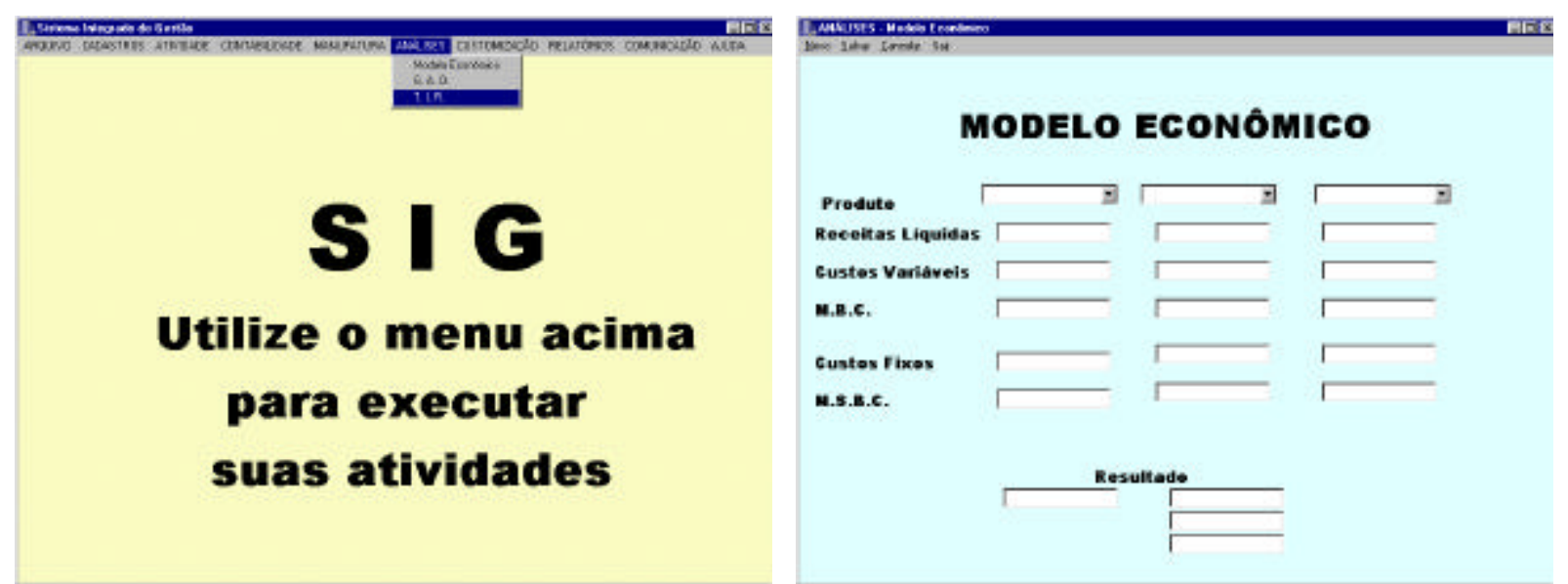

Figura 48 - Exemplo de Tela do Protótipo. 

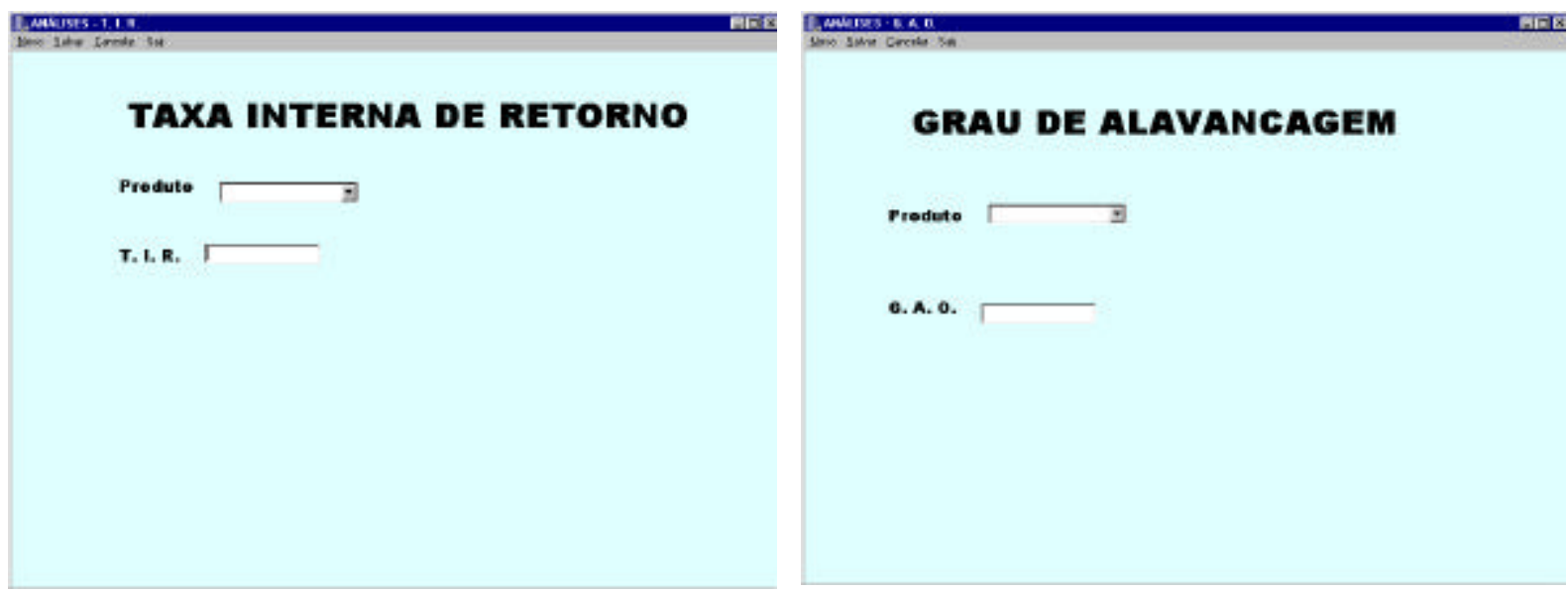

Figura 49 - Exemplo de Tela do Protótipo.

\section{6) CUSTOMIZAÇÕES}

Essa parte do aplicativo refere-se a adequações genéricas das empresas, tais como: moeda utilizada, formato de datas, início de ano fiscal, tipo de banco de dados, taxas de câmbio e outros. Essas particularizações do sistema podem ser alteradas com maior ou menor freqüência, dependendo dos interesses e das atividades da companhia. O conjunto de figuras, a seguir, ilustra como podem ser essas telas.
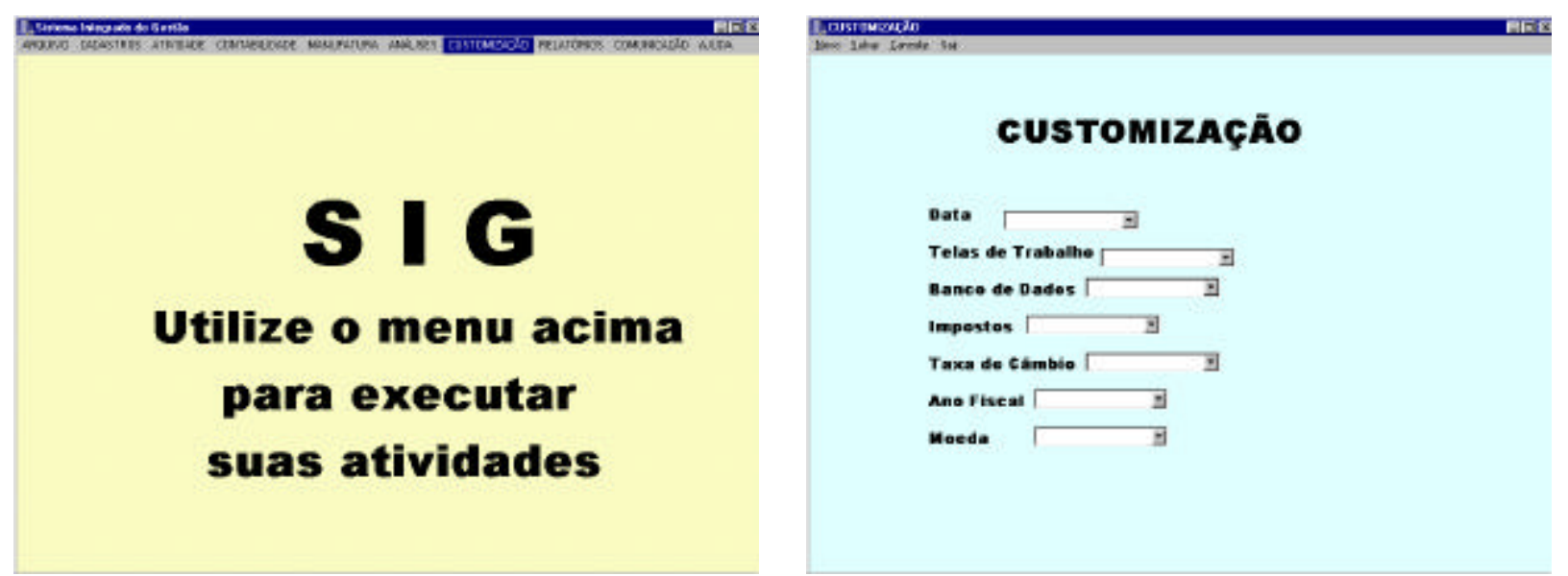

Figura 50 - Exemplo de Tela do Protótipo. 


\section{7) RELATÓRIOS}

Para a escolha de dados e formatos dos relatórios a serem apresentados, o sistema oferece algumas alternativas de composição. As telas relativas a essas alternativas são exemplificadas a seguir.
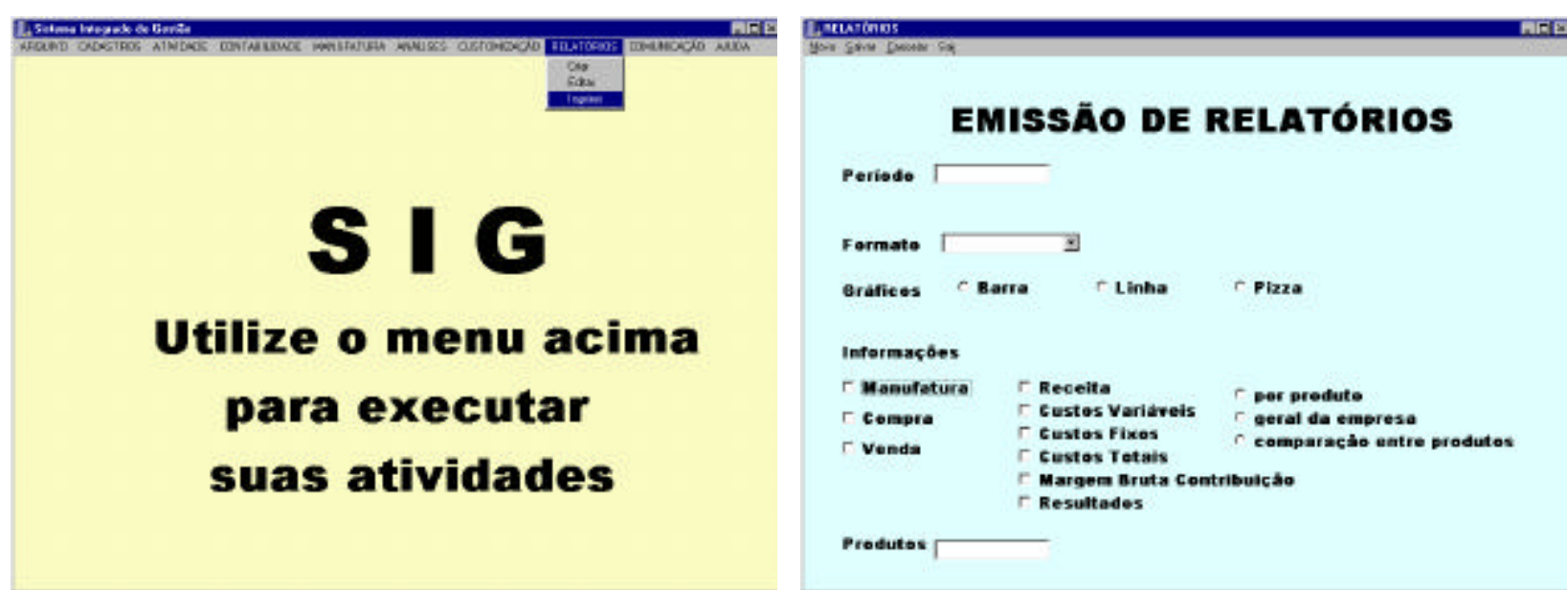

Figura 51 - Exemplo de Tela do Protótipo.

\section{8) COMUNICAÇÕES}

O software proposto permite que haja três tipos básicos de comunicação com os servidores. O primeiro tipo, mais utilizado pela empresa, é a comunicação direta com o servidor administrativo local (mesmo edifício ou planta industrial). O segundo tipo é a comunicação com um servidor administrativo remoto, ou seja, em outro local geográfico. Esse segundo tipo de comunicação, se comparado com os sistemas atualmente existentes, é mais um aspecto diferencial oferecido. O terceiro e último tipo de comunicação cliente/servidor é com o computador que controla a execução da manufatura. Não se pode esquecer de que, para esse tipo de comunicação, é preciso que a manufatura possua um alto grau de 
automação, normalmente conseguida com máquinas $\mathrm{CNC}$ e robôs industriais.
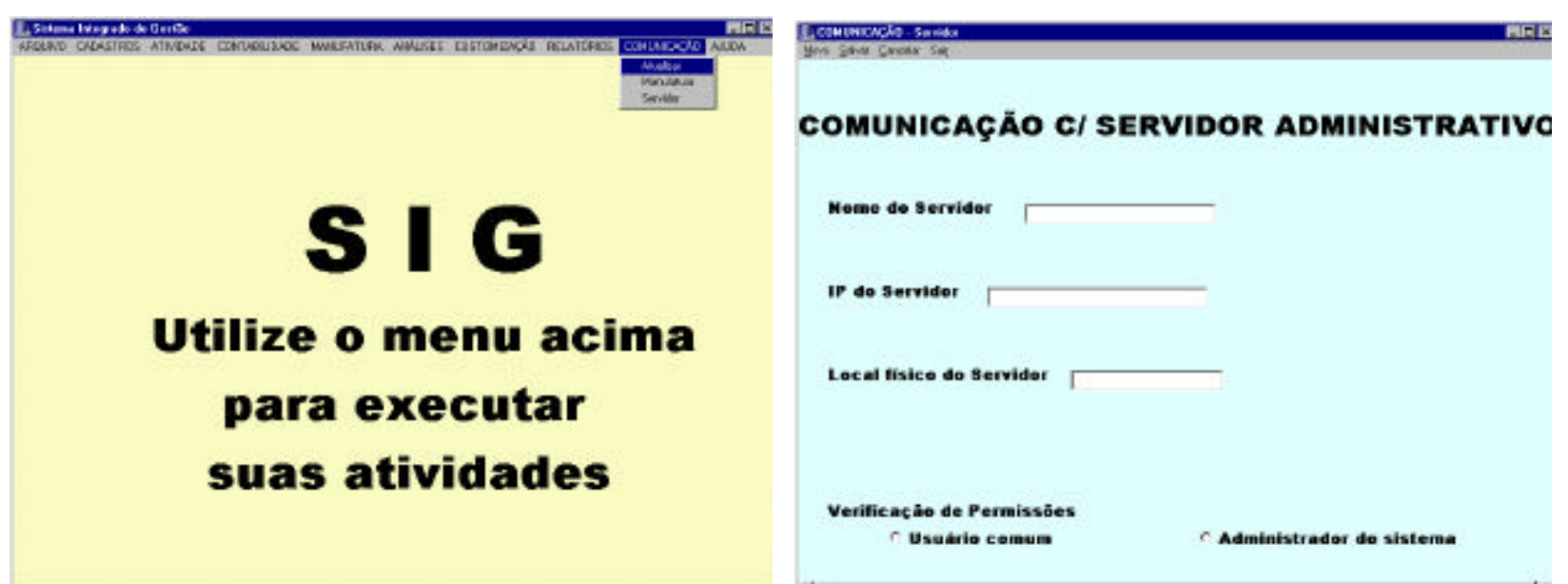

Figura 52 - Exemplo de Tela do Protótipo.

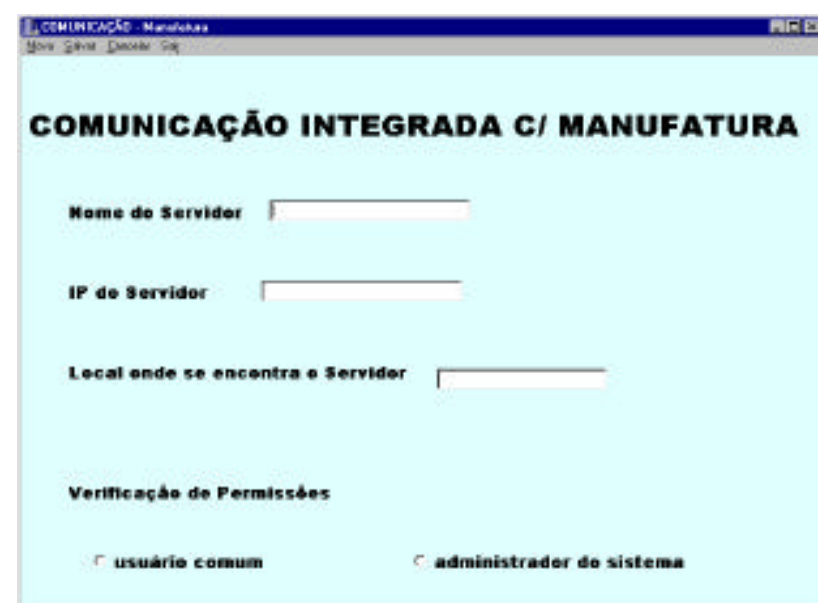

Figura 53 - Exemplo de Tela do Protótipo.

\section{COMENTÁRIO:}

Algumas telas do protótipo não aparecem neste capítulo, porém suas funções estão ao menos citadas nos comentários efetuados.

O conjunto de telas apresentadas é representativo, e suficiente, para demonstrar as idéias e conceitos sugeridos na pesquisa. 


\section{8 - ANÁLISE DO PROTÓTIPO}

A execução das pesquisas, a observação e a análise dos sistemas citados e, principalmente, a associação das idéias apresentadas à tecnologia disponível indicam que o desenvolvimento proposto para os SIGs representa um avanço significativo dentro da Tecnologia de Informação e nos sistemas administrativos.

É fundamental ter em mente que as características específicas dos Sistemas Especialistas e dos Sistemas Inteligentes serão oportunamente incorporadas à estrutura do protótipo. Em outras palavras, isso significa que o sistema registrará as formas de cálculo, critérios e parâmetros preferenciais (ex: mix de produção, restrições técnicas, custos gerenciais e outros) e, quando solicitado, disponibilizará essas formas ao usuário.

Numa fase posterior, o aplicativo, após obter o resultado com as opções escolhidas, poderá compará-lo com as demais alternativas possíveis e informar ao usuário se as opções utilizadas são as mais indicadas para a empresa.

A incorporação dessas características ao protótipo busca a melhor utilização dos dados consolidados, o que terá por conseqüência a otimização dos recursos administrados pelo sistema.

É conveniente destacar que, uma alternativa pode ser momentaneamente melhor que outras, porém ela pode não estar de 
acordo com a política ou com o planejamento da companhia, o que acabará por inviabilizá-la. Sendo assim, recomenda-se a análise dos resultados em conjunto com o planejamento da empresa.

Outro fato também observado é que, ao utilizar o modelo proposto, a empresa poderá funcionar como uma Empresa Virtual, cuja área administrativa não necessita de um espaço físico definido, permitindo que a alta administração possa acompanhar o desempenho da empresa a distância.

Para colocar essas idéias em prática, é necessário haver um esforço concentrado na área de Automação, onde se incluem trabalhos de pesquisa sobre os temas Interface Homem x Máquina, Controles Programáveis e Programação Livre de Incompatibilidades.

O modelo registra os conceitos utilizados, estabelecendo uma fonte acadêmica (não comercial) de referência sobre o assunto. Dessa forma, esse documento serve como orientação técnica sobre a evolução dos sistemas integrados de gestão e fornece sugestões e subsídios para o desenvolvimento de outros trabalhos relacionados ao tema.

\section{1) Características Gerais do Protótipo}

Existem inúmeras características relevantes na estrutura e na utilização do sistema proposto. Entre os aspectos gerais existentes no protótipo, destacam-se os seguintes pontos: 


\section{1.a) Concepção}

O sistema é concebido para realizar cálculos e tarefas administrativas, baseando-se em diferentes alternativas de políticas e estratégias empresariais. Em outras palavras, busca o melhor aproveitamento dos recursos produtivos, através da utilização de técnicas e filosofias administrativas modernas.

\section{1.b) Estruturas e Formas de Organização}

Além de escolha, implantação e operação de novas tecnologias de manufatura, o sistema também considera as novas formas de organização do trabalho, visando à melhoria do conjunto na empresa, o que leva a um aumento de produtividade.

\section{1.c) Variedades de Técnicas}

O sistema deve permitir a utilização de estruturas e técnicas utilizadas para a tomada de decisões nos processos produtivos (exemplo: MRP, PPCP ou outras).

\section{1.d) Critérios e Parâmetros}

O trabalho de documentação ficaria incompleto se não houvesse, paralelamente, uma preocupação com o estabelecimento de critérios e parâmetros, usados para orientar o planejamento da empresa.

\section{1.e)Conhecimento de Condições}

Para que a orientação seja adequada, é importante que os usuários tenham conhecimento das condições de trabalho e do mercado em que atuam, por exemplo: demanda, vendas, custos, margens, investimentos, taxas, balanços, orçamentos e produtividade, entre outros.

\section{1.f) Customização}

O protótipo busca atualizar algumas estruturas funcionais da empresa que não mais se adequavam às necessidades 
administrativas e às tecnologias disponíveis. Essas estruturas devem ser customizadas, e não, apenas atualizadas de maneira genérica.

\section{1.g) Banco de dados}

O protótipo utiliza um banco de dados único, o que possibilita a consolidação dos dados e a execução de cálculos mais acurados.

\section{1.h) Simulação}

O protótipo favorece o uso das ferramentas de simulação, facilitando a visualização e a comparação de resultados.

\section{1.i) Níveis Hierárquicos}

O protótipo possibilita a redução de alguns níveis gerenciais intermediários.

\section{1.j) Administração em Tempo Real}

O sistema proposto permite que a alta administração da empresa possa gerir suas filiais em tempo real, independentemente do local geográfico em que se situem.

\section{1.k) Desenvolvimento Conjunto}

Os fabricantes de equipamentos, em parceria com os fabricantes de programas de gestão, devem elaborar conjuntos (máquina+ software) que permitam ao sistema administrativo da empresa ser capaz de organizar também a manufatura.

\subsection{I) Qualificação de Funcionários}

A redução de níveis gerenciais intermediários é compensada pelo aumento de funcionários qualificados cuja preocupação principal concentra-se na preparação de estruturas, interfaces e cálculos para as análises. 
Esses aspectos constituem a base necessária para integrar e automatizar a empresa de maneira inteligente, o que significa que o sistema deve atuar não só na parte organizacional, mas também, na técnica, onde estão incluídos temas como: compatibilidade de sistemas, lógica de programação, interfaces, seqüência de manufatura, carga de máquinas, tempos de preparação, aderência do modelo lógico e outros.

\section{2) Características específicas}

Entre os vários aspectos específicos do software, faz-se necessário comentar alguns aspectos principais.

A inclusão do conhecimento e da sensibilidade da análise deve, pouco a pouco, ser incorporada pelo sistema, através do seu componente inteligente (capacidade de aprender). De maneira geral, nota-se que a maioria dos programas especialistas ignoram alguns aspectos e condições de contorno iniciais, existentes dentro do contexto da indústria. Como conseqüência desse abandono, muitos programas acabam se limitando a resolver cálculos simples com maior rapidez, pouco acrescentando ao desenvolvimento de novas ferramentas tecnológicas. As políticas de decisão da empresa devem estar inseridas na base de conhecimento desse programa. Também é importante saber como as decisões sugeridas por esse programa serão enviadas à área de produção e como serão postas em prática. 


\section{2.a) Desenvolvimento do Software}

A metodologia empregada para a elaboração do programa (PSP, CMM etc.) não estava em discussão neste trabalho, entretanto a realização de testes, fornecimento de feedback e eventuais ajustes são fundamentais para o desenvolvimento do sistema aplicativo em discussão.

\section{2.b) Estruturas}

É importante que o sistema possua um conjunto básico de relações entre cadastros, funções e atividades, permitindo que a estrutura lógica e hierárquica atenda às necessidades da empresa.

\section{2.c) Módulos}

Os módulos de cálculos são complementares entre si, formando um sistema único de administração de empresas e contêm várias filosofias e políticas administrativas, possibilitando que a empresa opte por aquela que seja mais adequada aos seus interesses.

\section{2.d) Banco de Dados}

O Banco de Dados utilizado deve preencher estes requisitos: ser normalizado; dar possibilidade de relacionamento entre tabelas distintas; permitir a adição de tipos de dados e registros; e compartilhar os registros da empresa, consolidando/fornecendo as mesmas informações para todos os setores da companhia.

\section{2.e) Telas de Interface}

O design das telas deve contemplar a melhor localização das lacunas a serem preenchidas, além de possuir informações e indicações dos dados que devem ser fornecidos pelo usuário. A cor do fundo de tela também é uma característica que traz sensação agradável, ou não, ao funcionário que utiliza o aplicativo. 


\section{2.f) Cálculos}

A velocidade de execução, assim como a precisão nos cálculos, é regida pelos algoritmos e pela potência dos computadores empregados. Além desse fato, destaca-se que os vários cálculos realizados pelo software se baseiam em políticas de administração industrial, estratégias empresariais, legislação contábil e em restrições técnicas e comerciais.

\section{2.g) Cadastros}

As informações sobre fornecedores, compradores, processos e produtos são registradas no Banco de Dados através das telas de Cadastro. Uma vez que o espaço de memória para esses registros não constitui um obstáculo, podem-se enriquecer os cadastros com informações usadas com pouca freqüência. Entretanto, não se pode esquecer de que o preenchimento de tais cadastros representa tempo de mão-de-obra e portanto, pagamento de funcionário.

\section{2.h) Administração a Distância}

O protótipo prevê a comunicação via Internet, porém tal aplicação não chegou a ser desenvolvida, uma vez que, para tal, são necessários conhecimentos profundos na área de telecomunicações.

\section{2.i) Integração com a Manufatura}

Da mesma forma que o item anterior, o protótipo prevê a existência dessa comunicação, porém para o desenvolvimento dessa aplicação, além da área de telecomunicações, são também necessários conhecimentos na área de programação de máquinas CNC. 
Além dos resultados comentados, considera-se certo o advento de outros fatos (positivos ou não) durante e após a implementação dos sistemas propostos. Porém tais acontecimentos não foram previstos neste trabalho e dependem de inúmeras variáveis, tais como: cultura e porte da empresa, ramo de atividades, tempo e forma de implementação, grau de automação da empresa e muitos outros.

\section{3) AVALIAÇÃO PRELIMINAR DO PROTÓTIPO}

Como era de se esperar, o modelo proposto possui características prós e contras que servem para uma avaliação preliminar. Serão comentadas a seguir as principais características observadas.

\subsection{1) VANTAGENS DO SISTEMA}

Entre as principais vantagens competitivas do sistema proposto, podemse destacar as seguintes:

- Não há, até o momento, nenhum Sistema Integrado de Gestão que possua tantas características inerentes aos Sistemas Especialistas ou Inteligentes.

- As empresas eliminarão as dificuldades geográficas, podendo administrar suas filiais a distância.

- A administração acima citada poderá ser feita em tempo real, independendo inclusive de fusos horários. 
- O Corpo Diretivo da empresa terá à sua disposição os dados de toda a companhia, uma vez que haverá integração de todos dados através do banco de dados, onde quer que ele esteja centralizado.

- Como fora citado anteriormente, haverá uma modificação da mão-deobra utilizada, tornando-a mais tecnicamente qualificada, visando à melhoria de processos e análises e reduzindo um ou mais níveis de gerenciamento intermediário.

- O sistema proposto acabará por incentivar uma discussão técnica sobre critérios, parâmetros, estratégia, políticas e análises, necessários para a empresa alcançar melhores resultados.

\subsection{2) DESVANTAGENS DO SISTEMA}

Em contrapartida, existem algumas desvantagens nesse sistema proposto, entre as quais podem ser destacadas como principais as seguintes:

- Existência de dificuldade na customização do sistema para atender à empresa de maneira correta e otimizada. A customização pode ser ainda mais complexa no caso de empresas com manufatura flexível e controles variáveis.

- Em função das modernizações e da troca de tecnologias, será necessário treinar mão-de-obra para a utilização do sistema proposto. 
Nesse contexto, deve haver uma preocupação com o aprendizado do funcionamento correto da empresa. Esse treinamento implica tempo e investimentos.

- Outros tipos de desembolsos que podem inviabilizar a troca de sistemas são: o custo de compra, a customização e a implantação do novo sistema.

- Um fator que deve ser levado em consideração é a resistência natural dos funcionários em utilizar um sistema novo. Para vencer essa resistência, é aconselhável a atuação de membros da cúpula administrativa.

- Com o sistema proposto, há uma obrigatoriedade de transmitir informações corretas, no tempo adequado, o que impõe um certo desconforto entre os funcionários, uma vez que as falhas pessoais poderão ser rastreadas até se identificar o seu autor.

- Será necessário o estabelecimento de estratégias claras e compreensíveis, ou haverá o risco de ter a imprecisão de seus planos compreendida como falha ou erro de planejamento.

\subsection{3) IMPACTOS DECORRENTES DA IMPLEMENTAÇÃO}

As empresas só iniciam o processo de identificação e mensuração dos impactos decorrentes da implantação de sistemas integrados quando o sistema é concretamente implantado. Em conseqüência dessa condição, 
tem-se, a princípio, apenas uma noção dos impactos da implementação do sistema proposto que servirão como ponto de partida para a redução desses impactos.

Se, por um lado, existe a facilidade de acesso a dados operacionais e financeiros em tempo real, criando organizações mais flexíveis e democráticas, no sentido oposto, constata-se que os sistemas integrados envolvem a centralização do controle da informação e a padronização de processos. Uma recente pesquisa, desenvolvida pelo Departamento de Produção da Fundação Getúlio Vargas, destaca que muitas companhias são pressionadas a adotar os Sistemas ERP, seja pela concorrência, seja por suas matrizes, mas tais empresas nem sempre ficam satisfeitas com os resultados alcançados.

Os dados levantados no estudo coordenado pelo professor Thomaz Wood Jr. indicam que $90 \%$ das empresas afirmam ter adotado o ERP para acompanhar a tendência de mercado e $45 \%$ o fizeram por pressão da matriz ou de seus acionistas. (Fonte: http://www.infoexame.com.br/ plantaoinfo, 18/10/1999)

A complexidade dos dados que fazem parte hoje da rotina das empresas é também uma preocupação que influi na decisão para $95 \%$ das companhias. Os resultados, porém, não são completamente satisfatórios, segundo a pesquisa. Das empresas ouvidas, 35\% não obtiveram ganhos em termos de competitividade e 35\% não reduziram ciclos ou rotinas administrativas com a implantação do software. 
Outros dados negativos são o fato de $45 \%$ admitirem que não obtiveram ganhos em atendimento ao cliente.

Entre os pontos positivos da implantação do ERP, as pesquisadas apontam integração efetiva das funções (95\%), melhoria da comunicação $(80 \%)$ e melhoria do controle de processos (80\%). (Fonte: http://ourinhos.com.br/perin/interest.html - 22/07/99)

As vantagens competitivas - tais como: velocidade na obtenção de dados gerenciais ou a exatidão no planejamento da manufatura de determinada encomenda - alcançadas com a utilização de sistemas ERP compensam os seus altos custos de implementação. Pode-se tomar como exemplo dessa afirmação o caso da empresa HP, que reduziu o tempo entre encomenda e entrega de produtos de 26 para 8 dias. Ou ainda a IBM, que tornou praticamente instantâneo o cálculo de preços que, antes da implantação do sistema ERP, era de aproximadamente seis horas. (Fonte: http://www.executivosfinanceiros.com.br/114mat1.htm\#erp,

22/07/99). As primeiras informações provenientes de companhias que utilizam sistemas integrados de primeira linha indicam um custo anual de manutenção estimado em $75 \%$ do seu valor de implementação. (Fonte: http://www.ksr.com.br/erp.htm, 22/07/99)

\section{Comentário extra:}

Os sistemas integrados utilizam durante os períodos de implementação e validação (que podem durar entre doze e vinte meses) o processamento 
paralelo. Porém, a continuidade de processamento paralelo é uma prática que não se sustenta, uma vez que toda informação oficial da companhia deve ser transmitida pelo sistema integrado.

Entretanto, algumas tarefas disponibilizadas pelo sistema (por exemplo, as simulações) nem sempre são suficientes para o usuário definir suas estratégias. Essas insuficiências acabam obrigando os usuários a realizarem várias simulações e análises em paralelo. Quando a melhor solução é encontrada, o usuário deve enviá-la e oficializá-la através do sistema integrado. Alguns aspectos considerados desvantajosos no uso dos sistemas integrados criam uma forte resistência à sua implementação, porém entende-se que a consolidação da cultura empresarial deverá reduzir essa contrariedade. 


\section{9 - CONSIDERAÇÕES FINAIS}

Como esperado, a pesquisa ora apresentada não esgota o assunto. Ao contrário, o trabalho oferece várias alternativas para o desenvolvimento de outras pesquisas que dão continuidade a esse tema, dentre as quais podem ser destacadas as seguintes:

- Desenvolvimento e melhoria de sistemas de inferências;

- Bases de conhecimento específico;

- Comunicação com o computador central de manufatura;

- Melhoria de interfaces (telas, voz e outros);

- Integração de sistemas ERP de empresas que compõem uma Supply Chain; e

- Políticas e estratégias de atendimento de mercado.

Entretanto o ponto considerado mais relevante deste trabalho é a nova visão sobre os SIGs formalizada e trazida à discussão, ou seja, a evolução dos sistemas administrativos do ERP para o E-ERP, chegando até ao I-ERP.

A observação dos sistemas atuais do mercado e da tecnologia disponível, assim como as análises das requisições das empresas e de suas relações organizacionais (internas e externas), levam à constatação das necessidades evolucionárias, ao mesmo tempo que mostram algumas tendências no desenvolvimento de sistemas de gestão. 
Além da modernização citada, também é importante destacar a criação de uma nomenclatura inicial para os próximos estágios dos sistemas integrados.

- Sistemas E-ERP (Expert Enterprise Resources Planning)

- Sistemas I-ERP (Intelligent Enterprise Resources Planning)

Em relação aos sistemas atuais, o trabalho referenciou várias vantagens que devem ser alcançadas (tornando o sistema altamente competitivo), algumas desvantagens e eventuais problemas que interferem na implementação.

É preciso também destacar que o sistema proposto incentiva uma nova e ampla discussão técnica sobre conhecimentos, critérios, parâmetros, estratégias, políticas e até análises que devem ser incrementadas nos sistemas de gestão, assim como a maneira de introduzi-las através de sistemas de inferências, para que, conseqüentemente, as empresas alcancem melhores desempenhos.

Por outro lado, deve-se entender que, no atual estágio, o desenvolvimento de bases de conhecimentos, sistemas de inferências, políticas e critérios de atendimento de mercado representam por si só um trabalho de reengenharia, uma vez que essas pesquisas devem ser realizadas considerando os avanços tecnológicos aplicados nos sistemas gerenciais, tais como: rede de computadores, sistemas de gestão, 
internet, inteligência artificial, bancos de dados, linguagem de programação avançada e outros.

Olhando em outra direção, imagina-se que será uma questão de tempo para que haja uma preocupação em integrar os computadores e sistemas utilizados na administração da empresa com os computadores que comandam o processo de manufatura, como o Computer Aided Manufacturing (CAM).

Uma última consideração é que a linha de pesquisa acima citada possui uma conotação diferenciada, pois, ao mesmo tempo que se nota uma preocupação em tornar o processo inteiramente automatizado - sem contato de mão-de-obra - deve haver uma ponderação lógica para que não haja a extinção das vagas (postos operacionais) de trabalhadores. Fato esse recentemente discutido no artigo "Toyota reinventa trabalho em linha de montagem" de Steven Butler, publicado no jornal O Estado de São Paulo de 12/01/1999. 


\section{0 - REFERÊNCIAS BIBLIOGRÁFICAS}

ACKOF, R. Creating the corporate future. New York, John Wiley, 1981.

ARMITAGE, H.; ATKINSON, A. The choice of productivity measures in organizations. Boston, Harvard Business School, 1990.

BARRELLA, W.D., BRUNSTEIN, I; Sistemas Flexíveis de Informações Baseadas em Medidas de Produtividade - Dissertação de Mestrado Escola Politécnica da USP - maio 1995.

BARRELLA, W. D., BRUNSTEIN, I - Sistemas Flexíveis de Informação - Encontro Nacional de Engenharia de Produção - in: anais Enegep/98 - UFF - Niterói - RJ - 1998.

BARRELLA, W. D., BRUNSTEIN, I - Bases Conceituais para o Desenvolvimento de um Sistema Especialista para Indústria Encontro Nacional de Engenharia de Produção - in: anais Enegep/98 - UFF - Niterói - RJ - 1998.

BELHOT, R. - Concepção da Base de Conhecimento de um Sistema Especialista: Uma Aplicação - Tese de Doutorado, Escola Politécnica, Universidade de São Paulo, São Paulo, 1991.

BIAZZI, F. A Perspectiva Sócio-Técnica. Dissertação (Mestrado), Escola Politécnica, Universidade de São Paulo, São Paulo, 1993.

BROCKHOFF, K.; CHAKRABARTI, A.; HAUSCHILDT, J.; PEARSON, A. do Handbook of Technology Management (Gerard H. "Gus" Gaynor) cópia xerox - s/d, s/l.

BUFFA, E.; MILLER J. - Production-Inventory Systems: Planning and Control - Illinois, Richard D Irwin Inc., 1979.

BURBIDGE, J. The Principles of Production Control - McDonald and Evans Ltd. - England - 1978.

BUTLER, S Toyota reinventa trabalho em linha de montagem publicado no jornal O Estado de São Paulo - pág. B14 - Caderno de Economia - Internacional; 12/01/1999.

CAREY, J. Human factors in management information systems. New Jersey, Ablex Publishing, 1988. 
CARRIE, A. - Simulation of Manufacturing Systems - Wiley, New York, 1988.

CHERNS, A. Priciples of Sociotechnical Design Revised - Human Relations, v. 40, no 3, p.153-162, 1987. In BIAZZI, F. A Perspectiva Sócio-Técnica. Dissertação (Mestrado), Escola Politécnica, Universidade de São Paulo, São Paulo, 1993.

CHERNS, A. The Principles of Sociotechnical Design - Human Relations, v. 29, no 8, p.783-92, 1976.

COLLEMAN, D et alii., Desenvolvimento Orientado a Objetos, $\mathbf{0}$ Método Fusion, ed. CAMPUS, 1996.

CORRÊA, H.; GIANESI, I.; CAON, M.- Planejamento, Programação e Controle da Produção - MRPII / ERP: conceitos uso e implementação, Ed ATLAS, Brasil, São Paulo, 1997.

DAVENPORT, T. H. Putting the Enterprise into the Enterprise System - Harvard Business Review - Julho-Agosto - 1998.

DILLON, A - Designing Usable Eletronic Text - Ergonomic Aspects of Human Information Usage, Taylor\&Francis, Great Britain - 1994.

d'YDEWALLE G., RENSBERGEN J. Van (Editors) - Perception and Cognition, Advances in Eye Movement Research, North-Holland, Netherland, 1993.

EHRICH, R W.; WILLIGES R C. (Editors) - Human-computer dialogue design - Advances in Human Factors / Ergonomics 2, Elsevier, Amsterdam - 1986.

EMERY, F.; TRIST, E. Socio-Technical Systems. In CHURCHMAN, C.W; VERHULST, M. Management Science Models and Techniques. Pergamon, s.l., v. 2, p. 83-97, 1960.

EMERY, F.; TRIST, E. The Causal Texture of Organizational Enviroments. Human Relations, v. 18, s/no, p.21-32, 1963. In BIAZZI, F. A Perspectiva Sócio-Técnica. Dissertação (Mestrado), Escola Politécnica, Universidade de São Paulo, São Paulo, 1993.

FEIGENBAUM, E in HARMON \& KING - Expert Systems: Artificial Inteligence in Business - 1985 - New York, Ed Wiley.

FERREIRA, A. Novo dicionário da língua portuguesa, Editora Nova Fronteira, Rio de Janeiro, 1994. 
FITZPATRICK, K; BAKER, J; DAVE D; An Application of Computer Simulation to Improve Scheduling of Hospital Operating Room Facilities in the United States - International Journal of Computer Applications in Technology, 1993.

GALBRAITH, J. Information processing determinants of organization structure, organizational design. Addison Wesley, Massaschussets, 1977.

GUERRINI, F Um Modelo Integrado de Administração de Produção para Empresas de Construção Civil, Tese de Doutorado, Escola de Engenharia de São Carlos EESC, São Carlos - 1999.

GRUDNITSKI, G.; BURCH, J. Informations systems: theory and practice. Singapore, John Wiley \& Sons, 5 ed., 1989.

GUIMARAES, T. The evolution of the information center. Datamation, v.30, no11, p. 127-30, Jul., 1984.

HABERKORN, E. A Teoria do ERP Makron Books - São Paulo 1999.

HABERMAS, J. The theory of communicative action, vol. 1: reason and the rationalization of society. Beacon Press, Boston, 1984. In HIRSCHHEIM, R.A., Office automation: a social and organizational perspective. John Wiley \& Sons, Chichester, 1989.

HARMON, P. KING D., Sistemas Especialistas - Ed. Campus - Rio de Janeiro, 1988.

JOHNSON, H. Measurement for competitive excellence. Boston, Harvard Business School, 1990.

KILLMANN, R. Impact of organizational culture on the implementation of computer and information technology. Trabalho apresentado no Computer and Information Technology Simposium Texarkana, East Texas State University, June, 1983.

MARSHAK, R. et al. Data base management systems. New York, McGraw-Hill, 1985.

MARTIN, J. Engenharia de informação. Rio de Janeiro, Ed. Campos, 1991.

MEISTER, D.; RABIDEAU G. Human Factors Evaluation in System Development, John Wiley \& Sons, New York, 1967. 
MEYER, W. Expert Systems in Factory Management - Knowledgebased CIM, Eliis Horwood Books in Information Technology, England, 1990.

ORLICKY, J. Material Requirements Planning, McGraw-Hill, New York, 1975.

RESENDE M. Planejamento e Controle da Produção Teoria e Prática da Indústria Mecânica no Brasil - Tese de Doutorado Escola de Engenharia de São Carlos da Universidade de São Paulo - São Carlos - 1989.

ROCKART, J BULLEN C; The Rise of Managerial Computing, Dow Jones-Irwin, 1986.

SACOMANO, J. B. Análise da estrutura funcional do planejamento e controle da produção e suas técnicas auxiliares Tese de Doutorado - Escola de Engenharia de São Carlos da Universidade de São Paulo - São Carlos - 1990.

SALERNO, M. Mudança Organizacional e Trabalho Direto em Função de Flexibilidade e Performance da Produção Industrial. São Paulo, 1994

SALERNO, M. Projeto Organizacional e Trabalho em Grupos na Produção. São Paulo, 1995

SALVENDY, G.; SMITH, J. (Editors) - Designing and Using HumanComputer Interfaces and Knowledge Based Systems - Advances in Human Factors / Ergonomics, Elsevier, Amsterdam - 1989.

van der VEER G. C., BAGNARA S., KEMPEM G. A. M. (Editors) Cognitive Ergonomics - Contributions from Experimental Psychology, North-Holland, Netherland, 1992.

van EIJNATTEN, F. M. The Paradigm That Changed the Work Place. Stockolm, Arbeitslivscentrum 1993.

WISNER, A.- Por Dentro do Trabalho - Ergonomia: Método \& Técnica, FTD/Oboré, Brasil, s.d..

ZARIFIAN, P , Produção Flexível de Lácteos Frescos, Anexo ao caderno de encargos PROFIL da BSN, outubro 1992.

ZACCARELLI, S. Planejamento e Controle da Produção, Livraria Pioneira Editora, São Paulo, 1967 


\section{REFERÊNCIAS DA INTERNET}

BELLOQUIM, A - http://www.ia.cti.br/ spin/CMM1.htm - 01/10/99

GIURLANI, S; http://www.uol.com.br/computerworld/computerworld/280/g capa1.htm - A Nova Fronteira do ERP - 22/07/99

ROZENFELD, H; ZANCUL, E - http://www.numa.org.br/conhecimentos/ ERP_v2.html - 09/10/99.

http://www.sis.bris.ac.uk/ ma7170/public_html/history.html - History of Artificial Intelligence - 12/01/99

http://agrosoft.com/ag95/papers/doc44.htm - Sistema Inteligente de Apoio a Produção Agrícola - 03/11/98

http://bis.cba.cmich.edu/whatiserp.htm - 14/10/99

http://carol.wins.uva.nl/ ammar/FedDB/project/prodnet/prodnet.html -

Virtual Enterprise Management - 28/04/98

http://cepanet01.cepa.com.br/ccjb/sist_esp.htm-Sistemas Especialistas $-03 / 11 / 98$

http://jacques.ic.cti.br/ic/pqps/cmm.htm- 01/10/99

http://labic.icmsc.sc.usp.br/recopeia/introdução.html - Sistemas Inteligentes para a Engenharia - 03/11/98

http://omni.bus.ed.ac.uk/opsman/roleplay/oak22.htm - MRP \& MRP2 27/04/98

http://omni.bus.ed.ac.uk/opsman/roleplay/oak7.htm - Brief Overview of MRP - 27/04/98

http://ourinhos.com.br/perin/interest.html - 22/07/99

http://penta.ufrgs.br/gr952/trab1/geren2.html - Sistemas especialistas baseados em conhecimento -03/11/98

http://penta.ufrgs.br/gr952/trab1/geren21.html - Inteligência Artificial

Distribuída - 04/05/98

http://produto2.pep.ufrj.br/abepro/enegep96/a/a9024.htm - Avaliação de Softwares de PCP no Mercado Nacional - 28/04/98

http://www.bus.orst.edu/faculty/brownc/es_tutor/es_tutor.htm- Introdução a Sistemas especialistas e Inteligência Artificial - 29/10/98

http://www.campus.fortunecity.com/princeton/117/psp/psp.htm - 01/10/99 http://www.catalao.com.br/alta2.htm -Sistemas Especialistas $03 / 11 / 98$ 
http://www.cognitiosite.com/poli94.html - Modelos de Conhecimento $03 / 11 / 98$

http://www.din.uem.br/ia/especialistas/ - Sistemas Especialistas $18 / 08 / 98$

http://www.din.uem.br/ia/especialistas/Elementos.html - Elementos de Sistemas Especialistas - 03/11/98

http://www.doc.fcee.upt.pt/fcee/users/jfr/jfrgp1.htm - Gestão de Produção - 06/04/98

http://www.dsc.ufpb.br.br/versao1.0/grupo_ia/publicacoes.html - GIA Publicações - 04/05/98

http://www.eng.uminho.pt/ dps/pessoas/jdac/cadeiras/IGCPprograma.ht $\mathrm{ml}$ - Gestão e Controle da Produção - 06/04/98

http://www.eps.ufsc.br/ martins/fuzzy/cbr/apres/int2.htm - Avaliação de sugestões - 04/05/98

http://www.eps.ufsc.br/disserta/jamilton/capit_2/imagens/f22_jam.htm

Estrutura de Sistema Especialista - 04/05/98

http://www.eps.ufsc.br/labs/lia/pp/ Planejamento da Produção $28 / 04 / 98$

http://www.eps.ufsc.br/teses/vergara/cap1/ - Simulação Cognitiva $12 / 11 / 98$

http://www.executivosfinanceiros.com.br/114mat1.htm\#erp - 22/07/99

http://www.fee.unicamp.br/feec/cg/disciplinas/ea-043.htm- Programação da Produção em Sistemas de Manufatura-06/04/98

http://www.fgvsp.br/cursos/pec/cursem/p8011a.htm - Administração da

Produção e Operações Competitivas - 28/04/98

http://www.fgvsp.br/public/rae/r_psi362.htm - Administração da

Produção e Sistemas de Informação - 28/04/98

http://www.fgvsp.br/servi/consult/poi.htm - Produção, Logística e Operações Industriais - 06/04/98

http://www.friburgoonline.com.br/compscientia/mta1.htm - Tecnologia M e sistemas abertos - 04/05/98

http://www.gap.com.br/industr.htm - Sistema Industrial Integrado 06/04/98

http://www.infoexame.com.br/plantaoinfo - Pesquisa da FGV aponta falhas do ERP - - 18/10/1999

http://www.icmsc.sc.usp.br/ solange/lA/iag_int/ - História da Inteligência artificial - 12/01/99 
http://www.inf.furb.rct-sc.br/ jomi/publicacoes/sminco_5_1.htm Implementação de um Sistema Especialista na WEB utilizando JAVA - 03/11/98

http://www.inf.ufsc.br/ lea/paulase1.htm - Sistemas Especialistas 03/11/98

http://www.ksr.com.br/erp.htm - 22/07/99

http://www.les.inf.puc-rio.br/socinfo/nestor/Cuerpo.htm - 01/10/99

http://www.mandic.com.com.br/cplan/2/10/16/31/cplan31.htm

Planejamento e Controle da Produção - 06/04/98

http://www.meya.com/garqua_p.htm - Sistema Integrado de Manufatura $-28 / 04 / 98$

http://www.microsiga.com.br/htmls/jr020msi.html - SIGAPCP - 06/04/98 http://www.microsoft.com/brasil/casos/moderni.htm - Modernidade no chão de Fábrica - 24/11/98

http://www.obelix.cepro.cefetpr.br/cefet/cpgei/informatica/celso.html - IA, Aplicações em Controle e em tempo real - 04/05/98

http://www.pie.warwick.ac.uk/Training//GDS/simulation_of_production_sy stems.htm - Simulação de sistemas de Produção - 13/04/98

http://www.puccamp.br/ labi/staff/nov-1994.html - Sistemas de Informação e Sistemas de Apoio à Decisão - 03/11/98

http://www.santaelisa.com.br/ind1.htm - Automação: o caminho para aumentar a produtividade $-28 / 04 / 98$

http://www.tricord.com $/ 3 / 3^{2} 5$.detail.html - Intelligent Management Subsystem - Detail - 27/12/96

http://www.tu-harburg.de/allgemein/fsp/forschung95/fb95-1.07.007.html Planejamento de Ambientes auxiliado por Computador para Sistemas Especialistas - 18/05/98

http://www.tu-harburg.de/allgemein/fsp/fsp2/ab207.html - Técnicas de Automação - 18/05/98

http://www.ulbra.tche.br/ danielnm/ia/defbas/de.html - Definições básicas de IA - 03/11/98

http://www.uol.com.br/computerworld/computerworld/280/gcapa2.htm 22/07/99

http://www.whatis.com/erp.htm - 14/10/99

http://www2.datasul.com.br/portugues/framework/pgenerico.htm- Datasul $-09 / 11 / 98$ 